CARLOS HUMBERTO MORA BEJARANO

\title{
AVALIAÇÃO EXERGOECOLÓGICA DE PROCESSOS DE TRATAMENTO DE ESGOTO
}

São Paulo

2009 
CARLOS HUMBERTO MORA BEJARANO

\title{
AVALIAÇÃO EXERGOECOLÓGICA DE PROCESSOS DE TRATAMENTO DE ESGOTO
}

\author{
Tese Apresentada à Escola Politécnica \\ da Universidade de São Paulo para \\ obtenção do título de Doutor em \\ Engenharia
}

São Paulo

2009 


\title{
AVALIAÇÃO EXERGOECOLÓGICA DE PROCESSOS DE TRATAMENTO DE ESGOTO
}

\author{
Tese Apresentada à Escola Politécnica \\ da Universidade de São Paulo para \\ obtenção do título de Doutor em \\ Engenharia
}

Área de Concentração:

Engenharia Mecânica

Orientador:

Prof. Dr. Silvio de Oliveira Jr.

\section{São Paulo}


Este exemplar foi revisado e alterado em relação à versão original, sob responsabilidade única do autor e com a anuência de seu orientador.

São Paulo, 23 de Abril de 2009

Assinatura do autor

Assinatura do orientador

\section{FICHA CATALOGRÁFICA}

\section{Mora-Bejarano, Carlos Humberto}

Avaliação exergoecológica de processos de tratamento de esgoto / C.H. Mora-Bejarano. - ed. rev. -- São Paulo, 2009. $144 \mathrm{p}$.

Tese (Doutorado) - Escola Politécnica da Universidade de São Paulo. Departamento de Engenharia Mecânica.

1. Estações de tratamento de águas residuárias 2. Desenvolvimento sustentável 3. Meio ambiente 4 . Impactos ambientais I. Universidade de São Paulo. Escola Politécnica. Departamento de Engenharia Mecânica II. t. 
A Deus, a meu amor Alexandra Eugenia, aos meus pais Eduardo e Lucila e a meus irmãos Martha Lucia, Eduardo e William. 


\section{AGRADECIMENTOS}

Ao professor Silvio de Oliveira Júnior, pela amizade, apoio, paciência e orientação durante todos estes anos de trabalho.

Ao Professor Jurandir e aos professores do Departamento de Engenharia Mecânica que, em seu momento, aportaram conhecimentos e experiência nas salas de aula e nas discussões acadêmicas de textos científicos.

À professora Dione pela valiosa ajuda no esclarecimento das dúvidas que apareceram ao estudar os processos de tratamento de esgoto.

Ao pessoal das secretarias: Lucy, Mariana, Moacir, pela colaboração recebida em todos estes anos. Aos colegas de pós-graduação com os quais tive uma aproximação maior no laboratório, lugar de estudo e de partilha de temas acadêmicos e científicos, assim como de descontração e de formação de verdadeiros laços de amizade. Como esquecer os momentos do "cafezinho", e do bom papo dos colegas que já foram embora - Celso, Luiz Felipe, Silas, Giancarlo, Cristian, Marcelo, Amaury - e dos que ficam nesta caminhada - Ricardo, Juan Carlos, Hector.

Ao pessoal da Sabesp, pelo fornecimento dos dados da ETE Barueri, ao pessoal de Ptar de Ginebra, assim como aos engenheiros Roberto Pomar e Luz Helena Mora pelo fornecimento dos dados da ETE Cañaveralejo.

À minha esposa Alexandra Eugenia, que foi minha amiga e minha companheira neste tempo todo, que compreendeu as noites e dias de estudo sem descanso, e me ajudou escutando sobre meu trabalho e minhas dúvidas. À minha família, que suportou a distância e a saudade, especialmente aos meus pais, que sempre estiveram me apoiando, mesmo desde longe, e a todos que colaboraram direta ou indiretamente, na execução deste trabalho. 
À minha irmã Martha Lucia pela amizade, apoio e constante estimulo não só em nível acadêmico, mais principalmente em nível pessoal durante toda minha vida.

Finalmente, agradeço ao CNPq pelo apoio financeiro através da bolsa de estudos (durante os primeiros dois anos e meio de doutorado), e à Universidade Nacional da Colômbia Sede Palmira que foi fundamental para minha manutenção no Brasil durante o último ano e para a conclusão da tese. 
"Si, pues, coméis o bebéis, o hacéis otra cosa, hacedlo todo para la gloria de Dios".

(1 Corintios 10:31) 


\section{RESUMO}

O presente trabalho propõe uma metodologia científica, com critérios bem definidos, para avaliar e quantificar o desempenho ambiental e a renovabilidade de processos de tratamento de esgoto, numa base única: a exergia. O desempenho ambiental é quantificado através do cálculo da eficiência exergética ambiental, definida como a razão da exergia do efeito útil do processo pela exergia total consumida dos recursos humanos e naturais, incluindo todas as entradas exergéticas. O cálculo da renovabilidade é feito por meio do índice exergético de renovabilidade definido como como a razão entre a exergia dos produtos pela soma das exergias não renováveis, a exergia destruída, a exergia de desativação e a exergia das emissões e residuos. A metodologia foi aplicada a três processos de tratamento de esgoto: dois biológicos (aeróbio e anaeróbio) e um físico-químico (TQA). O cálculo dos indicadores exergéticos foi realizado para cada um destes processos e foi observado que o processo com maiores valores de desempenho ambiental e renovabilidade, considerando o metano e o lodo do processo como efeito útil, foi o processo RAFA Lagoa Facultativa, com valores respectivamente de $\eta_{\text {exerg,amb }}(0,983)$ e $\lambda(7,060)$. A análise dos resultados mostrou que a metodologia proposta é uma ferramenta útil na avaliação e comparação do desempenho ambiental e da renovabilidade de processos de tratamento de esgoto.

Palavras chaves: eficiência exergética, reator anaeróbio de fluxo ascendente com manto de lodo, lagoa facultativa, lodos ativados, tratamento primário quimicamente assistido, sistemas de tratamento de esgoto, índice exergético de renovabilidade. 


\begin{abstract}
This work proposes a scientific methodology, with well defined criteria, to assess and quantify the environmental performance and renewability of wastewater treatment processes on a single base: the exergy. The environmental performance was measured by calculating the environmental exergy efficiency defined as the exergy ratio of the useful effect of the process to the total exergy consumed by human and natural resources, including all the exergy inputs. The renewability calculation was done using the renewability exergy index defined as the exergy ratio of the products to the sum of the non-renewable exergy, destroyed exergy, deactivation exergy and the emissions and waste exergy. The methodology was applied to three wastewater treatment processes: biological (aerobic and anaerobic) and physicochemical (CEPT) processes. The exergy indicators were calculated for each of these processes and it was observed that the process with the higher environmental performance and renewability values, considering the methane and sludge of process as useful effect, was the Facultative Lagoon - UASB process, with values, respectively, of $\eta_{\text {env,exerg }}$ (0.983) and $\lambda(7.060)$. The results analysis showed that the proposed methodology is a useful tool in the evaluation and comparison of environmental performance and renewability of wastewater treatment processes.
\end{abstract}

Keywords: exergy efficiency; upflow anaerobic sludge blanket reactor; facultative lagoon, activated sludge, chemically enhanced primary treatment, wastewater treatment systems, renewability exergy index. 


\section{LISTA DE FIGURAS}

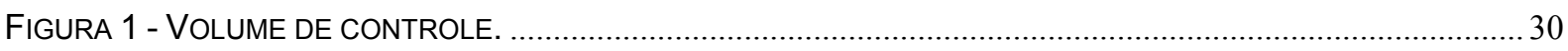

FIGURA 2 - FLUXOGRAMA DO PROCESSO DA ETE BARUERI (ADAPTADO DE SABESP, 2002).......................... 79

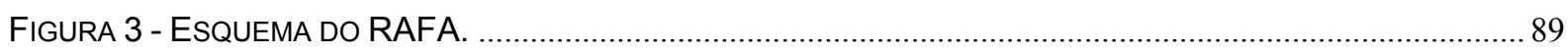

Figura 4 - FluXograma do PROCESSO dA ETE CAÑAVERALEJo (AdAPTADO DE EMCALI, 2001)...............93

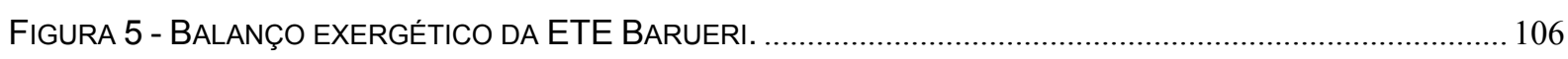

FIGURA 6 - BALANÇO EXERGÉTICO DO SISTEMA RAFA-LAGOA FACULTATIVA. .............................................. 106

FIGURA 7 - BALANÇO EXERGÉTICO DA ETE CAÑAVERALEJO........................................................................ 106 


\section{LISTA DE TABELAS}

TABELA 1 - COMPARAÇÃO DE CUSTOS E DA ÁREA REQUERIDA PARA OS PROCESSOS DE TRATAMENTO DE ESGOTO ESTUDADOS

TABELA 2 - DADOS ANUAIS DA CARACTERIZAÇÃO DO ESGOTO BRUTO (AFLUENTE) E DO EFLUENTE FINAL DA

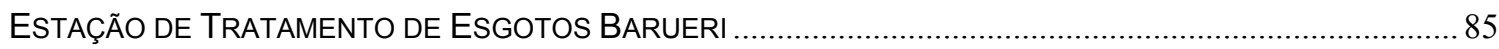

TABELA 3 - DADOS DOS CONSUMOS E DOS SUBPRODUTOS GERADOS NA ETE BARUERI ..................................... 86

TABELA 4 - DADOS DA COMPOSIÇÃO QUÍMICA DO LODO DESAGUADO GERADO NA ETE BARUERI ....................... 86

TABELA 5 - CARACTERIZAÇÃO DO ESGOTO BRUTO (AFLUENTE) E DO EFLUENTE FINAL DA ESTAÇÃO DE

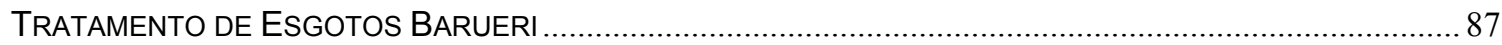

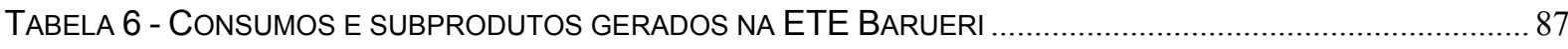

TABELA 7 - COMPOSIÇÃO QUÍMICA DO LODO DESAGUADO GERADO NA ETE DE BARUERI ................................... 88

TABELA 8 - DADOS DA CARACTERIZAÇÃO DO ESGOTO BRUTO (AFLUENTE) DO RAFA E DO EFLUENTE FINAL DA

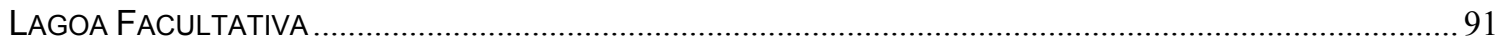

TABELA 9 - DADOS DOS CONSUMOS E DOS SUBPRODUTOS GERADOS NO SISTEMA RAFA - LAGOA

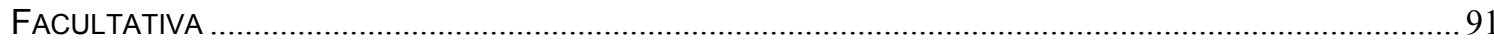

TABELA 10 - DADOS DA COMPOSIÇÃO QUÍMICA DO LODO DESAGUADO GERADO NO RAFA .................................. 91

TABELA 11 - CARACTERIZAÇÃO DO ESGOTO BRUTO (AFLUENTE) DO RAFA E DO EFLUENTE FINAL DA LAGOA

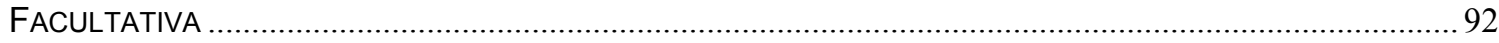

TABELA 12 - CoNSUMOS E SUBPRODUtOS GERADOS No SISTEMA RAFA - LAGOA FACULTATIVA ....................92

TABELA 13 - COMPOSIÇÃO QUÍMICA DO LODO DESAGUADO GERADO NO RAFA …………................................92

TABELA 14 - DADOS ANUAIS DA CARACTERIZAÇÃO DO ESGOTO BRUTO (AFLUENTE) E DO EFLUENTE FINAL DA

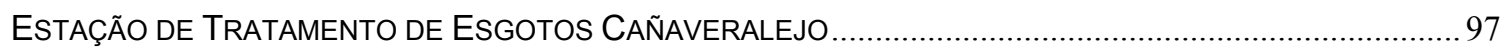

TABELA 15 - DAdOS DOS CONSUMOS E DOS SUBPRODUTOS GERADOS NA ETE CAÑAVERALEJO ……..............98

TABELA 16 - DADOS DA COMPOSIÇÃO QUÍMICA DO LODO DESAGUADO GERADO NA ETE CAÑAVERALEJO ........98

TABELA 17 - CARACTERIZAÇÃO DO ESGOTO BRUTO (AFLUENTE) E DO EFLUENTE FINAL DA ESTAÇÃO DE

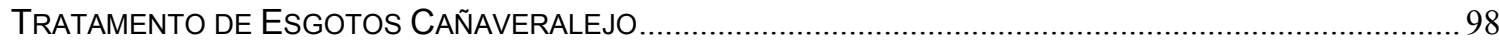

TABELA 18 - CoNSUMOS E SUBPRODUTOS GERADOS NA ETE CAÑAVERALEJO_..............................................99

TABELA 19 - CoMPosIÇÃo QUÍMICA DO LODO DESAGUADO GERADO NA ETE CAÑAVERALEJO ...........................99

TABELA 20 - EXERGIA QUÍMICA PADRÃO DOS ELEMENTOS E COMPOSTOS QUÍMICOS ENVOLVIDOS NOS

PROCESSOS DE TRATAMENTO DE ESGOTO EM KJG ${ }^{-1}$ 100

TABELA 21 - FLUXOS DE EXERGIA ASSOCIADOS AO ESGOTO BRUTO (AFLUENTE) E AO EFLUENTE FINAL PARA A

ESTAÇÃO DE TRATAMENTO DE ESGOTOS BARUERI MISTURA NÃO IDEAL 101

TABELA 22 - FLUXOS DE EXERGIA ASSOCIADOS AOS CONSUMOS E AOS SUBPRODUTOS GERADOS NA ETE

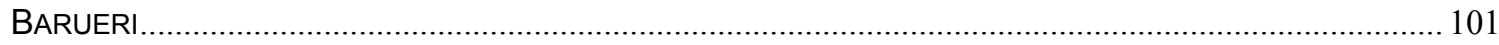

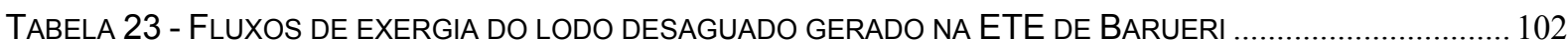

TABELA 24 - FLUXOS DE EXERGIA DO ESGOTO BRUTO (AFLUENTE) DO RAFA E DO EFLUENTE FINAL DA LAGOA

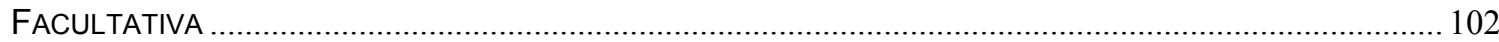


TABELA 25 - FLUXOS DE EXERGIA ASSOCIADOS AOS CONSUMOS E AOS SUBPRODUTOS GERADOS NO SISTEMA

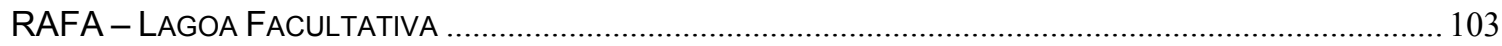

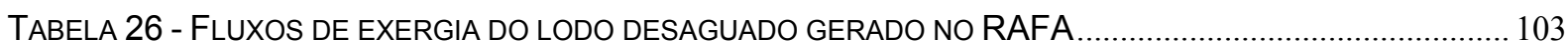

TABELA 27 - FLUXOS DE EXERGIA ASSOCIADOS AO ESGOTO BRUTO (AFLUENTE) E AO EFLUENTE FINAL PARA A

EstaÇÃo de TRATAMENTO de Esgotos CAÑAVERALEJo Mistura NÃo IDEAL..... 104

TABELA 28 - FLUXOS DE EXERGIA ASSOCIADOS AOS CONSUMOS E AOS SUBPRODUTOS GERADOS NA ETE

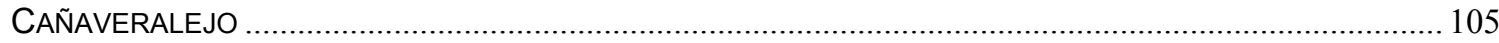

TABELA 29 - FLUXOS DE EXERGIA DO LODO DESAGUADO GERADO NA ETE CAÑAVERALEJO .............................. 105

TABELA 30 - VALORES DOS FLUXOS DE EXERGIA DE ENTRADA, SAÍDA, DESTRUÍDA E PERDIDA PARA OS

Processos de TRATAMENTO de Esgoto da ETE BARUERI, do SISTEMA RAFA - LAGOA FACULTATIVA

E PARA A ETE CAÑAVERALEJO

TABELA 31 - VALORES DA EFICIÊNCIA EXERGÉTICA AMBIENTAL E DO INDICADOR EXERGÉTICO DE

RENOVABILIDADE, PARA OS PROCESSOS DE TRATAMENTO DE ESGOTO DA ETE BARUERI, DO SISTEMA

RAFA - LAGOA FACULTATIVA E PARA A ETE CAÑAVERALEJO 107

TABELA 32 - VALORES DA EFICIÊNCIA EXERGÉTICA AMBIENTAL E DO INDICADOR EXERGÉTICO DE

RENOVABILIDADE, PARA OS PROCESSOS DE TRATAMENTO DE ESGOTO DA ETE BARUERI E DO SISTEMA

RAFA - LAGOA FACULTATIVA 109

TABELA 33 - RESUMO COMPARATIVO DOS VALORES DA EFICIÊNCIA EXERGÉTICA AMBIENTAL E DO INDICADOR EXERGÉTICO DE RENOVABILIDADE PARA OS PROCESSOS DE TRATAMENTO DE ESGOTO ANALISADOS ... 111

TABELA 34 - CLASSES DE USO DE CORPOS D'ÁGUA

TABELA 35 - LIMITES DOS PARÂMETROS DE QUALIDADE DE ACORDO COM A RESOLUÇÃO CONAMA 20/86.. 132

TABELA 36 - LIMITES DOS PARÂMETROS DE QUALIDADE DE ACORDO COM O DECRETO ESTADUAL 8468/76 . 134

TABELA 37 - LIMITES DE EMISSÃo CONFORME A RESOLUÇÃO CONAMA 20/86 E DECRETO ESTADUAL

$8468 / 76$

TABELA 38 - LIMITES DE EMISSÃO PARA OS EFLUENTES LANÇADOS NOS CORPOS DE ÁGUA, CONFORME O

DECRETO 1594 DE 1984

TABELA 39 - LIMITES DE EMISSÃO PARA OS EFLUENTES LANÇADOS NAS REDES DE ESGOTOS, CONFORME O

DECRETO 1594 DE 1984

TABELA 40 - LIMITES DE EMISSÃO CONFORME O DECRETO 1594 DE 1984

TABELA 41 - CÁLCULO DA EXERGIA ASSOCIADA À VAZÃO AFLUENTE DO RAFA 138

TABELA 42 - CÁLCULO DA EXERGIA ASSOCIADA À VAZÃO EFLUENTE DA LAGOA FACULTATIVA .......................... 138

TABELA 43 - CÁLCULO dA EXERGIA ASSOCIADA À VAZÃO AFLUENTE DA ETE BARUERI. 139

TABELA 44 - CÁLCULO DA EXERGIA ASSOCIADA À VAZÃO EFLUENTE DA ETE BARUERI 140

TABELA 45 - CÁLCULO DA EXERGIA ASSOCIADA À VAZÃO AFLUENTE dA ETE CAÑAVERALEJO.. 141

TABELA 46 - CÁlCULO DA EXERGIA ASSOCIADA À VAZÃO EFLUENTE DA ETE CAÑAVERALEJO 142

TABELA 47 - CÁLCULO DA EXERGIA ASSOCIADA AO LODO DESAGUADO PRODUZIDO NO RAFA 143

TABELA 48 - CÁLCULO DA EXERGIA ASSOCIADA AO LODO DESAGUADO PRODUZIDO NA ETE BARUERI 143

TABELA 49 - CÁLCULO DA EXERGIA ASSOCIADA AO LODO DESAGUADO PRODUZIDO NA ETE CAÑAVERALEJO144 


\section{LISTA DE ABREVIATURAS E SIGLAS}

$\mathrm{ABC}$

ABC Paulista

ACUAVALLE

Sociedad de Acueductos y Alcantarillados del Valle del Cauca

ACV

Análise de Ciclo de Vida

AECV

Avaliação Exergética do Ciclo de Vida

CAPS

Chemically Assisted Primary Sedimentation

CEPT

Chemically Enhanced Primary Treatment

CETE

Centro Experimental de Tratamento de Esgoto

CPTM

Companhia Paulista de Trens Metropolitanos

$\mathrm{CNPq}$

Conselho Nacional de Desenvolvimento Científico e Tecnológico

CONAMA

Conselho Nacional do Meio Ambiente

COT

Carbono Orgânico Total

COPLADES

Plano Diretor de Esgotos

DBO

Demanda Bioquímica de Oxigênio

$\mathrm{DBO}_{U}$

Demanda Última de Oxigênio

DFU

Drenagem de Fundo

DQO

Demanda Química de Oxigênio

DTO

Demanda Teórica de Oxigênio

EI95

Eco - Indicador 95

EMCALI

Empresas Municipales de Cali

EQPE

Exergia Química Padrão Especifica

EQRE

Exergia Química Relativa Especifica

ETE

Estação de Tratamento de Esgoto

$\mathrm{GIRH}$

Gestão Integrada do Recurso Hídrico

IPS

Índice do Processo Sustentável

IT

Interceptor Tiête

NTK

Nitrogênio Total Kjeldahl

OECD

Organization for Economic Cooperation and Development

$P V C$

Policloreto de Vinila

RAFA

Reator Anaeróbio de Manta de Lodo de Fluxo Ascendente

RMSP

Região Metropolitana de São Paulo 
SABESP

SS

SST

SSV

$S T$

TAC

TLEP

TQA

UASB

UFRJ

UPVC

WTP
Companhia de Saneamento Básico do Estado de São Paulo Sólidos em suspensão

Sólidos em suspensão total

Sólidos em suspensão voláteis

Sólidos totais

Tanques de Acumulação

Toneladas Limpas Equivalentes de Petróleo

Tratamento Quimicamente Assistido

Upflow Anaerobic Sludge Blanket Reactor

Universidade Federal de Rio de Janeiro

Cloreto de Polivinila não Plastificado

Wastewater Treatment Plant 


\section{LISTA DE SÍMBOLOS}

\section{Símbolos Latinos}

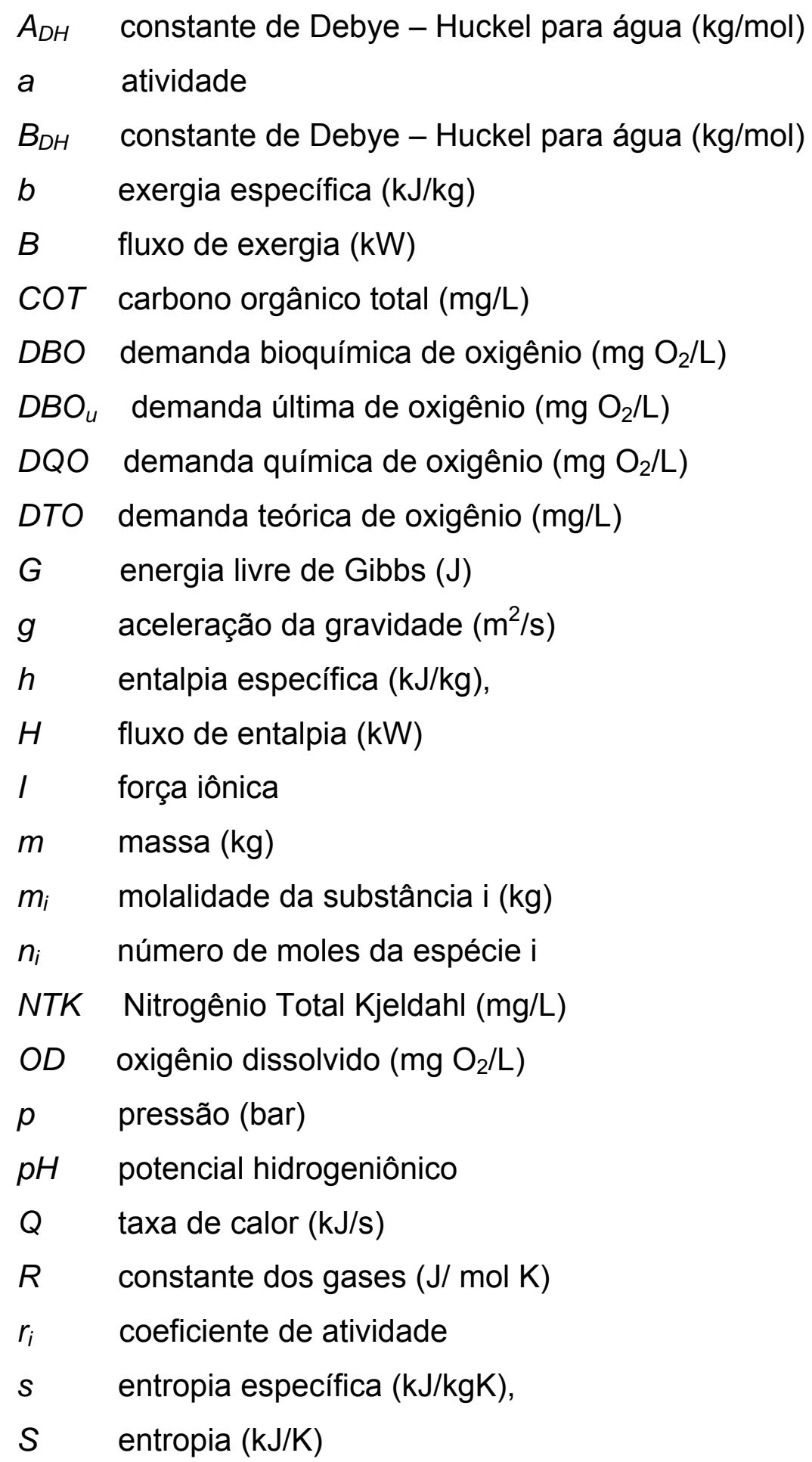


SS sólidos em suspensão ( $\mathrm{mg} / \mathrm{L})$

SST sólidos em suspensão total ( $\mathrm{mg} / \mathrm{L})$

SSV sólidos em suspensão voláteis $(\mathrm{mg} / \mathrm{L})$

ST sólidos totais $(\mathrm{mg} / \mathrm{L})$

$T$ temperatura (K)

$U \quad$ fluxo de energia interna (W)

$u \quad$ energia interna especifica $(\mathrm{kJ} / \mathrm{kg})$

$v \quad$ velocidade $(\mathrm{m} / \mathrm{s})$

$v \quad$ volume específico $\left(\mathrm{m}^{3} / \mathrm{kg}\right)$,

$V \quad$ volume $\left(\mathrm{m}^{3}\right)$

W trabalho $(\mathrm{kJ})$

$x_{i} \quad$ fração molar do componente i

$z \quad$ elevação $(m)$

$z_{i} \quad$ carga íonica ou valencia

\section{Símbolos Gregos}

$\Delta \quad$ variação

$\xi \quad$ exergia

$\eta$, $\varepsilon$ eficiência exergética, ou índice exergético

$\mu \quad$ potencial químico $(\mathrm{J} / \mathrm{mol})$

$\dot{\sigma} \quad$ taxa de entropia produzida ( $\mathrm{kW} / \mathrm{K})$

$\Phi_{\mathrm{i}} \quad$ diâmetro efetivo do íon na solução (m)

$\lambda$ indicador exergético de renovabilidade

\section{Subscritos}




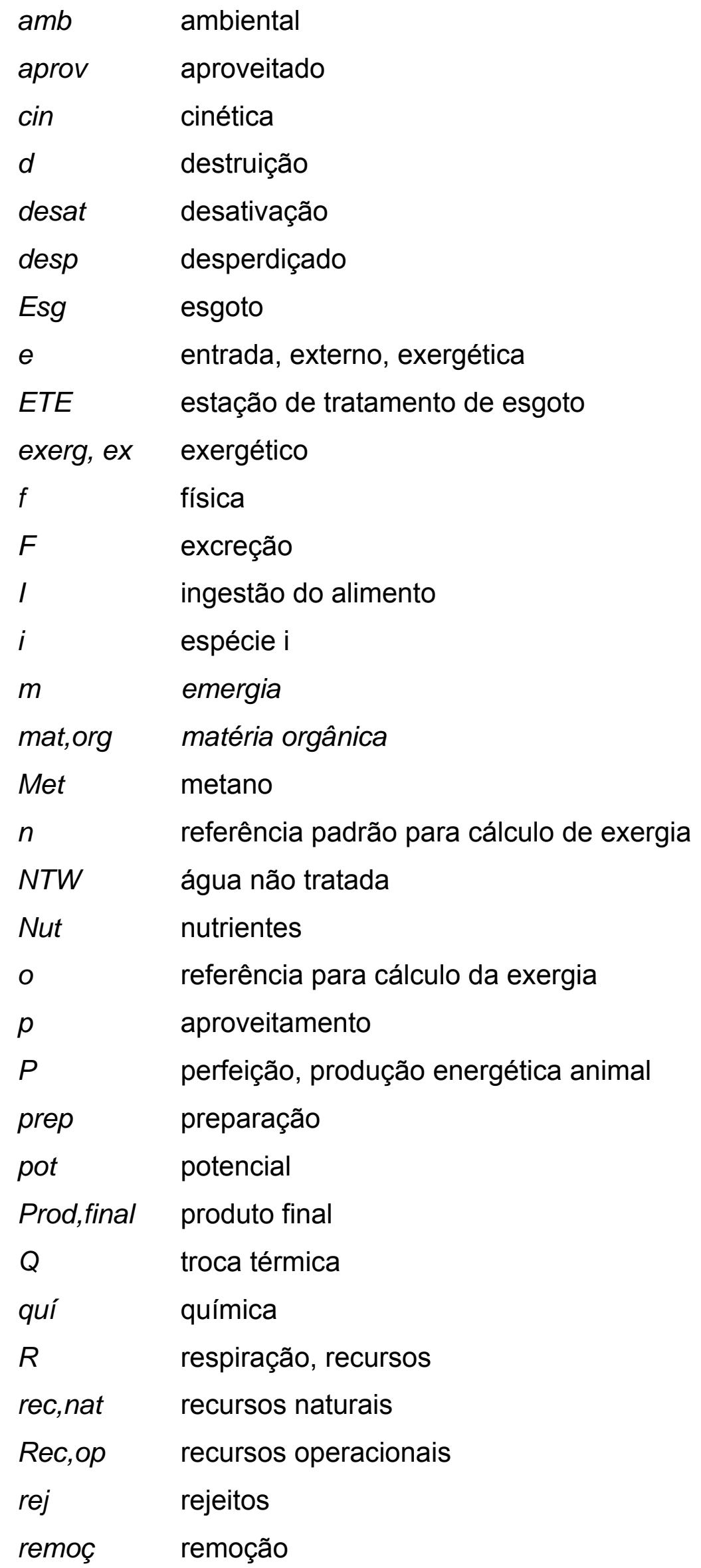




$\begin{array}{ll}\text { s } & \text { saída } \\ \text { Transp } & \text { transporte e espalhamento } \\ \text { TW } & \text { água tratada }\end{array}$

Superescrito

$\begin{array}{ll}- & \text { molar } \\ \text { s } & \text { sistema } \\ \text { * } & \text { estado de referência restrito } \\ & \text { taxa de variação temporal } \\ & \text { referencial/ estado de referência padrão }\end{array}$




\section{SUMÁRIO}

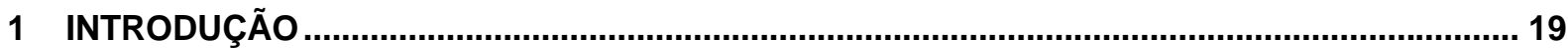

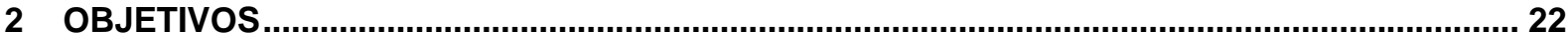

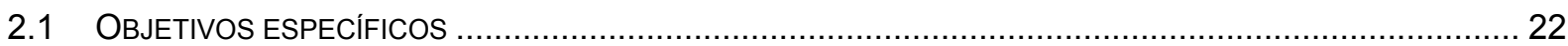

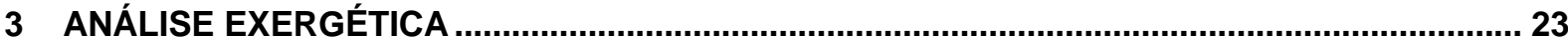

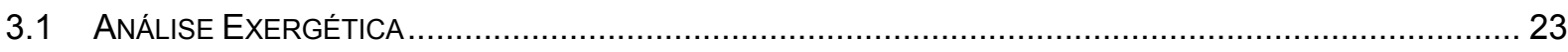

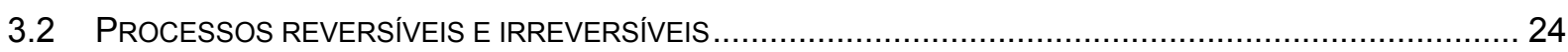

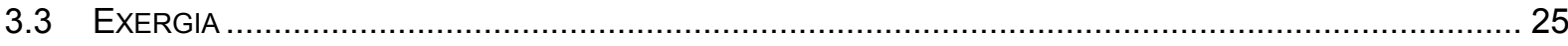

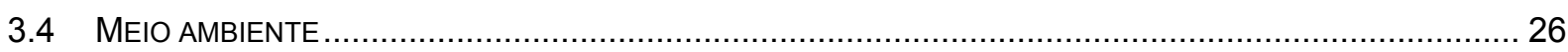

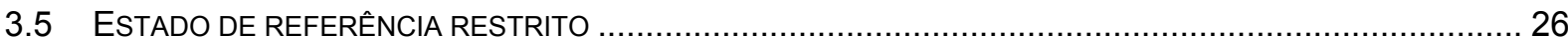

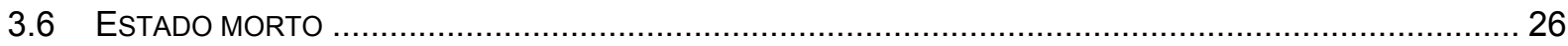

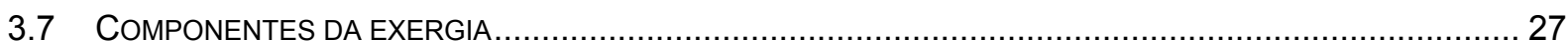

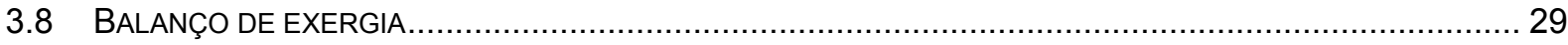

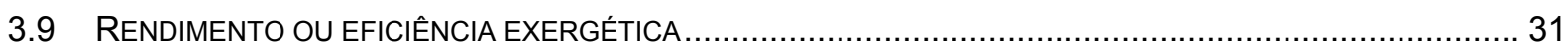

4 REVISÃO DE LITERATURA

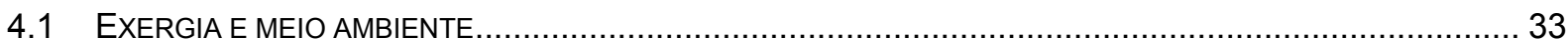

4.2 EXERGIA COMO UM INDICADOR ECOLÓGICO DE DESENVOLVIMENTO SUSTENTÁVEL ............................. 37

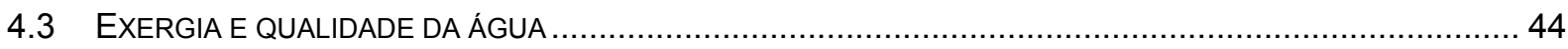

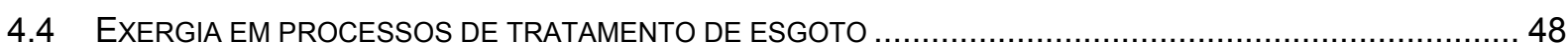

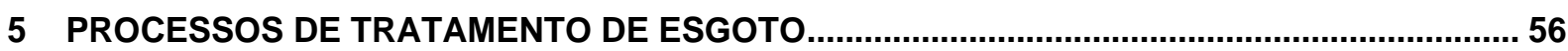

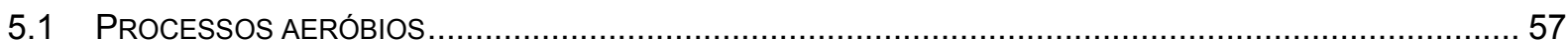

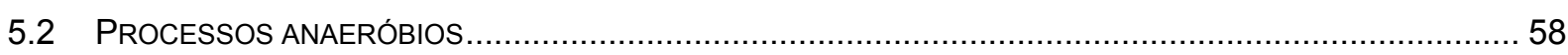

5.2.1 Reator Anaeróbio de Fluxo Ascendente com Manta de Lodo (RAFA)................................ 59

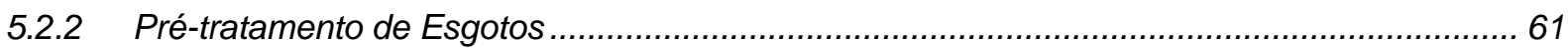

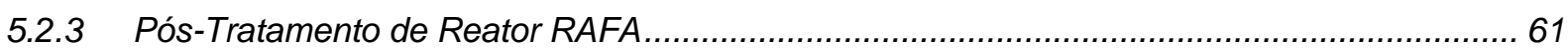

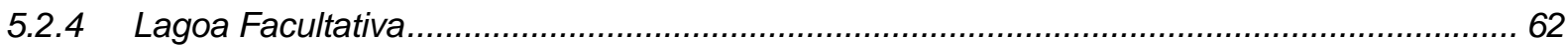

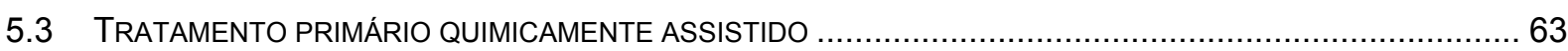

6 METODOLOGIA DA ANÁLISE EXERGOECOLÓGICA DE PROCESSOS DE TRATAMENTO DE

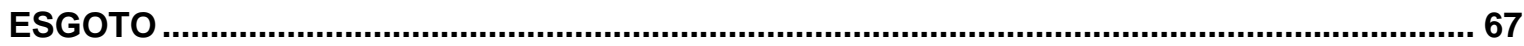

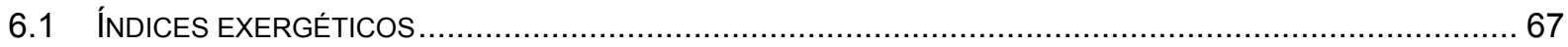

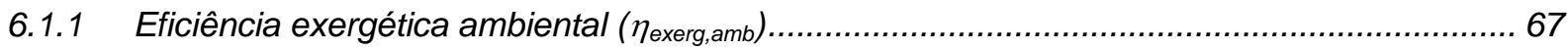

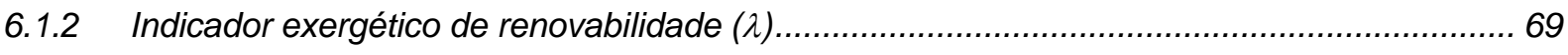

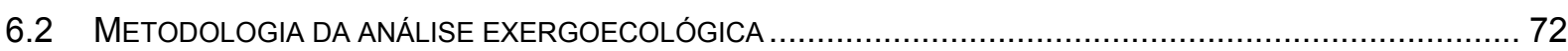

7 AVALIAÇÃO DO DESEMPENHO AMBIENTAL E DA RENOVABILIDADE DE PROCESSOS DE TRATAMENTO DE ESGOTO. 


\subsection{AVALIAÇÃO DO DESEMPENHO E DA RENOVABILIDADE DE TRÊS PROCESSOS DE}

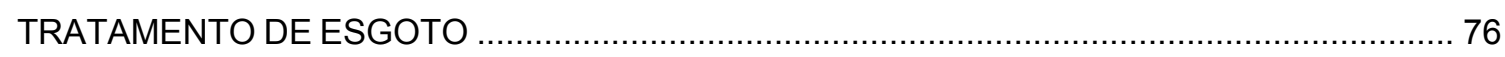

7.2 DESCRIÇÃO DOS PROCESSOS DE TRATAMENTO DE ESGOTO ESTUDADOS .................. 78

7.2.1 Estação de tratamento de esgotos de (ETE) Barueri........................................................ 78

Coleta e tratamento dos dados da Estação de Tratamento de Esgoto Barueri ................................... 84

7.2.2 Reator Anaeróbio de Fluxo Ascendente com Manta de Lodo (RAFA) e Lagoa Facultativa ... 88

Coleta e tratamento de dados do sistema RAFA - Lagoa Facultativa................................................ 90

7.2.3 Estação de tratamento de esgotos de (ETE) Cañaveralejo .................................................... 93

Coleta e tratamento dos dados da Estação de Tratamento de Esgoto Cañaveralejo, ETE................. 97

7.3 ANÁLISE EXERGÉTICA DAS ETES BARUERI, RAFA - LAGOA FACULTATIVA E DA ETE

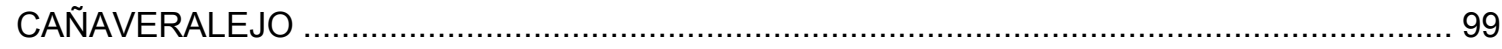

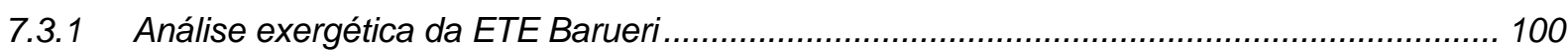

7.3.2 Análise exergética do sistema RAFA - Lagoa Facultativa .................................................. 102

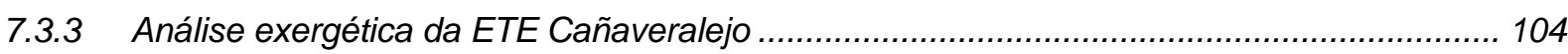

7.3.4 Cálculo dos índices exergéticos considerando o aproveitamento do metano e do lodo para os

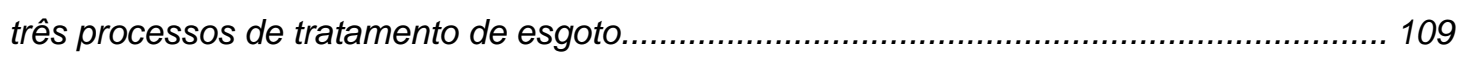

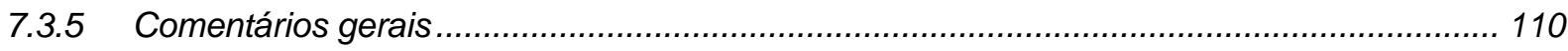

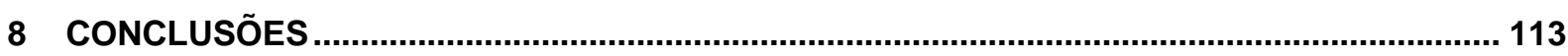

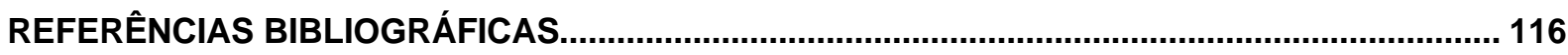

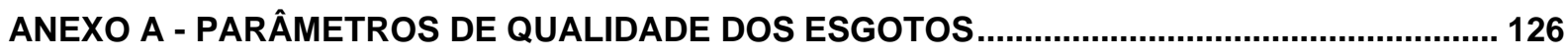

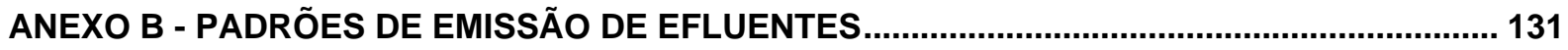

ANEXO C - MEMORIAL DE CÁLCULO - DA ETE BARUERI, SISTEMA RAFA - LAGOA

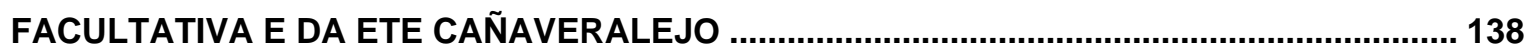




\section{INTRODUÇÃO}

A crescente preocupação com a disponibilidade mundial da água exige de todos uma consciência a respeito da utilização desse recurso, já que a água potável encontrada na natureza sustenta a vida no planeta. No entanto, esse recurso tem-se tornado cada vez mais escasso. De 1970 a 1995, houve uma redução de $37 \%$ no volume da água disponível no planeta, e em 2002, a restrição da quantidade e qualidade da água já afetava a sobrevivência de 1,4 bilhões de pessoas. Nesta década, cerca de 250 milhões de pessoas distribuídas em 26 paises enfrentam escassez crônica de água (Almeida et al., 2002).

Os processos industriais, que usam grandes volumes de água, contribuem com a contaminação dos corpos de água, principalmente pela falta de sistemas de tratamento para os grandes volumes de efluentes líquidos produzidos. Segundo Benvenutti e Frank (2000), a indústria é responsável por 60\% da Demanda Bioquímica de Oxigênio (DBO), pela presença de material em suspensão e por $90 \%$ dos resíduos tóxicos na água, além do despejo de $75 \%$ do resíduo orgânico. Além disso, tem-se uma contribuição importante na poluição da água devido à atividade agrícola, aos esgotos sanitários e aos resíduos domésticos. O impacto ambiental nos corpos d'água é reduzido pelo aumento da eficiência dos processos industriais e dos processos de tratamento de águas residuárias existentes.

Há uma crescente demanda por sistemas de tratamento de esgoto mais sustentáveis, no entanto, os critérios para caracterizar esses sistemas não estão completamente desenvolvidos. É um desafio projetar sistemas de tratamento de esgoto sustentáveis que visem efeitos positivos para o ambiente, a sociedade e a economia.

As visões mais futuristas dos sistemas de tratamento de esgoto valorizam o nível de capacitação do pessoal de operação das ETEs, a geração de empregos, a estética da estrutura física da estação de tratamento, a minimização das emissões atmosféricas, dos custos de operação e da utilização da energia, assim como a maximização da eficiência de tratamento. Vários autores têm trabalhado na elaboração de diversos índices de sustentabilidade para sistemas de tratamento de 
esgoto, entre os quais incluem a exergia (Lundin; Molander; Morrison, 1997; Balkema; Preisig; Otterpohl; Lambert, 2002; Miranda; Teixeira, 2004; Palme; Lundin; Tillman; Molander, 2005; Jie; Xiang-Sheng; Xue-Zheng, 2007; Muga; Mihelcic, 2008). A análise exergética é uma ferramenta importante na análise da sustentabilidade de um sistema de tratamento de esgoto.

Segundo Szargut et al., (1988), a exergia é definida como a quantidade de trabalho obtida quando uma massa é trazida até um estado de equilíbrio termodinâmico com os componentes comuns do meio ambiente, por meio de processos reversíveis envolvendo interação apenas com esses componentes. A exergia é apropriada para avaliação ecológica da água porque ela apresenta uma medida termodinâmica unificada para avaliação objetiva de recursos, qualidade e impacto ambiental.

Hellstrom (1997) mostrou como a análise exergética poderia ser usada para estimar o consumo de recursos físicos em uma estação de tratamento de esgoto. Alguns pesquisadores também sugeriram que a quantificação do impacto ambiental pode ser melhor conduzida pelo emprego do conceito de exergia (Rosen e Dincer (1997); Dincer e Rosen (1998); Gong (1999); Rosen e Dincer (2001); Rosen (2002); Wall e Gong (2001); Wall (2002)). Outros foram além e calcularam esses impactos baseados na exergia (Bastianoni (1998); Botero (2000); Creyts e Carey (1997); Gong e Wall (2001); Makarytchev (1997); Rosen e Dincer (1999); Szargut (2002)).

O conceito de exergia tem sido utilizado no campo ecológico e ambiental por Jorgensen (1988,1992); Fuliu (1997), e como um indicador ecológico e uma função objetivo, no modelamento ecológico para sistemas aquáticos (Bendoriccio e Jorgensen (1997); Jorgensen e Nielsen (2007)). Além disso, tem sido utilizado na avaliação da qualidade da água, ilustrando as relações entre a exergia e os parâmetros de qualidade da água tais como DBO, DQO e COT (Tai; Matsushige e Goda (1986); Hellstrom (1997, 1999, 2003a,b); Zaleta-Aguilar; Ranz e Valero (1998); Gallegos-Muñoz et al. (2003); Valero et al. (2006); Huang et al. (2007); Chen e Ji (2007); Chen et al. (2007)).

Neste trabalho, foi desenvolvida uma metodologia científica, para avaliar e quantificar o desempenho ambiental e a renovabilidade de processos de tratamento de esgoto, mediante o cálculo da eficiência exergética e o índice exergético de renovabilidade. Essa metodologia foi aplicada a processos de tratamento biológicos 
e fisico-químicos. Entre os biológicos foi avaliado um sistema composto por reator anaeróbio de manta de lodo de fluxo ascendente (RAFA) - lagoa facultativa, localizado na área rural de Ginebra (Colômbia), e um processo de lodos ativados da estação de tratamento de esgoto Barueri localizada na região metropolitana de São Paulo. O processo fisico-químico avaliado foi o tratamento quimicamente assistido da estação de tratamento de esgoto Cañaveralejo, localizado na área urbana de Cali (Colômbia). A análise dos resultados mostrou que esse método pode ser usado para avaliar e comparar a renovabilidade e o desempenho ambiental de processos de tratamento de esgoto. 


\section{OBJETIVOS}

O objetivo deste trabalho foi definir uma metodologia científica para analisar exergeticamente processos de tratamento de esgoto, e por meio do cálculo da eficiência exergética e de um índice exergético de renovabilidade, comparar o desempenho ambiental e a renovabilidade desses processos.

\subsection{Objetivos específicos}

Os objetivos específicos deste trabalho foram:

- Estabelecer uma metodologia para a análise exergética de processos de tratamento de esgoto.

- Avaliar e comparar exergeticamente várias tecnologias de tratamento de esgoto.

- Demonstrar que a análise exergética é uma ferramenta útil na avaliação e comparação do desempenho ambiental e da renovabilidade dos processos de tratamento de esgoto. 


\section{ANÁLISE EXERGÉTICA}

\subsection{Análise Exergética}

O balanço de energia, baseado na primeira lei da Termodinâmica, é um método efetivo para quantificar as diferentes formas de energia transferidas entre um sistema e suas vizinhanças. Além disto, fornece informação sobre as mudanças da energia acumulada nos sistemas. Por meio do balanço energético também é possível avaliar a eficiência dos processos de conversão de energia. Ele trata as interações de trabalho e calor como formas equivalentes de energia em trânsito, porém não oferece informação sobre a diferença da qualidade entre estas grandezas. No balanço energético, por exemplo, $1 \mathrm{~kJ}$ de calor e $1 \mathrm{~kJ}$ de trabalho são tratados da mesma forma; no entanto, a qualidade da energia na forma de trabalho é maior que a do calor. Além disso, o balanço de energia não pode estimar a degradação da qualidade da energia dentro de um processo, uma vez que ele obedece a primeira lei da Termodinâmica, que é uma lei de conservação.

Segundo Tsatsaronis (1993), o balanço de energia, baseado na primeira lei da Termodinâmica falha na análise dos processos de conversão de energia devido a que essa lei:

- não reconhece qualquer perda num reator químico adiabático ou num processo de estrangulamento adiabático;

- não mostra que uma parte da entalpia de um fluxo ou da taxa de transferência de calor é inútil termodinamicamente;

- não detecta qualquer degradação na qualidade da energia num trocador de calor adiabático;

- identifica o condensador de uma instalação de potência como o componente responsável pela eficiência relativamente baixa da instalação, sendo que, na verdade, a caldeira é a responsável. 
Como o conceito de exergia está baseado na primeira e segunda leis da Termodinâmica, com a análise exergética é possível identificar a localização e as magnitudes das perdas exergéticas dentro de um processo ou sistema. A exergia é perdida ou consumida em todos os processos reais, tornando-se o recurso limitante para o funcionamento de todos os sistemas (Huang et al., 2007). Quando essa análise é aplicada aos processos de conversão de energia, caracteriza como a exergia do combustível é usada e destruída nesses processos; além disto, ela oferece as seguintes vantagens:

- usada como uma medida comum de entradas e saídas, possibilita o cálculo da eficiência exergética, a saber, a razão das saídas pelas entradas exergéticas totais (incluindo utilidades). Essa razão fornece uma indicação do potencial teórico de futuras melhorias para um processo;

- o uso da análise exergética fornece uma medida comum para diferentes processos ou produtos;

- a análise exergética é uma ferramenta efetiva para atingir uma utilização eficiente da energia com mínimo impacto ambiental e para entender as questões ambientais;

- outra vantagem está relacionada à definição da exergia, já que ela pode estimar a degradação da qualidade da energia dentro de um processo.

- Segundo Szargut et al., (1988), o principal propósito de uma análise exergética é descobrir as causas e estimar quantitativamente a magnitude da imperfeição dos processos de conversão de energia.

\subsection{Processos reversíveis e irreversíveis}

Um processo reversível para um sistema é definido como aquele que, tendo ocorrido, pode ser invertido sem deixar vestígios no sistema e no meio. Ou seja, é reversível se, após ter ocorrido, os estados iniciais do sistema e seus arredores podem ser restaurados sem efeitos residuais em qualquer um deles. Já um processo irreversível é aquele que ao ser invertido deixa vestígios no sistema e no meio. $\mathrm{O}$ 
processo reversível é um processo ideal, pois todos os processos reais são irreversíveis. Segundo Kotas (1985), o processo reversível, embora seja uma idealização, é conceitualmente útil porque pode ser descrito mais facilmente em termos matemáticos do que um processo irreversível e, além disso, pode ser usado convenientemente como um padrão de perfeição para os processos reais.

Existem muitas causas, chamadas irreversibilidades, que tornam um processo irreversível. Entre elas, podem-se mencionar:

- $\quad$ atrito mecânico entre sólidos;

- $\quad$ aquecimento elétrico (Efeito Joule);

- $\quad$ perda de carga em escoamentos;

- $\quad$ troca de calor com gradiente de temperatura;

- misturas;

- $\quad$ reações químicas;

- difusão.

Um processo irreversível é acompanhado inevitavelmente de um aumento da entropia do universo (sistema e vizinhanças). Desta forma, o aumento da entropia pode servir como uma medida da imperfeição dos processos reais.

\subsection{Exergia}

Segundo Szargut et al., (1988), a exergia é definida como a máxima quantidade de trabalho obtida quando uma massa é trazida até um estado de equilíbrio termodinâmico com os componentes comuns do meio ambiente, por meio de processos reversíveis; envolvendo interação apenas com esses componentes. 


\subsection{Meio ambiente}

Para possibilitar o cálculo da exergia de um sistema ou fluxo é necessário definir uma referência que permita avaliar o máximo trabalho possível a ser realizado por um sistema. Essa referência é o meio ambiente. Considera-se meio ambiente a porção da vizinhança do sistema estudado cujas propriedades (pressão, temperatura e potencial químico) não se alteram significativamente ao interagir com o sistema.

O conceito de meio ambiente usado na análise exergética exige que ele esteja em estado de perfeito equilíbrio termodinâmico, ou seja, o meio deve ser homogêneo, não podendo possuir qualquer gradiente de pressão, temperatura, potencial químico, energias cinética e potencial. Embora o meio ambiente real seja complexo, procurase, em geral modelá-lo como uma composição de substâncias existentes em abundância na atmosfera, oceanos e crosta terrestre.

\subsection{Estado de referência restrito}

Segundo Kotas (1985), o estado de referência restrito é aquele no qual as condições de equilíbrio térmico e mecânico entre o sistema e o ambiente são satisfeitas. Para que isto ocorra é necessário que as pressões e as temperaturas do sistema e o ambiente sejam iguais. O adjetivo restrito indica que, sob tais condições, as substâncias do sistema estão controladas por uma barreira física que evita a troca de matéria entre o sistema e o ambiente. Por isto não existe um equilíbrio químico entre o sistema e o ambiente.

\subsection{Estado morto}

Segundo Kotas (1985), o estado morto é definido como aquele no qual as condições de equilíbrio térmico, mecânico e químico entre o sistema e o ambiente são 
satisfeitas (equilíbrio termodinâmico total). Assim, além das pressões e temperaturas, os potenciais químicos das substâncias do sistema e o ambiente devem ser iguais. Sob estas condições de equilíbrio termodinâmico total entre o sistema e o ambiente, o sistema não pode sofrer nenhuma mudança de estado por meio de alguma forma de interação com o ambiente.

\subsection{Componentes da exergia}

Desprezando efeitos pouco comuns na análise de processos, como os efeitos nucleares, magnéticos, elétricos e de tensão superficial, a exergia total de um sistema pode ser dividida em quatro componentes: exergia física, cinética, potencial e química.

$B=B_{f}+B_{\text {cin }}+B_{\text {pot }}+B_{q u i ́}$

Em base mássica:

$b=b_{f}+b_{\text {cin }}+b_{\text {pot }}+b_{\text {quí }}$

As energias cinética e potencial podem ser totalmente convertidas em trabalho, portanto correspondem às exergias cinética e potencial, como segue:

$B_{\text {cin }}=m \frac{\mathrm{v}^{2}}{2}$ e $\quad B_{p o t}=m g z$

$\mathrm{Na}$ análise de sistemas, esses componentes geralmente têm valor zero ou são desprezíveis frente aos valores de entalpia (h), e energia interna (u).

A exergia física é igual à máxima quantidade de trabalho obtida quando um sistema ou fluxo de uma substância passa de um estado inicial ao estado de referência restrito. Para um sistema, a exergia física é dada por: 
$B_{f}^{s}=B-B^{*}+p_{0}\left(V-V^{*}\right)-T_{0}\left(S-S^{*}\right)$

Em base mássica:

$b_{f}^{s}=b-b^{*}+p_{0}\left(v-v^{*}\right)-T_{0}\left(s-s^{*}\right)$

e para um fluxo:

$\dot{B}_{f}=\dot{m}\left(h-h^{*}-T_{0}\left(s-s^{*}\right)\right)$

Em base mássica:

$b_{f}=h-h^{*}-T_{0}\left(s-s^{*}\right)$

No cálculo da exergia física basta que o meio seja caracterizado pela pressão e a temperatura do estado de referência restrito $\left(p_{o}\right.$ e $\left.T_{o}\right)$.

A exergia química é igual à máxima quantidade de trabalho obtida quando um sistema ou fluxo é levado do estado de referência restrito ao estado morto. Para um sistema, tem-se:

$B_{\text {qui }}^{s}=U^{*}+p_{0} V^{*}-T_{0} S *-\sum_{i=1}^{n} \mu_{0, i} N_{i}=\sum_{i=1}^{n}\left(\mu_{i}^{*}-\mu_{0, i}\right) N_{i}$

já para um fluxo em base molar tem-se:

$\bar{b}_{\text {qui }}=\bar{h}^{*}-T_{0} \bar{S}^{*}-\sum_{i=1}^{n} \mu_{0, i} x_{i}$ 
A exergia química molar total de uma mistura composta por i espécies químicas se define como:

$\bar{b}_{\text {quí }}=\sum_{i}\left(\mu_{i}-\mu_{0, i}\right) x_{i}+R T_{0} \sum_{i} x_{i} \ln \left(a_{i}\right)$

A exergia total para um sistema é dada por:

$B^{s}=U+p_{0} V-T_{0} S-\sum_{i=1}^{n} \mu_{0, i} N_{i}$

e para um fluxo, tem-se:

$\bar{b}=\bar{h}-T_{0} \bar{s}-\sum_{i=1}^{n} \mu_{0, i} x_{i}$

\subsection{Balanço de exergia}

A análise exergética é uma aplicação sistemática da primeira e segunda leis da Termodinâmica na avaliação do desempenho dos processos de conversão de energia, permitindo a efetiva avaliação termodinâmica dos processos, uma vez que quantifica as irreversibilidades que ocorrem durante o desenvolvimento destes processos.

O emprego combinado da primeira e segunda leis da Termodinâmica permite que se estabeleça o balanço de exergia. Considerando-se o volume de controle mostrado 
na Fig. 1, pode-se escrever os balanços de energia e entropia, para condições de regime permanente:

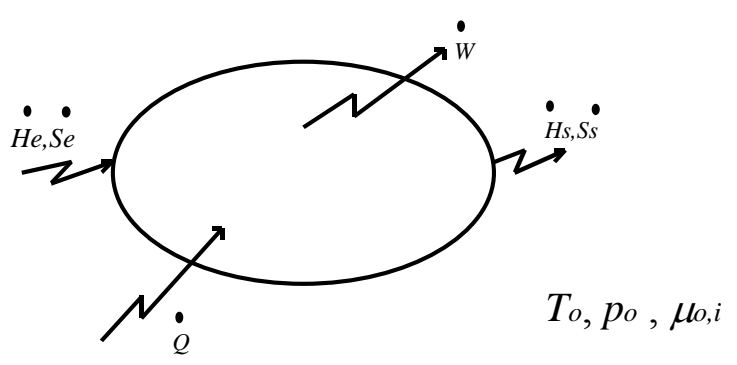

Figura 1 - Volume de controle.

Balanço de Energia (desprezando as energias cinética e potencial):

$\dot{Q}-\dot{W}=\dot{H}_{s}-\dot{H}_{e}$

Balanço de Entropia:

$\frac{\dot{Q}}{T}+\dot{\sigma}=\dot{S}_{s}-\dot{S}_{e}$

Multiplicando-se a eq. (3.14) por (- $\left.T_{o}\right)$ e somando à eq. (3.13) tem-se:

$$
\dot{H}_{s}-\dot{H}_{e}-T_{o}\left(\dot{S}_{s}-\dot{S}_{e}\right)=\dot{Q}\left(1-\frac{T_{o}}{T}\right)-\dot{W}-T_{o} \dot{\sigma}
$$

A eq. (3.15) é o balanço de exergia válido para o volume de controle considerado. Este balanço é formado pelos seguintes termos:

(variação da taxa de exergia entre os fluxos de entrada e saída) = (taxa de exergia associada ao calor trocado) + (taxa de exergia pura = trabalho realizado) - (taxa de exergia destruída) 
A variação de exergia entre os fluxos de entrada e saída do volume de controle caracteriza o máximo trabalho que poderia ser obtido entre os estados de entrada e saída (trabalho reversível). Essa capacidade de realizar trabalho é igual à somatória composta pelas seguintes parcelas:

- taxa de trabalho que seria obtido de um motor térmico reversível operando entre os níveis de temperatura $T$ e $T_{o}$, consumindo $\dot{Q}$ e liberando calor para o meio ambiente a $T_{o}$ (essa taxa de trabalho é a exergia associada ao calor trocado);

- trabalho efetivamente realizado (taxa de exergia pura);

- trabalho disponível destruído devido à existência de processos irreversíveis (taxa de exergia destruída $\left.=T_{0} \dot{\sigma}\right)$.

A eq. (3.15) do balanço de exergia pode ser considerada como a lei da degradação da energia, uma vez que permite a quantificação da redução da capacidade de realização de trabalho, devido à ocorrência de processos irreversíveis durante o desenvolvimento dos processos de conversão de energia.

Dessa forma, é comprovado que a capacidade de realização de trabalho (exergia) não se conserva, sendo sempre reduzida toda vez que houver algum processo irreversível ocorrendo no volume de controle analisado.

As perdas exergéticas dos processos de conversão de energia podem ser divididas em duas partes, uma parte devida à destruição da exergia provocada pelas irreversibilidades do sistema; e a outra parte é a exergia perdida, que é a associada aos fluxos de material ou energia rejeitada ao ambiente.

\subsection{Rendimento ou eficiência exergética}

A eficiência exergética é definida como um parâmetro usado para avaliar o rendimento termodinâmico. A eficiência exergética (rendimento exergético, eficiência de segunda lei, efetividade, ou eficiência racional) fornece uma medida real do rendimento de um processo de conversão de energia do ponto de vista 
termodinâmico. Existem várias definições para a eficiência exergética, algumas delas são:

- Grau de Perfeição:

$\eta_{\mathrm{P}}=\frac{\text { exergia dos produtos úteis }}{\text { exergia da alimentação }}$

- Rendimento/Eficácia exergético:

$$
\begin{gathered}
\eta_{\text {ex }}=\frac{\text { exergia útil produzida }}{\text { consumo de exergia }} \\
\eta_{\text {ex }}=\frac{\sum(\text { exergia de saída })}{\sum(\text { exergia de entrada })}
\end{gathered}
$$

Bejan; Tsatsaronis; Moran (1996), na definição da eficiência exergética, utilizaram os termos produto e combustível para identificar, respectivamente, o resultado desejado produzido por um sistema e os recursos gastos para gerar o produto. A eficiência exergética é dada pela razão entre a exergia do produto e a do combustível. Kotas (1985) definiu a eficiência exergética que chamou de "eficiência racional" em termos de produção desejada e alimentação necessária. Gallegos-Muñoz et al. (2003) definiram a eficiência exergética para uma estação de tratamento de esgoto como a razão da diferença entre a exergia da água não tratada e a exergia da água tratada, pela exergia dos recursos necessários (consumo elétrico e mecânico da estação). A razão entre a exergia da produção desejada e a da alimentação necessária fornece a eficiência exergética. As quatro definições estão de acordo com as eq.(3.16, 3.17, 3.18 e 3.19$)$.

$$
\eta_{\mathrm{ETE}}=\frac{(\text { exergia da água não tratada }- \text { exergia da água tratada })}{(\text { exergia dos } \text { recursos })}
$$




\section{REVISÃO DE LITERATURA}

Este capítulo apresenta uma revisão sistemática do estado da arte da utilização da exergia em questões relacionadas com meio ambiente, como um indicador ecológico de desenvolvimento sustentável, qualidade da água e processos de tratamento de esgoto.

\subsection{Exergia e meio ambiente}

A sociedade humana confronta-se com problemas ambientais, tais como a super exploração de recursos, degradação do meio ambiente, danos de bens e serviços ecológicos, que vêm em detrimento do desenvolvimento sustentável. Estudos baseados em princípios e conceitos físicos, como a exergia e a segunda lei da Termodinâmica, esclarecem esses problemas.

A busca pelo aumento da eficiência e da redução de custos no projeto e operação de um sistema levou os pesquisadores a procurarem entender as causas reais das ineficiências e o custo real das fontes de energia. Nesse contexto, surgiram as primeiras pesquisas sobre o desenvolvimento da análise de exergia, que foi iniciado por Bosjankovic. O termo "exergia" foi introduzido por Rant como uma nova palavra para definir a "capacidade de trabalho", expressão esta utilizada inicialmente por Bosjankovic (Tsatsaronis, 1993). Rant (1956) apud Oliveira (1996) definiu a exergia como a parte da energia que pode ser completamente convertida em qualquer outra forma de energia e é usada para estimar a eficiência termodinâmica de um processo baseado na Segunda Lei da Termodinâmica.

Embora o método da análise de exergia seja considerado como moderno para a análise dos sistemas de energia, os seus fundamentos básicos foram introduzidos no século XIX, seguindo a formulação matemática da Segunda Lei da Termodinâmica, e de conceitos termodinâmicos introduzidos por Clausius, Tait, 
Thomson, Gibbs e Maxwell (Tsatsaronis, 1993). A partir desses primeiros trabalhos surgiram diversas linhas de pesquisa, que estudaram os problemas ambientais e suas ligações com as atividades humanas do ponto de vista da termodinâmica.

A análise exergética é um método técnico para diagnosticar, avaliar e otimizar processos de conversão de energia. O estudo da exergia tem sido aplicado a plantas de potência (Bejan et al., 1996; Kotas, 1985) nas quais as oportunidades de economia de energia são identificadas. Entretanto, o estudo tem sido ampliado à análise de plantas de processo e recursos naturais (Gaggioli, 1980), em que o balanço exergético é uma ferramenta importante para calcular a demanda energética em cada componente da planta, bem como sua relação com o custo energético.

Vários pesquisadores têm desenvolvido teorias biofísicas, que ligam as teorias termodinâmicas e a energia com seu entorno. Nos anos 1970, devido à crise do petróleo, incrementou-se a pesquisa dedicada a explicar as relações entre o meio ambiente e energia.

Tribus; Mclrvine (1971) apud Rosen; Dincer (1997) sugeriram a realização de uma análise exergética dos processos naturais que acontecem na Terra, para formar uma base a fim de elaborar um planejamento ecologicamente confiável e, por meio dessa base, indicar a distorção causada no meio ambiente por mudanças em escala global.

A análise de processos baseada na segunda lei da termodinâmica ganhou relevância, e apareceram vários trabalhos no campo da engenharia química sobre análises de fluxos de energia, introduzindo o conceito de exergia. Entre esses trabalhos, tem-se o de Voigt (1978) apud Tai; Matsushige e Goda (1986), que fez uma avaliação de processos energéticos através da entropia e a exergia, e o de Moran (1982) apud Tai; Matsushige e Goda (1986), que apresentou uma análise de disponibilidade como um guia para o uso eficiente da energia.

Já na década dos anos 1980, alguns pesquisadores sugeriram que a quantificação do impacto ambiental dos processos de energia podia ser feita pelo emprego do conceito de exergia, e que a melhor forma para unir a segunda lei e o impacto ambiental era por meio da exergia porque essa é uma medida do desvio do estado termodinâmico de um sistema em relação ao estado termodinâmico de equilíbrio com o ambiente (Szargut (1980); Edgerton (1982) apud Rosen; Dincer 1997). 
Talvez a melhor definição de exergia tenha sido dada por Szargut et al., (1988), que a definiu como a quantidade de trabalho obtida quando uma massa é trazida até um estado de equilíbrio termodinâmico com os componentes comuns do meio ambiente, por meio de processos reversíveis, envolvendo interação apenas com estes componentes.

Além da aplicação convencional de avaliar a eficiência ou eficácia de sistemas de utilização de energia e detectar quantitativamente as causas de imperfeição termodinâmica de processos térmicos ou químicos, a exergia desperta grande interesse na contabilização dos recursos ambientais, avaliação de impacto ambiental, avaliação de custos ecológicos e modelagem ecológica. A contabilidade de recursos em termos exergéticos tem sido realizada nas escalas nacionais (Wall, 1987;1990;1994) ou no setor industrial, dando muita atenção ao relacionamento entre a utilização da exergia e os impactos ambientais, e à destacada relação da análise exergética para o desenvolvimento sustentável.

Em uma combinação do método exergético com a Análise de Ciclo de Vida (ACV), Ayres; Ayres; Martinás (1996) propuseram efetuar uma contabilidade ao longo do ciclo de vida de produtos, e calcular a exergia usada e perdida como uma medida da eficiência técnica, com a qual é convertida a exergia contida nos recursos naturais em serviços finais. Os autores calcularam os valores de exergia para dois processos, um de produção de cloro e o outro de produção de PVC e apresentaram os resultados por meio da análise de ciclo de vida. Os resultados permitiram concluir que a exergia era apropriada para usos estatísticos gerais, como uma medida comum da qualidade da matéria-prima e de fluxos, e como uma medida das emissões e de seu potencial para causar prejuízos ambientais.

Na linha da análise de ciclo de vida, outros trabalhos importantes são os de Ayres; Ayres; Martinás (1997) e Ayres (1998), que propuseram a exergia como uma medida agregada do fluxo de recursos naturais, assim como dos resíduos gerados pelo subsistema econômico, uma vez que é uma função que pode ser calculada tanto para os recursos energéticos como para os não energéticos; e o de Finnveden e Ostlund (1997) que desenvolveu uma análise de ciclo de vida baseada na exergia, introduzindo o conceito de exergia na metodologia de avaliação de ciclo de vida ambiental e usando-a como um indicador uniforme de impacto ambiental total. 
Ainda na década de 1990 apareceram vários trabalhos que explicavam as relações entre a exergia e o impacto ambiental. Um destes trabalhos foi feito por Rosen; Dincer (1997) que apresentaram três relações entre exergia e impacto ambiental: a destruição da ordem/criação do caos, a degradação dos recursos naturais e as emissões da exergia dos rejeitos. Nesse trabalho, concluíram que a utilidade potencial da análise exergética na direção e solução de problemas ambientais é de grande importância.

Creyts; Carey (1997) apresentaram uma medida objetiva unificada chamada exergia estendida, a qual foi definida como o mínimo trabalho possível requerido para trazer um sistema de seu estado inicial até um estado de referência ambientalmente aceitável. Essa medida permitiu a avaliação do impacto ambiental dos processos industriais, calculando a exergia que deve ser adicionada no tratamento dos rejeitos dos processos, para diminuir o impacto desses sobre o ambiente. O uso da exergia estendida em combinação com bases de dados permite ao projetista integrar objetivamente critérios ambientais nos estágios do planejamento do projeto industrial.

Makarytchev (1997) fez uma análise de Segunda Lei que permitiu a avaliação dos impactos ambientais da cogeração de um combustível e potência elétrica a partir do carvão. Essa análise foi baseada na evolução do ciclo de vida da exergia contida em vetores energéticos envolvidos no processo, e forneceu uma abordagem coerente com as avaliações do consumo de recursos e taxas de poluição ambiental, permitindo uma avaliação ambiental diferente da abordagem termoeconômica.

Na linha da ecologia industrial, Dincer; Rosen (1998) apresentaram as relações entre os problemas ambientais mais relevantes (a chuva ácida, o esgotamento do ozônio estratosférico e o efeito estufa) e os conceitos de exergia, ambiente e desenvolvimento sustentável. Da análise dessas relações concluíram que, para os processos de energia, é necessária a implementação de medidas que levem ao aumento da eficiência exergética, à estabilização ou redução dos gases de efeito estufa e à substituição de combustíveis fosseis.

Continuando nessa linha, Rosen; Dincer (1999) identificaram as relações entre os valores das exergias químicas das substâncias encontradas nas emissões, e as medidas do impacto ambiental. Essas relações conduziram a procedimentos para 
avaliar os efeitos prejudiciais sobre o ambiente e para predizer o potencial que uma substância tem para provocar um impacto no ambiente. Os autores apresentaram duas correlações do potencial por meio de parâmetros exergéticos, que avaliam os custos ambientais da poluição. O primeiro parâmetro proposto foi o custo para remover um poluente de uma emissão ao ambiente, e o outro parâmetro foi o custo para prevenir um escape de uma emissão prejudicial ao ambiente.

Em uma aplicação da análise exergética a processos mitigadores de impacto ambiental, Lattouf; Oliveira (2003) apresentaram uma metodologia para a avaliação de diferentes alternativas de processos para a mitigação do impacto ambiental. Os autores propuseram dois índices exergéticos para comparar as alternativas de processo, o índice $\eta_{d}$ :

$$
\eta_{d}=\left(\mathrm{B}_{\text {contaminante }}-\mathrm{B}_{\text {rejeito }}-\mathrm{B}_{\text {produto }}\right) /\left(\mathrm{B}_{\text {insumos }}\right)
$$

quando o objetivo do processo é a destruição da exergia do contaminante, e o índice $\eta_{p}:$

$\eta_{p}=\left(\mathrm{B}_{\text {rejeito }}+\mathrm{B}_{\text {produto }}\right) /\left(\mathrm{B}_{\text {contaminante }}+\mathrm{B}_{\text {insumos }}\right)$

quando o objetivo do processo é a maximização do aproveitamento da exergia do contaminante. Os estudos de caso analisados foram: a) tratamento de emissões atmosféricas, b) remediação de um sítio contaminado e c) gerenciamento de resíduo sólido. Para cada caso consideraram três alternativas de processo. A partir dos resultados obtidos, os autores concluíram que a exergia acumulada é uma ferramenta útil para a quantificação do custo ambiental de processos mitigadores de impactos ambientais. O rendimento exergético é um critério inovador para a avaliação da sustentabilidade desses processos.

\subsection{Exergia como um indicador ecológico de desenvolvimento sustentável}


O conceito de exergia tem sido ampliado e generalizado além do campo da Termodinâmica clássica, tornando-se cada vez mais proeminente em aplicações para avaliação de sistemas ecológicos.

Com uma sólida base científica em física, a exergia tem sido adotada como um indicador ecológico e uma função objetivo para modelagem ecológica e avaliação ambiental. Partindo da definição de exergia e de características implícitas no conceito, sugeriu-se que a exergia tem potencial como uma função objetivo de um ecossistema dinâmico e pode ser usada para descrever a estrutura e o desenvolvimento de um ecossistema. Além disso, mostrou-se que a exergia e a exergia específica podem ser aplicadas como indicadores para avaliar o estado ecológico de um ecosistema (Jorgensen (1988, 1992), Jorgensen et al. (1995)).

Na linha da ecologia, Zhou; Ma; Hinman (1996) apresentaram uma análise exergética ecológica, para descrever os processos físico-químicos nos organismos. Partindo das equações do balanço de exergia para uma planta e um animal, definiram a "eficiência exergética ecológica" como um índice para avaliar a perfeição termodinâmica de diferentes processos ecológicos. Zhou; Ma; Hinman (1996) propuseram quatro índices de eficiência exergética ecológica:

a) "eficiência exergética do processo ecológico de um animal", definida como:

$$
\eta_{e}^{1}=\left(\mathrm{B}_{\mathrm{P}}+\mathrm{B}_{\mathrm{R}}+\mathrm{B}_{\mathrm{F}}+\mathrm{B}_{\mathrm{Q}}\right) / \mathrm{B}_{\mathrm{I}}
$$

na qual $B_{P}$ é a exergia contida nos processos de produção energética do animal, $B_{R}$ é a exergia associada à respiração, $B_{F}$ é a exergia associada aos processos de excreção (fezes e urina), $B_{Q}$ é a exergia associada à troca térmica do animal com seu ambiente e $B_{\perp}$ é a exergia associada ao processo de ingestão do alimento;

b) "eficiência exergética de assimilação" definida como:

$$
\eta_{e}^{2}=\left(\mathrm{B}_{\mathrm{P}}+\mathrm{B}_{\mathrm{R}}\right) / \mathrm{B}_{1}
$$

este índice mede a habilidade dos organismos para assimilar a exergia;

c) "eficiência exergética de produção" definida como: 
$\eta_{e}^{3}=\mathrm{B}_{\mathrm{P}} /\left(\mathrm{B}_{\mathrm{I}}-\mathrm{B}_{\mathrm{F}}-\mathrm{B}_{\mathrm{Q}}\right)$

este índice mede a habilidade dos organismos para produzir exergia, e;

d) "eficiência exergética de respiração" definida como:

$\eta_{e}^{4}=\mathrm{B}_{\mathrm{R}} /\left(\mathrm{B}_{1}-\mathrm{B}_{\mathrm{F}}-\mathrm{B}_{\mathrm{Q}}\right)$

este índice expressa a fração da exergia assimilada que os organismos usam para manter suas atividades vitais.

Finalmente, concluíram que o índice $\eta_{e}{ }^{1}$ pode ser usado como uma função objetivo na otimização termoeconômica de um ecossistema, e que o método desenvolvido é uma ferramenta útil nas pesquisas de fluxo e produção de exergia em sistemas biológicos.

Vários pesquisadores consideram a exergia dos depósitos sobre a terra como um indicador ecológico de desenvolvimento sustentável e como o recurso limitante para o funcionamento de todos os sistemas, uma vez que os processos da vida que agem na terra estão acumulando constantemente exergia nos depósitos.

Baseado na teoria do custo exergético e o cálculo do custo exergético de reposição dos recursos, Ranz (1999), Botero (2000) fez uma avaliação exergética dos recursos naturais (minerais, água e combustíveis fósseis). Para o caso dos minerais, usou um modelo de avaliação termodinâmica que levou em conta as características físicas e químicas que fazem esses recursos úteis e disponíveis para o homem tendo em conta as limitações tecnológicas atuais. A partir dos resultados obtidos por meio do modelo demonstrou que a terra, devido à concentração dos minerais na crosta, encontra-se numa condição muito mais próxima da máxima dispersão do que uma situação hipotética de estoque, na qual todos os elementos estariam totalmente ordenados. Para os combustíveis fósseis, usou o conceito do custo exergético de abatimento, por meio do qual é possível determinar quanta exergia do combustível é necessária para o abatimento de suas emissões, contando para isso com a melhor tecnologia disponível; propôs uma nova unidade de medida energética chamada "TLEP" (toneladas limpas equivalentes de petróleo) que permitiu expressar o capital 
natural limpo como aquela reserva de energia fóssil que apesar de ser usada na sua totalidade, não teria conseqüências desastrosas para o meio ambiente.

No caso da água, propôs avaliar o componente renovável deste recurso, por meio do seu custo exergético de reposição, que definiu como a exergia requerida para devolver um recurso (água) a um ecossistema em suas condições originais (químicas, físicas, biológicas e bacteriológicas), usando as melhores tecnologias disponíveis. Os resultados obtidos dessa forma indicaram que seriam necessárias de 0,4 a 6,4 vezes mais energia de combustíveis fósseis por ano para substituir só parte das funções do ciclo hidrológico.

Botero (2000) afirmou que a exergia entendida como a quantidade mínima de trabalho que é necessário investir para, por meio de um processo reversível, obter uma substância ou recurso a partir de um ambiente de referência, é a mínima energia que investiu a natureza para fornecer os recursos naturais nas condições específicas (físicas e químicas) que os diferenciam do entorno, e os fazem úteis para o subsistema econômico.

Nessa linha, Sciubba $(2001,2003 a, 2003 b)$ discutiu um novo paradigma para o cálculo do custo ambiental real pela realização da contabilidade exergética estendida, e forneceu uma estrutura para avaliação integrada de questões relacionadas ao capital, trabalho e impacto ambiental. Szargut et al. (2002) redefiniu o índice de consumo cumulativo ou as perdas de exergia dos recursos dos depósitos, como um índice de custo ecológico, e usou o termo "custo ecológico" para expressar o consumo cumulativo de exergia não renovável ligado com a fabricação de produtos especiais. Dessa forma, a minimização do custo ecológico conduz à minimização do esgotamento dos recursos naturais não renováveis, podendo contribuir assim à proteção do ambiente natural.

Similarmente, Wall e Gong (2001a) sugeriram que a exergia dos depósitos poderia ser considerada como uma medida do valor dos sistemas vivos atuais e um indicador de sustentabilidade ambiental, uma vez que uma redução deste depósito de exergia levaria inevitavelmente a uma destruição do sistema de apoio da vida sobre a terra.

A exergia das emissões pode ser considerada um indicador de efeitos ambientais e a exergia incorporada nos rejeitos uma medida do potencial para causar danos 
ambientais (Gong e Wall, 2001b). Os autores analisaram a exergia a partir da definição dada pela OECD (Organization for Economic Cooperation and Development) para um indicador ecológico. Indicador ecológico é um parâmetro, ou um valor derivado de parâmetros, que fornece informação, descreve o estado de um fenômeno, ambiente ou área, com uma importância estendida além do valor associado com o parâmetro. Para demonstrar que a exergia é um indicador ecológico, fizeram uma comparação entre o indicador ecológico chamado Ecoindicador 95 (EI95) e a exergia. Para o estudo de caso usaram os dados de Cornelissen (1997) apud Gong; Wall (2001b). Os autores aplicaram o indicador EI95 e a exergia às emissões da produção de uma caneca de porcelana e uma xícara de poliestireno. Da análise dos resultados, os autores concluíram que a exergia pode ser uma melhor medida do dano e um bom indicador ecológico visto que uma elevada eficiência exergética significa menos rejeitos (de exergia) ao ambiente ou menos prejuízo ambiental (maior aproveitamento da exergia dos recursos e menor destruição e perda de exergia). Além disso, a exergia foi introduzida na metodologia da avaliação de ciclo de vida ambiental e utilizada como um indicador unificado do impacto ambiental total.

$\mathrm{Na}$ área da pesquisa que relaciona a exergia com a sustentabilidade, Wall (2002) propôs que para projetar os sistemas de administração e conversão de energia de uma sociedade sustentável, é necessário aplicar a exergia pois ela clarifica a situação por meio da exposição das perdas de um processo e das emissões ao ambiente. O conceito de exergia quantifica esses fluxos, os quais são minimizados, a fim de encontrar condições sustentáveis. Dessa forma, Wall (2002) concluiu que a exergia é um conceito apropriado e necessário para o desenvolvimento de uma engenharia de energia em harmonia com a natureza.

Jorgensen e Svirezhev (2004) apresentaram em seu livro dois tópicos de interesse. O primeiro deles é como calcular a exergia da matéria orgânica viva, e o outro é uma aplicação da exergia como um indicador ecológico. No primeiro aspecto, apresentase a exergia como a resposta da diferença existente entre a matéria orgânica viva e morta, sendo que essas diferem pelo conteúdo de exergia. Já na aplicação da exergia como um indicador ecológico, os autores discutiram a relação entre exergia e integridade de um ecossistema e observaram que a integridade se reflete em dois aspectos do estado organizacional de um ecossistema: o funcional e o estrutural, no 
qual a função se refere às atividades globais do ecossistema e a estrutura se refere à interconexão entre os componentes do sistema. As medidas da função indicam a quantidade da energia que está sendo capturada pelo sistema. Por outro lado, as medidas da estrutura indicam o caminho através do qual a energia se transfere no sistema. A integridade está associada com a habilidade do sistema para alcançar e manter seu ponto de operação ótimo.

Os autores observaram que a exergia expressa a biomassa do sistema e a informação que essa biomassa carrega. A exergia também expressa a energia necessária para decompor a matéria orgânica. $O$ índice de exergia relativa pode ser uma medida da integridade de um ecossistema por que ele cumpre com os seguintes pontos da definição de integridade de ecossistema de Costanza (1992) apud Jorgensen e Svirezhev (2004):

a) a exergia considera a informação contida nos genes;

b) a exergia é sensível à perda da biomassa provocada por doenças nos organismos, e esse fato dá uma vantagem ao uso da exergia como um indicador ecológico;

c) a exergia é uma medida da complexidade, por exemplo, a matéria viva tem maior exergia que os mesmos elementos em forma orgânica (matéria morta), e esses por sua vez têm maior exergia que os elementos na forma inorgânica;

d) a exergia está relacionada à resistência de um ecossistema;

e) a exergia pode ser considerada como um potencial para o crescimento, e é nesse contexto que há uma relação entre a exergia estocada no ecossistema e a habilidade do ecossistema para capturar exergia a partir da radiação solar.

Porém, a exergia não abrange o balanço entre os componentes do sistema e a biodiversidade, por isto se faz necessária a utilização de indicadores suplementares de integridade na avaliação do ecossistema.

Bastianoni et al. (2005) apresentaram quatro índices diferentes de eficiência para analisar diferentes aspectos de sustentabilidade de processos e sistemas. $\mathrm{Na}$ definição dos índices que usaram na análise dos sistemas, utilizaram a exergia da saída do processo ( $\left.B_{\text {saída }}\right)$, a exergia armazenada no sistema $\left(B_{a}\right)$ e a exergia de entrada ( $\left.B_{\text {entrada }}\right)$ necessária para conduzir um processo ou um sistema. $A$ exergia de 
saída é o conteúdo exergético da saída de um processo, a exergia armazenada é o mesmo conteúdo exergético cumulativo definido pelo Szargut et al., (1988), a exergia de entrada é a relacionada com a criação e manutenção do sistema. Além destes termos usaram a definição de emergia, quantificação dos fluxos energéticos da terra em termos da energia solar $\left(E_{m}\right)$, como uma forma para quantificar o trabalho necessário na natureza para obter um dado produto ou um fluxo.

Bastianoni et al. (2005) definiram os seguintes índices ou eficiências:

1. Uma eficiência de segunda lei, também chamada de grau de perfeição:

$$
\mathrm{B}_{\text {saída }} / \mathrm{B}_{\text {entrada }}
$$

2. Uma eficiência em termos de emergia:

$$
\mathrm{B}_{\text {saída }} / \mathrm{E}_{\mathrm{m}}
$$

3. Uma eficiência que descreve o nível de organização mantido por uma quantidade de fluxo exergético entrante. Esse índice não pode ser visto como uma eficiência, ele tem unidades de tempo:

$$
\mathrm{B}_{\mathrm{a}} / \mathrm{B}_{\text {entrada }}
$$

e por último apresentaram a relação:

$$
\mathrm{B}_{\mathrm{a}} / \mathrm{E}_{\mathrm{m}}
$$

Essa relação é importante para saber qual é o trabalho que a biosfera tem desempenhado para manter certa organização, informação e exergia, e o conceito de emergia dá uma medida apropriada para esse trabalho. Esse índice também apresenta unidades de tempo.

Os autores aplicaram esses índices em dois sistemas agrícolas similares. Da análise dos quatro índices concluíram que a equação (4.10) é mais orientada para o campo ecológico, pois é mais abrangente e está baseada em emergia e exergia armazenada. Por outro lado, a equação (4.7) é a mais orientada para o campo 
energético econômico. Finalmente, concluíram que os quatro índices apresentados só representam uma parte de uma avaliação completa de sustentabilidade.

Chen (2005, 2006), em um estudo sistemático sobre consumo global de exergia, apresentou a exergia cósmica como a base produtiva necessária fundamental para todas as atividades econômicas e ecológicas sobre a terra, e a escassez de disponibilidade de exergia cósmica como o recurso natural fundamental para a ecosfera e a sociedade humana, tendo essa última uma forte implicação no desenvolvimento sustentável. Nesses trabalhos, ele desenvolveu um conceito chamado de exergia incorporada, a partir da generalização de duas teorias, a teoria da exergia embutida de Odum e a exergia cumulativa de Szargut em uma estrutura conceitual. Nessa estrutura, ele definiu o valor ecológico para um fluxo rejeitado como negativo e igual em magnitude à exergia incorporada correspondente, em termos da exergia total consumida no tratamento de rejeitos humanos ou na degradação natural de um fluxo rejeitado. O autor concluiu que a exergia incorporada pode ser considerada como um indicador para avaliação ecológica de sistemas.

\subsection{Exergia e qualidade da água}

Jorgensen e coautores pesquisadores (Bendoricchio e Jorgensen (1997); Jorgensen et al. (2002); Marques et al. (1997)) têm trabalhado na modelagem exergética de sistemas aquáticos tais como lagos e áreas costeiras, demonstrando e ilustrando os relacionamentos entre exergia e biomassa, biodiversidade, composição das espécies, e outras propriedades dos ecosistemas.

Entre estes trabalhos, tem-se o de Fuliu (1997), que aplicou os conceitos de exergia e exergia estrutural como indicadores ecológicos na descrição e avaliação do estado de desenvolvimento do ecossistema do lago Chaohu na China. A exergia estrutural mede a capacidade do ecossistema para utilizar os recursos disponíveis. O autor demonstrou e analisou as relações dos indicadores definidos com o estado trófico, a biodiversidade, a biomassa e a composição das espécies. Os resultados mostraram que um aumento da exergia estrutural implica no desenvolvimento do ecossistema 
do lago e a eficácia no tratamento da poluição acompanhado por um aumento da biodiversidade, organismos mais complexos e diminuição da eutrofização. Também observou que as mudanças da exergia podem expressar as mudanças da estrutura ou dos componentes do ecossistema. Finalmente concluiu que a exergia e a exergia estrutural podem servir como indicadores ecológicos que fornecem informações apropriadas sobre o estado de desenvolvimento do ecossistema do lago e seus efeitos sobre a qualidade da água.

Numa outra aplicação da análise exergética para corpos aquáticos, Zaleta-Aguilar; Ranz e Valero (1998) realizaram uma contabilidade preliminar de recursos, em termos da disponibilidade da água do rio, quantificada como o fluxo de exergia mecânica, térmica e química dentro do fluxo do rio. Na busca de uma medida unificada para a disponibilidade do rio Ebro, aplicaram a análise exergética para avaliar, e comparar a capacidade hídrica de um rio desde sua nascente até sua foz. Os autores utilizaram a informação fornecida pela análise exergética na comparação das disponibilidades nos diferentes estágios do rio, o que ajudou a entender melhor o processo de degradação ao qual o rio foi submetido. Na quantificação do conteúdo exergético das substâncias orgânicas, propuseram um composto orgânico único para representar uma molécula orgânica média que possibilitava o cálculo da magnitude dos compostos orgânicos; a molécula proposta foi um lipídio quimicamente expresso por $\mathrm{C}_{39} \mathrm{H}_{80} \mathrm{O}_{3}$, e por meio de medidas de laboratório de DQO, estimaram a massa de oxigênio por litro de água do rio consumidos na reação de degradação, obtiveram dessa forma a quantidade de moles de substância orgânica média por litro de água. Finalmente concluíram que a abordagem exergética cumpriu com os objetivos, pois ela forneceu um critério unificado na hora de fazerem diagnósticos e quantificar mudanças ao longo do curso do rio.

Valero et al. (2006) apresentaram uma nova abordagem de análise que chamaram de "Física Hidronômica" como um guia para avaliar custos ambientais; aplicaram a exergoecología (definida como a avaliação exergética dos recursos naturais da terra a partir de um ambiente de referência) ao recurso natural aquático, para propor uma estrutura de custos universais, transparente e objetiva, capaz de mostrar o custo físico real da água. Finalmente, concluiram que essa metodologia deve complementar outras abordagens de análise de custos, a fim de desenvolver uma análise econômica a partir de uma perspectiva multidimensional e multidisciplinar. 
Outros trabalhos importantes que ligam o conceito de exergia com a avaliação da qualidade da água são mais recentes como o de Chen e Ji (2007), que introduziram o conceito termodinâmico de exergia química na avaliação da qualidade da água, para desenvolver indicadores objetivos unificados. Um desses indicadores que denominaram de exergia química padrão específica (EQPE), baseada nas substâncias de referência global, foi utilizado para avaliar a qualidade da água padrão. O outro indicador definido foi a exergia química relativa específica (EQRE), baseado em um espectro de substâncias de referência associadas com alguns padrões de qualidade da água especificados. Esse último indicador foi desenvolvido para a avaliação prática da qualidade da água, com conceitos relacionados à capacidade de suporte, bem estabelecidos em termos exergéticos.

A situação de déficit de suporte aparece para um valor positivo de EQRE, na qual a quantidade de poluentes exergéticos na água excede a quantidade que o corpo aquático poderia soportar. Já a capacidade de suporte tem-se quando é calculado um valor negativo de EQRE, o que implica que as quantidades de poluentes exergéticos na água estão abaixo da quantidade que o corpo aquático poderia soportar; esses limites são especificados pela norma ou padrão. É preferível ter para os corpos aquáticos uma grande capacidade de suporte ou um pequeno déficit de suporte (Chen e Ji, 2007). Com base nos resultados obtidos num projeto de coleta de dados, avaliaram a qualidade da água de 72 rios e 24 lagos do mundo. Os resultados foram apresentados como um estudo de caso detalhado para mostrar a adaptabilidade dos indicadores definidos na avaliação da qualidade da água. Assim, o conceito termodinâmico de exergia tem ganhado ampla aceitação no campo ecológico e ambiental como uma medida unificada do desvio de um sistema a partir de seu ambiente de referência.

Huang et al. (2007), baseados nos trabalhos de Chen (2005, 2006), mostraram que a exergia é um indicador adequado para a avaliação ecológica, uma vez que ela fornece uma medida termodinâmica unificada de avaliação objetiva de recursos. Essa definição surgiu a partir da análise de que a exergia cósmica é um recurso natural fundamental, que conduz e sustenta a ecosfera e a sociedade humana, associado com o raciocínio de que a escassez da disponibilidade de exergia cósmica sobre a terra tem fortes implicações no desenvolvimento sustentável, e ao fato de que na elaboração e sustentação de uma utilidade como um produto, serviço 
ou emissão sempre aparece um consumo de exergia. Da análise desses três argumentos, os autores concluíram que a exergia pode ser considerada como uma medida unificada na avaliação ecológica.

Para aplicar o conceito de exergia na avaliação da qualidade da água, apresentaram um estudo de caso do Rio Huangpu. Da comparação da análise exergética com outros métodos de avaliação ecológica, concluíram que a análise produz resultados mais realistas e fornece valores físicos consistentes, úteis na quantificação da poluição da água. Finalmente, expressaram que a exergia incorporada nos poluentes oferece uma medida bastante confiável do potencial para provocar danos ambientais, os quais representam o custo termodinâmico da poluição da água e o estado ecológico do ambiente aquático.

Chen et al. (2007), baseados na teoria da exergia dos recursos, propuseram um índice exergético unificado e objetivo para avaliar a quantidade e a qualidade da água do corpo principal do Rio Amarelo, e verificaram a quantidade disponível real da água do rio do ponto de vista termodinâmico ecológico. Eles definiram o índice de potencial exergético como a razão da densidade exergética pela aceleração gravitacional, para descrever diferentes capacidades de trabalho ao longo do corpo principal do rio. Finalmente, baseados na medida exergética proposta apresentaram a variação temporal e espacial dos recursos aquáticos da corrente principal do rio. Como resultado do estudo foi observado que, comparada com outros métodos de avaliação convencional da água, a avaliação exergética produz resultados de valoração termodinâmica e fornece um método consistente, do ponto de vista biofísico, para quantificar a disponibilidade real dos recursos aquáticos. A avaliação exergética dos recursos aquáticos é uma medida unificada da qualidade e da quantidade da água.

Jorgensen e Nielsen (2007), baseados em trabalhos anteriores, introduziram uma forma modificada da exergia que chamaram de eco-exergia, como um indicador ecológico relativo, e calcularam a exergia da matéria orgânica morta e de vários organismos a partir dessa definição. A eco-exergia mede o desvio do sistema a partir do equilíbrio químico (exergia química), mas também pode ser usada como uma medida do desenvolvimento do sistema considerado. Com essa aplicação, os autores observaram que a eco-exergia poderia ser um bom indicador do grau de desenvolvimento de um ecossistema e uma medida da dificuldade para destruí-lo, 
porém não é possível calcular esse valor para todo o ecossistema por causa da sua complexidade. Além da eco-exergia definiram a eco-exergia específica como a ecoexergia por unidade de biomassa e observaram que esses dois índices podem ser aplicados diretamente como indicadores de sustentabilidade e ilustraram esse fato através de três estudos de caso em ecossistemas aquáticos. Nessa linha de raciocínio, concluiram que a exergia torna-se, portanto, uma medida da capacidade de carga e da resistência do sistema e apresentaram uma aplicação do índice a dados da literatura relacionados com ecossistemas. Além disso, mostraram como calcular a exergia da matéria orgânica e organismos e discutiram como a exergia poderia ser aplicada para medir a sobrevivência. Finalmente, concluiram que o índice de eco-exergia ainda precisa ser mais aplicado para demonstrar a utilidade do método e para mostrar como os índices exergéticos podem ser traduzidos à informação ecológica aplicável.

\subsection{Exergia em processos de tratamento de esgoto}

O conceito de exergia também tem sido usado para avaliação de processos de tratamento de esgoto, ilustrando a relação entre a exergia e parâmetros de qualidade da água.

O primeiro e um dos trabalhos mais importantes nesse campo foi realizado por Tai; Matsushige e Goda (1986) no qual, para expressar de uma forma mais simples os processos complexos que ocorrem no tratamento de esgoto, usaram um método sistemático de avaliação da exergia dos compostos orgânicos e discutiram a relação entre índices comuns de qualidade da água e a exergia química. Os autores relacionaram a exergia química da matéria orgânica no esgoto com características do esgoto como DQO (Demanda Química de Oxigênio), DTO (Demanda Teórica de Oxigênio) e COT (Carbono Orgânico Total). Observaram que a exergia é útil na análise Termodinâmica de processos de tratamento de esgoto baseada na Segunda Lei da termodinâmica. Os autores também observaram que as exergias de 138 compostos orgânicos mostravam uma correspondência consistente com os valores 
teóricos de DTO. Esses poluentes incluem compostos orgânicos simples e complexos, carboidratos, proteínas, ácidos graxos e produtos sintéticos. Para o cálculo da exergia expressaram o composto orgânico da forma $\mathrm{C}_{\mathrm{a}} \mathrm{H}_{\mathrm{b}} \mathrm{O}_{\mathrm{c}}$.

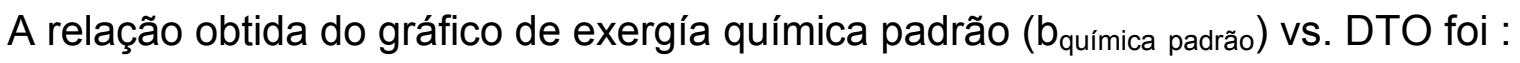

$b_{\text {química padrão }}(\mathrm{J} / \mathrm{L})=13,6 \times$ DTO $(\mathrm{mg} / \mathrm{L})$

Tai; Matsushige e Goda (1986) observaram que a DTO representa indiretamente a magnitude da energia útil. Da observação das relações entre DBO - DTO e entre DQO - DTO chegaram à equação :

$b_{\text {química padrão }}(\mathrm{J} / \mathrm{L})=13,6 \times \mathrm{DQO}(\mathrm{mg} / \mathrm{L})$

Além disso, os autores observaram que com relação à formação de $\mathrm{CO}_{2}$ por oxidação, a relação entre COT - DTO é bastante importante e do gráfico (b $b_{\text {quimica }}$ padrão) vs. COT encontraram a equação :

$\mathrm{b}_{\text {quimica padrão }}(\mathrm{J} / \mathrm{L})=45 \times \mathrm{COT}(\mathrm{mg} / \mathrm{L})$

A partir dos resultados, concluíram que é possível determinar as exergias das substâncias orgânicas presentes no esgoto, cujos componentes são desconhecidos, por meio das relações descritas anteriormente. Finalmente concluíram que a energia disponível das substâncias presentes no esgoto pode ser expressa por meio da exergia, para efeito de avaliação de processos biológicos, tais como os de lodos ativados, do ponto de vista termodinâmico, e recomendaram o uso da exergia química padrão para a avaliação do requerimento energético de um sistema de tratamento de esgoto e para determinar o sistema mais eficiente do ponto de vista da energia entre vários processos químicos e biológicos de tratamento de esgoto.

O potencial da análise exergética na abordagem e solução de problemas ambientais é substancial. Assim como no campo do saneamento ambiental, Hellstrom estimou e comparou o consumo de exergia dos recursos físicos em alguns sistemas de tratamento de esgotos. 
Hellstrom (1997) mostrou através de um estudo de caso como uma análise exergética poderia ser usada para estimar o consumo de recursos físicos em uma estação de tratamento de esgoto localizada ao norte da Suíça. Da análise dos resultados, concluiu que o valor do calor é superestimado em uma análise energética convencional e também que a matéria orgânica presente no esgoto representa o maior fluxo de exergia. Deixou em aberto como poderia ser estimado o valor da exergia dos nutrientes e observou que a análise exergética é uma importante ferramenta na análise da sustentabilidade de processos de tratamento de esgoto, mas notou que devido a que o valor da exergia não considera a qualidade biológica da matéria, esse método deve ser aplicado paralelamente com a análise da toxicidade e do uso de recursos.

Hellstrom (1999) analisou e comparou três sistemas de tratamento de esgoto diferentes: um sistema com remoção de nutrientes, um sistema com separação de urina e um sistema de tratamento com separação de urina e fezes. Definiu o consumo de exergia total como:

$B_{\text {Total }}=\left(B_{E s g}+B_{\text {Rec }, \text { Op }}+B_{\text {Transp }}\right)-\left(B_{\text {Met }}+B_{\text {Nut }}\right)$

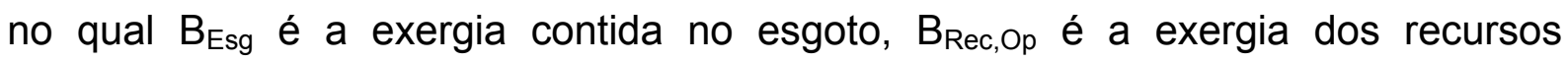
operacionais do sistema de tratamento, $B_{\text {Transp }}$ é a exergia associada ao transporte e espalhamento da urina e dos biosólidos, $B_{\text {Met }}$ é a exergia do biogás (metano) e $B_{\text {Nut }}$ é a exergia dos nutrientes. Hellstrom concluiu que o consumo de exergia total é maior para sistemas de tratamento biológicos com remoção de nutrientes e mínimo para sistemas com separação de urina e fezes, isto porque o potencial de recuperação de exergia aumenta, se a separação de recursos for usada.

O conceito de exergia liga os campos de recursos e ambiente, o qual faz dela uma ferramenta útil no desenvolvimento e projeto de uma sociedade sustentável. Nesse sentido e unido à preocupação com a disponibilidade mundial da água, há cada vez mais uma grande procura por sistemas de tratamento de esgoto sustentáveis. Nesse campo, Balkema et al. (2002) propuseram a utilização de uma estrutura de avaliação de sustentabilidade para sistemas de tratamento de esgoto similar à Análise de Ciclo de Vida (ACV), utilizando um conjunto multidisciplinar de indicadores de sustentabilidade. Apresentaram a recuperação de metano a partir da matéria 
orgânica, a separação de urina nos processos de recuperação de nutrientes e a remoção de metais pesados.

Hellstrom (2003a) utilizou a análise exergética para comparar vários sistemas de tratamento de esgoto utilizados na remoção de nutrientes, concentrando sua análise nos fluxos relacionados ao manejo e tratamento da matéria orgânica e dos nutrientes. Nesses processos, a energia e os compostos químicos não são consumidos, são somente transformados em outras formas. Finalmente, ele encontrou que o consumo de exergia total foi menor para o sistema com separação de urina e fezes e maior para o sistema de tratamento de esgoto com remoção de nutrientes.

Hellstrom et al. (2003b) compararam a eficiência de vários sistemas no manejo de fezes, urina e rejeitos orgânicos domésticos. Os aspectos de projeto que consideraram nos sistemas foram a separação de urina, utilização de vasos sanitários com sistema de vácuo, e processos avançados de recuperação de nutrientes como a osmose reversa. A análise foi feita comparando diferentes estratégias de projeto de sistemas de tratamento de rejeitos de vasos sanitários; a comparação incluiu o uso de recursos naturais, impacto ambiental e a possibilidade da recuperação dos nutrientes disponíveis nitrogênio $(N)$, fósforo $(P)$ e potássio $(K)$ para a agricultura.

Os autores só consideraram a operação dos sistemas, desconsiderando sua construção e manutenção. Os sistemas pesquisados foram: sistema de referência (0): no qual os rejeitos orgânicos domésticos são coletados separadamente e anaerobiamente digeridos, incluindo eliminação biológica de nitrogênio e eliminação química de fósforo; sistema (1): vasos sanitários com sistema de vácuo e tratamento anaeróbio; sistema (2): vasos sanitários com sistema de vácuo e tratamento aeróbio; sistema (3): vasos sanitários com sistema a vácuo e eliminação de nutrientes; nesse sistema também é incluída a eliminação biológica de nitrogênio e eliminação química de fósforo; sistema (4): vasos sanitários com sistema de vácuo e recuperação de nutrientes, nesse sistema os nutrientes do esgoto são recuperados e concentrados por meio de evaporação; sistema (5): vasos sanitários com sistema de vácuo e separação de urina, é o mesmo sistema (3), complementado com separação de urina; sistema (6): tratamento anaeróbio e eliminação de nutrientes; sistema (7): 
tratamento anaeróbio e recuperação de nutrientes; sistema (8): tratamento anaeróbio e separação de urina.

A análise dos resultados mostrou que todos os sistemas estudados produzem baixas emissões de nutrientes, que a separação da urina é viável para reciclagem de nutrientes como nitrogênio e potássio, na faixa de 50 a $70 \%$, e que no caso de ter um requerimento maior de reciclagem de nutrientes é mais apropriado um sistema que utilize um processo de recuperação de nutrientes. Também observaram que para os sistemas de vácuo, as quantidades máximas de água de arraste devem estar abaixo de 10 litros/dia para que sejam eficientes em termos do consumo de exergia, e concluiram que outros efeitos ambientais estão diretamente relacionados com a quantidade de exergia utilizada por sistema.

A exergia tem um papel fundamental na unificação de critérios de avaliação de estações de tratamento de esgoto, com relação à definição de índices para avaliar esses processos. Dentro dessa linha, Gallegos-Muñoz et al. (2003) analisaram a degradação da água do Rio Lerma no México em termos da sua exergia, fizeram uma análise termoeconômica para avaliar a viabilidade de construção de uma estação de tratamento de esgoto ao longo do rio, e desenvolveram um critério geral sustentado por conceitos exergéticos para o projeto da estação, no qual os autores observaram além da demanda exergética em cada componente da estação, sua relação com o custo exergético. Definiram uma eficiência exergética para uma estação de tratamento de esgoto como a razão da diferença entre a exergia da água não tratada $\left(\mathrm{B}_{\mathrm{NTW}}\right)$ e a exergia da água tratada $\left(\mathrm{B}_{\mathrm{TW}}\right)$, pela exergia dos recursos (consumo elétrico e mecânico da estação) $\left(B_{R}\right)$ da forma:

$\varepsilon=\left(B_{N T W}-B_{N T W}\right) /\left(B_{R}\right)$

Essa razão é importante na unificação de critérios de avaliação de estações de tratamento de esgoto. De acordo com os resultados obtidos, a eficiência exergética dos subsistemas I (decantador primário) e II (tanque de aeração) foi menor do que a eficiência exergética do subsistema III (decantador secundário). Isso é devido a que nesses sistemas (I e II) ocorre uma oxidação de compostos orgânicos com um elevado consumo de energia mecânica, e no subsistema III ocorre uma separação de sólidos com uma quantidade baixa de trabalho mecânico. A partir do balanço 
exergético também definiram o valor $(1+\varepsilon)$ como um índice de destruição de exergia e perdas por unidade de todo o trabalho consumido. Finalmente concluíram que a eficiência exergética definida, pode servir para comparar estações de tratamento de esgoto ou subsistemas das estações ou para diagnosticar o comportamento do mesmo sistema no tempo.

No campo da pesquisa da avaliação do impacto ambiental de processos de tratamento de esgoto, no Brasil, Mora-Bejarano; Oliveira (2004a,b,c; 2005, 2006) avaliaram o impacto ambiental de duas estações de tratamento de esgoto por lodos ativados da cidade de São Paulo a partir dos dados gerados pela análise exergética por meio de indicadores exergéticos. Os autores propuseram uma metodologia científica com critérios bem definidos para avaliar e quantificar o impacto ambiental de processos de tratamento de esgoto numa base única: a exergia. Mora-Bejarano e Oliveira (2004a,b,c; 2005, 2006) propuseram a eficiência exergética como um índice de impacto ambiental, que compreende os aspectos de rendimento energético e impacto ambiental dos processos de tratamento de esgoto. Além da eficiência exergética ambiental, usaram a taxa de poluição total que a definiram como a razão entre a exergia destruída e a exergia do efeito útil de um processo, para avaliar o impacto ambiental desses processos (Makarytchev, 1997). Dessa maneira, compararam e caracterizaram o desempenho exergético ambiental, e a destruição da exergia desses processos no ambiente. A partir da análise dos resultados, os autores observaram que a análise exergética dos impactos ambientais fornece uma abordagem coerente com as opções tecnológicas que priorizam a sustentabilidade entre as várias soluções ambientais. Finalmente, os autores concluíram que a exergia pode ser usada para quantificar o desempenho ambiental, e posteriormente, ser empregada como uma função objetivo para otimizar o desempenho ambiental desses processos.

Numa outra aplicação da exergia para a análise da sustentabilidade de sistemas de tratamento de esgoto, Kirk et al. (2005), no seu relatório sobre "métodos para comparar opções de tratamento de esgoto" apresentaram a análise exergética como uma medida simplificada de sustentabilidade e enfatizaram que a eficácia na avaliação da sustentabilidade de sistemas de tratamento de esgoto depende fortemente da escolha das fronteiras do volume de controle a ser estudado. Os autores apresentaram, dentro da categoria de análise de ciclo de vida, o método do 
IPS ou Índice do Processo Sustentável, que é um sistema de avaliação ecológica que mede o impacto ambiental total das atividades humanas. O conceito geral do IPS é comparar fluxos de massa e energia induzidos pelas atividades humanas com fluxos de massa da natureza em uma variedade de escalas (global e local). O IPS foi desenvolvido como um meio para avaliar processos industriais e ele está baseado na hipótese de que a exergia solar é a única base sustentável de uma economia. $O$ IPS é definido como a área necessária para o processo (área total) dividida pela área média de terra per capita na região de interesse para a análise. Kirk et al. (2005) destacaram que o IPS compara os impactos de um processo com a habilidade do ambiente natural para fornecer recursos renováveis e minimizar rejeitos. Dentro das aplicações do IPS, apresentaram uma avaliação de um sistema de esgoto de aqüicultura.

Belhani et al. (2008) aplicaram uma avaliação exergética do ciclo de vida (AECV) em uma estação de tratamento de esgoto por lodos ativados, para mostrar os efeitos ambientais e exergéticos da recuperação de biogás em um digestor de lodo. Os autores compararam dois métodos de recuperação: a) um queimador simples e b) uma máquina de potência e calor. A partir dos resultados, os autores observaram que a recuperação de biogás reduz o esgotamento dos recursos naturais, e diminui os impactos ecológicos da estação. Também observaram que a irreversibilidade aumenta no sistema devido à recuperação do biogás (mistura queimada), e pela adição de equipamentos no sistema (cenário b).

A comparação entre os dois tipos de unidades de recuperação mostrou que o cenário b não pode atender a demanda total de energia térmica para aquecimento do digestor e a secagem do lodo, no entanto ele permite reduzir o consumo de eletricidade em $22,7 \%$, e a exergia dos gases de escape pode ser aproveitada para outra função dentro do sistema.

Belhani et al. (2008) observaram que quando levavam em consideração aspectos como o esgotamento da camada de ozônio, oxidação fotoquímica, impactos ecotóxicos aquáticos marinhos e acidificação, o cenário (b) era melhor que o (a). No entanto, o resultado obtido era o oposto quando os parâmetros usados para a avaliação eram o esgotamento dos recursos abióticos, o potencial de aquecimento global, a irreversibilidade, e o excesso de potencial de trabalho. Finalmente, eles concluíram que é muito difícil fazer uma escolha entre os dois métodos de 
recuperação de biogás devido ao número de impactos a serem considerados, pois a escolha depende das prioridades das partes interessadas em relação aos critérios considerados (meio ambiente, eficiência, economia, etc).

Mora-Bejarano; Oliveira (2008a) realizaram uma análise exergética ambiental de um Reator Anaeróbio de Fluxo Ascendente com Manta de Lodo (Rafa), e o parâmetro exergético que utilizaram na análise foi a eficiência exergética ambiental. A partir dos resultados obtidos, os autores concluíram que a eficiência exergética ambiental é um indicador apropriado para avalição ecológica porque ele apresenta uma medida termodinâmica unificada de avaliação de recursos, qualidade dos processos de conversão de energia e impacto ambiental.

Mora-Bejarano; Oliveira (2008b) fizeram uma avaliação comparativa exergética ambiental de dois processos de tratamento de esgoto, a ETE Barueri, que é um processo aeróbio de tratamento secundário por lodos ativados, e um Rafa. Nesse trabalho, também usaram a eficiência exergética ambiental como parâmetro comparativo. Da análise dos resultados, os autores concluíram que a eficiência exergética ambiental identifica as ineficiências técnicas na conversão da matéria orgânica presente nos fluxos de esgotos e deixa claro que a tecnologia usada para utilizar a matéria orgânica do esgoto está longe de ser otimizada, pois a solução técnica não tem considerado a recuperação da exergia da matéria orgânica como um aspecto importante. 


\section{PROCESSOS DE TRATAMENTO DE ESGOTO}

A água é o componente mais abundante na matéria viva, mais de $60 \%$ da massa do homem é constituida por água, e em alguns animais aquáticos essa porcentagem chega a 98\%. A água é essencial para a manutenção da vida e fundamental na procura de um desenvolvimento sustentável. Dentre os principais usos da água, têmse o doméstico, industrial, irrigação, aquicultura, geração de energia elétrica e diluição de despejos. Dos $1,36 \times 10^{18} \mathrm{~m}^{3}$ de água disponíveis no planeta, apenas $0,8 \%$ é água doce, e dessa porcentagem $97 \%$ é subterrânea e $3 \%$ é superficial, e de fácil aproveitamento (Von Sperling, 1996a). Os limites para descarte nos corpos d'água são apresentados no anexo B.

A disposição de esgotos brutos em corpos receptores naturais, como lagoas, rios, oceanos, é uma prática que ainda hoje acontece nos países não desenvolvidos. Dependendo da carga orgânica contida nos esgotos, esses podem causar uma degradação do ambiente ou ser decompostos até um nível que não cause alterações no ecossistema (Van Haandel, 1999).

O tratamento de esgotos é fundamental para proteger o meio ambiente. Por meio dele, toda a água retirada da natureza, após ser utilizada, retorna com uma carga mínima de poluição. Esse tratamento tem como objetivo principalmente: remover o material sólido; reduzir a Demanda Bioquímica de Oxigênio; remover nutrientes e microrganismos patogênicos e reduzir as substâncias químicas indesejáveis.

É grande o desafio que se tem na área de tratamento de esgotos. É necessário projetar e operar estações de tratamento de uma forma eficiente e econômica, possibilitando a sustentabilidade e a sua expansão para um número cada vez maior de comunidades e indústrias.

Em termos gerais, os sistemas de tratamento de esgoto são classificados em dois grupos: os que utilizam operações unitárias e processos fisicoquímicos e os que se baseiam em processos biológicos. Os processos biológicos se dividem em processos aeróbios e anaeróbios, dependendo da necessidade ou não de ar na sua operação (Arvizu, 1996). 
As bactérias presentes nos processos biológicos de tratamento de esgoto purificam a água por meio do metabolismo celular, absorvendo e digerindo assim a matéria orgânica que polui as águas. Os tratamentos aeróbio e anaeróbio diferem pelo tipo de bactéria utilizada nessa tarefa. No tratamento aeróbio, esses microorganismos fazem a degradação do substrato com oxigênio, que é fornecido por sopradores de ar. O tratamento anaeróbio tem limitações na sua operação em paises frios. Isto se deve ao fato de que as bactérias que degradam a matéria orgânica na ausência de oxigênio só realizam essa função eficientemente para faixas de temperaturas entre $35{ }^{\circ} \mathrm{C}$ (ideal) e $60{ }^{\circ} \mathrm{C}$ (termofílicos). Em países de clima quente fornecem uma boa economia com respeito ao consumo de eletricidade, pois é dispensado o uso de sopradores de ar nos reatores (Reis, 2008).

\subsection{Processos aeróbios}

Os processos aeróbios são aqueles nos quais a redução da matéria orgânica presente no esgoto é feita por bactérias que consomem oxigênio e produzem gás carbônico e água. Entre os sistemas aeróbios tem-se: a lagoa facultativa, lagoa aerada facultativa, lodos ativados (convencional, aeração prolongada, de batelada) e os sistemas aeróbios com biofilmes (filtro de alta ou baixa carga e o biodisco). Entre os processos aeróbios, o sistema mais versátil e eficiente é o de lodos ativados (Von Sperling, 1996a).

Nesse tratamento, o efluente do decantador primário é destinado a um tanque de aeração, onde é misturado com o lodo ativado. Chama-se lodo ativado o floco produzido no esgoto pelo crescimento de bactérias ou outros organismos, na presença de oxigênio dissolvido. Esses flocos degradam a matéria orgânica presente no esgoto, a qual é sedimentada como lodo no decantador secundário. Parte deste material retorna ao processo, para garantir sempre a relação alimento/microrganismos no tratamento biológico, sendo o restante destinado às instalações de processamento de lodo. $O$ ar é introduzido nos tanques de aeração por meio de difusores. 
O tratamento biológico de esgotos por lodos ativados consiste em submeter a matéria orgânica presente nos esgotos a uma comunidade de microrganismos que crescem nas Estações de Tratamento de Esgotos (ETEs) para que promovam sua depuração (limpeza). O líquido devolvido ao rio tem cerca de $5 \%$ da carga afluente à estação.

Esses microrganismos utilizados no tratamento são conhecidos como decompositores. São os mesmos encontrados na natureza, só que nas estações de esgotos a quantidade é muito maior, devido às condições favoráveis para seu desenvolvimento, pois o alimento (matéria orgânica) é abundante. Essa comunidade de microorganismos é composta basicamente por bactérias, protozoários e micrometazoários.

\subsection{Processos anaeróbios}

O processo anaeróbio é um dos mais antigos utilizados para o tratamento de esgotos; é um processo no qual existe decomposição da matéria orgânica e inorgânica em ausência de oxigênio (Metcalf e Eddy, 1985).

A primeira contribuição importante para o tratamento anaeróbio de esgotos sanitários foi a fossa sética, desenvolvida em 1882, na França, denominada Fossa Automática Mouras; a partir daí apareceram outras concepções de tratamento, como o tanque séptico na Inglaterra em 1895, e o tanque Imhoff na Alemanha em 1905, e foi na Alemanha em 1927 onde foi instalado o primeiro digestor com aquecimento. A partir daí, a opção de digestão de lodo foi aceita e aplicada nas grandes cidades, e o aquecimento dos tanques de digestão era feito por meio da queima do próprio metano produzido no processo (McCarty, (1982) apud Van Haandel et al., 1999).

Na década de 1980, os reatores anaeróbios foram usados no tratamento de esgotos sanitários, principalmente na Holanda, Brasil, Colômbia, Índia e México.

Os digestores anaeróbios têm sido amplamente usados para o tratamento de resíduos sólidos, incluindo culturas agrícolas, dejetos de animais, lodos de ETEs e resíduo sólido urbano ou industrial. As finalidades de tal processo são remoção da 
matéria orgânica e de microrganismos patogênicos dos resíduos, produção de biogás como combustível e produção de lodo desaguado como adubo orgânico para recuperação de solos para a agricultura.

O tratamento anaeróbio dos esgotos domésticos tem se tornado atrativo em países de climas tropical e subtropical, havendo várias estações em operação em Brasil, no México, e na Colômbia, assim como na Indonésia, Venezuela, Equador, Índia, entre outros (Chernicharo, 1997).

\subsubsection{Reator Anaeróbio de Fluxo Ascendente com Manta de Lodo (RAFA)}

Vários tipos de reatores anaeróbios vêm sendo utilizados no Brasil para tratamento de esgoto sanitário de pequenas comunidades e de grandes cidades. Dentre esses podem-se citar as lagoas anaeróbias, os decanto-digestores, os filtros anaeróbios, os reatores de manto de lodo, os reatores de leito expandido ou fluidificado (Van Haandel et al., 1999).

O RAFA foi desenvolvido e aplicado na Holanda na década de 1970. Esse tipo de reator desempenha várias funções no tratamento de esgotos domésticos e industriais, sendo ao mesmo tempo um decantador primário, um reator biológico, um decantador secundário e um digestor de lodo (Van Haandel et al., 1999).

Com várias denominações no Brasil (RAFA, DAFA, RAFAALL, RALF etc.), é conhecido no mundo como UASB (Upflow Anaerobic Sludge blanket). Esse reator RAFA representa um grande avanço da tecnologia anaeróbia para o tratamento direto de esgoto e na prática tem demonstrado ser o de maior sucesso entre os reatores anaeróbios até hoje (Van Haandel et al., 1999).

O reator RAFA é um tanque onde o esgoto é introduzido pela superfície inferior (fundo) e sai na parte superior, estabelecendo um fluxo ascendente, através de um leito constituído por grânulos ou flocos que contêm elevada quantidade de microrganismos. O funcionamento do reator promove a separação de fases (sólidos, líquidos e gases) no esgoto introduzido. A maior parte dos sólidos em suspensão é retida no reator, devido às condições hidráulicas impostas. Os microrganismos 
agrupam-se em flocos ou grânulos sedimentáveis e, dessa forma, se forma uma camada espessa de lodo, através da qual a matéria orgânica solúvel é tratada pelos microrganismos presentes em alta concentração (Van Haandel et al., 1999).

O reator de manta de lodo tem muitas vantagens em relação aos processos aeróbios convencionais e essas são mais evidentes, quando é aplicado em locais de clima quente, como é o caso do reator localizado em Ginebra, Colômbia. Nessas situações pode-se esperar um sistema com as seguintes características principais (Chernicharo, 1997):

- sistema compacto, pequena área;

- baixo custo de implantação e de operação;

- baixa produção de lodo;

- baixo consumo de energia;

- eficiência de remoção de 65 - 75\%, de DBO/DQO;

- rápido reinício, mesmo após longas paralisações;

- elevada concentração do lodo excedente;

- bom desaguamento do lodo.

Embora os reatores RAFA apresentem muitas vantagens, as seguintes desvantagens são atribuídas aos mesmos (Chernicharo, 1997):

- emissão de mau cheiro;

- baixa capacidade em tolerar cargas tóxicas;

- elevado tempo para a partida do sistema;

- necessidade de pós-tratamento.

Quando o esgoto é doméstico, o sistema não apresenta problemas pela presença de compostos de enxofre e de materiais tóxicos, pois esses aparecem em níveis muito baixos. Se o reator for bem projetado, construído e operado, as duas primeiras desvantagens praticamente podem ser desconsideradas (Chernicharo, 1997).

Quanto à partida do sistema, essa pode ser realmente lenta (4 a 6 meses), mas apenas em situações em que não são utilizados inóculos. Em algumas situações nas 
quais foram utilizadas pequenas quantidades de inóculo (inferior a $4 \%$ do volume do reator), o período de partida foi reduzido a 2 ou 3 semanas (Van Haandel et al., 1999).

Outra desvantagem do reator de manta de lodo está relacionada com a qualidade de efluente produzido, a qual não se enquadra nos padrões estabelecidos pela legislação ambiental brasileira. No entanto alguns avanços já foram alcançados na questão do tratamento anaeróbio e do pós-tratamento (Chernicharo, 1997).

\subsubsection{Pré-tratamento de Esgotos}

A entrada de sólidos não biodegradáveis em reatores anaeróbios de alta taxa prejudica o processo de tratamento, pelo fato de que a acumulação desse material no equipamento, promove a formação de zonas mortas e caminhos preferenciais, diminuindo, além do volume de biomassa no sistema, a eficiência do tratamento. Por essa razão, é necessário incorporar no processo unidades de tratamento preliminar, como grades e caixas de areia (Chernicharo, 1997).

\subsubsection{Pós-Tratamento de Reator RAFA}

Um dos parâmetros mais controlados pelos órgãos de controle ambiental é a DBO. Vários estados brasileiros têm imposto como limite para a DBO dos efluentes um valor de $60 \mathrm{mgO}_{2} / \mathrm{L}$. Esse fato é o que mais tem restringido o uso de sistemas anaeróbios para o tratamento de esgoto, uma vez que o reator RAFA apresenta valores de DBO do efluente, na faixa de 60 a $100 \mathrm{mgO}_{2} / \mathrm{L}$, com uma eficiência de remoção de DBO de 55 a 75\%. Além desse problema, os reatores RAFA não apresentam uma remoção satisfatória em relação aos compostos nitrogenados e ao fósforo (Van Haandel et al., 1999).

Em vista dessas limitações, é muito importante aplicar um pós-tratamento nos efluentes dos reatores RAFA, para atender os requisitos da legislação ambiental e proteger os corpos d'água receptores. 
O papel do pós-tratamento é o de completar a remoção da matéria orgânica (Chernicharo, 1997).

Entre as alternativas de pós-tratamento de efluentes de reatores RAFA tem-se: filtro anaeróbio, lagoas de polimento, aplicação no solo, biofiltro aerado, filtro biológico e lodo ativado (Chernicharo, 1997).

No sistema de tratamento de esgoto de Ginebra é utilizada uma lagoa facultativa para fazer o pós-tratamento do efluente do reator RAFA, por essa razão a seguir descrevem-se as lagoas facultativas e os processos que acontecem no seu interior.

\subsubsection{Lagoa Facultativa}

A lagoa facultativa é uma lagoa de estabilização. O processo consiste na retenção do esgoto por um período de tempo longo o suficiente para que os processos naturais de estabilização da matéria orgânica se desenvolvam (Von Sperling, 1996b).

O esgoto afluente entra por uma extremidade da lagoa e sai pela extremidade oposta. Durante esse percurso, ocorrem vários mecanismos encarregados da purificação do esgoto. Esses mecanismos são observados em três zonas das lagoas, denominadas zona aeróbia, zona anaeróbia e zona facultativa.

A zona anaeróbia localiza-se no fundo da lagoa, no qual é formado um lodo pela sedimentação da matéria orgânica em suspensão (DBO particulada). Esse lodo é decomposto por microrganismos anaeróbios, e convertido, lentamente, em gás carbônico, água, metano e outros compostos.

A zona aeróbia localiza-se na camada mais superficial (menor a $50 \mathrm{~cm}$ ) da lagoa onde a matéria orgânica dissolvida (DBO solúvel), junto com a matéria orgânica em suspensão de pequenas dimensões, é oxidada por meio da respiração aeróbia. $O$ oxigênio necessário para esse processo é suprido pela fotossíntese realizada pelas algas (durante o dia). 
A zona facultativa está localizada entre as duas zonas descritas anteriormente, onde pode ocorrer a presença ou a ausência de oxigênio, e na qual existem diversos grupos de bactérias responsáveis pela estabilização da matéria orgânica. $\mathrm{Na}$ ausência de oxigênio livre são utilizados outros receptores de elétrons, como nitratos (condições anóxicas) e sulfatos e $\mathrm{CO}_{2}$ (condições anaeróbias) (Von Sperling, 1996b).

O efluente de uma lagoa facultativa tem as seguintes características principais: cor verde (devido às algas), elevado teor de oxigênio dissolvido, e sólidos em suspensão (CETESB, 1989) apud (Von Sperling, 1996b).

\subsection{Tratamento primário quimicamente assistido}

Surgiu em 1762, e foi um método de tratamento de esgoto muito utilizado na Inglaterra em 1870. A cal era usada em muitos casos como agente de precipitação, às vezes sozinha, e mais frequentemente junto com cloreto de cálcio, cloreto de magnésio, sulfato de alumina, sulfato ferroso, carvão vegetal e outras substâncias. 0 tratamento químico foi também muito usado nos Estados Unidos entre 1890 e 1900; com o desenvolvimento do tratamento biológico, abandonou-se a utilização de produtos químicos. Há registros de que nos primeiros anos da década de 1930 houve tentativas para desenvolver novos métodos de tratamento químico e foram instaladas algumas estações (Metcalf e Eddy, 1985).

O tratamento quimicamente assistido no tratamento do esgoto considera a adição de produtos químicos com a finalidade de alterar o estado físico dos sólidos dissolvidos e em suspensão e facilitar sua eliminação por sedimentação.

A precipitação química é usada: a) como uma forma de melhorar o desempenho das instalações de decantação primária; b) como etapa básica no tratamento independente físico-químico do esgoto, e c) para eliminação do fósforo.

\section{a) Melhoria do desempenho dos tanques de decantação.}


O melhoramento do processo de sedimentação primária, se dá pela aplicação de coagulantes químicos. A coagulação química do esgoto provoca a aglomeração de sólidos muito finos e de matériais coloidais em flocos com capacidade de se separar no sedimentador. Os reagentes que podem ser usados como coagulante primário são sais de ferro, sais de alumínio e cal; desses os mais utilizados no tratamento do esgoto os sais de ferro (EMCALI, 2001). Com a precipitação química é possível eliminar de 80 a $90 \%$ dos sólidos em suspensão, de 70 a $80 \%$ da $\mathrm{DBO}_{5}$ e de 80 a $90 \%$ das bactérias coliformes. Os valores comparáveis de eliminação para tanques de decantação primária, corretamente projetados e operados sem adição de reagentes, estão entre 50 a $70 \%$ para os sólidos em suspensão, de 25 a $40 \%$ para a $\mathrm{DBO}_{5}$ e de 25 a $75 \%$ para as bactérias coliformes (Metcalf e Eddy, 1985).

Este processo recebe vários nomes, sendo o mais utilizado o de Tratamento Primário Quimicamente Assistido - TQA (CEPT - Chemically Enhanced Primary Treatment, ou CAPS - Chemically Assisted Primary Sedimentation). No TQA, são removidos os sólidos em suspensão por meio de processos físico-químicos de coagulação, floculação e sedimentação. Na coagulação são empregadas baixas concentrações de sais de ferro, combinadas ou não com polímeros catiônicos; a floculação é alcançada após a adição suplementar de polímeros aniônicos e a ação de forças eletrostáticas que promovem a aglomeração das partículas coaguladas em flocos de maior tamanho; na sedimentação observa-se o incremento da velocidade de sedimentação das partículas em função do aumento do seu tamanho. A unidade de decantação é similar à unidade de decantação convencional, agregando-se apenas o sistema de dosagem e aplicação de coagulantes e polímeros (CETE Poli /UFRJ, 2001).

Em contraste aos tratamentos convencionais, o processo físico-químico TQA destrói o gás sulfídrico do esgoto, não gera aerossol, ocupa uma área diminuta quando comparado com os outros tratamentos de esgoto, e trata rapidamente o esgoto (cerca de uma hora vs. semanas em lagoas). Com isso, o tratamento do esgoto pode ser efetuado dentro da cidade, em meio às casas. Simplesmente por eliminar o transporte de esgoto bruto a longas distâncias, o TQA pode propiciar uma economia considerável, por exemplo, metade do custo no sistema global (transporte + tratamento), sem considerar a economia adicional no próprio tratamento. Pode ainda 
tratar esgoto misturado com água pluvial proveniente de sistemas combinados ou unitários, que estão sujeitos a mudanças repentinas de vazão e de contaminates (Tsukamoto, 2002).

Na Tabela 1 é apresentada uma comparação do custo de implementação e da área per capita requerida para os processos de tratamento de esgoto estudados neste trabalho.

Tabela 1 - Comparação de custos e da área requerida para os processos de tratamento de esgoto estudados

\begin{tabular}{|l|c|c|}
\hline \multicolumn{1}{|c|}{ Processo de Tratamento } & $\begin{array}{c}\text { Custo de implementação } \\
\text { (US\$ / hab) }\end{array}$ & $\begin{array}{c}\text { Área requerida } \\
\left(\mathbf{m}^{2} / \mathbf{h a b}\right)\end{array}$ \\
\hline Lagoa Facultativa & $10-30$ & $2,5-5,0$ \\
\hline Rafa & $20-40$ & $0,05-0,10$ \\
\hline Rafa + Lagoa Facultativa & $30-50$ & $1,5-2,5$ \\
\hline Lodos Ativados Convencionais & $60-120$ & $0,20-0,30$ \\
\hline Tratamento Quimicamente Assistido & $7-25$ & $0,002-0,005$ \\
\hline
\end{tabular}

(Adaptado de Tsukamoto, 2002)

\section{b) Tratamento físico-químico independente.}

Em muitos locais, o descarte de rejeitos industriais no sistema de coleta de esgoto produz um esgoto que não é tratável por meios biológicos. Nessas situações, o tratamento físico-químico é uma solução alternativa. O problema que apresenta esse método de tratamento, e que tem limitado seu uso, é o da manipulação e descarte de grandes volumes de lodo que resulta da adição dos produtos químicos (Metcalf e Eddy, 1985).

\section{c) Eliminação do fósforo}


Os produtos químicos que são utilizados para a eliminação do fósforo incluem a cal, o sulfato de aluminio e o sulfato ou cloreto férrico. Os polímeros também têm sido usados com bons resultados juntamente com a cal e o sulfato de aluminio. Para conseguir a eliminação do fósforo, esses reagentes são aplicados diretamente na água, em processos de tratamento biológico e em processos posteriores ao tratamento biológico (Metcalf e Eddy, 1985). 


\section{METODOLOGIA DA ANÁLISE EXERGOECOLÓGICA DE PROCESSOS DE TRATAMENTO DE ESGOTO}

A exergia como um critério unificado de avaliação quantitativa e qualitativa fornece informação sobre o processo de degradação termodinâmica da água provocada pela poluição (Valero et al., 2006). Dessa forma, um aumento na exergia da poluição da água leva a uma diminuição no valor ecológico do ambiente aquático (Huang et al., 2007).

Baseado nessa premissa, a exergia pode ser usada na avaliação do requerimento energético de um sistema de tratamento de esgoto e na determinação do sistema mais eficiente do ponto de vista da energia entre vários processos químicos e biológicos de tratamento de esgoto (Tai; Matsushige e Goda, 1986).

Neste trabalho, é proposta uma metodologia científica que aplica a análise exergética na avaliação e comparação de tecnologias de tratamento de esgoto, a qual é complementada pelo uso de índices exergéticos que visam o aproveitamento da exergia contida no esgoto e nos subprodutos do processo de tratamento.

\section{1 Índices exergéticos}

Os índices utilizados na análise são a eficiência exergética ambiental e o índice exergético de renovabilidade.

\subsubsection{Eficiência exergética ambiental ( $\eta_{\text {exerg,amb) }}$}

O impacto ambiental dos processos de tratamento de esgoto pode ser classificado em três partes: a primeira, associada ao consumo dos recursos naturais, a segunda à eficiência com a qual o processo converte a energia disponível nos recursos em outras formas de energia e, a terceira parte relacionada aos rejeitos e emissões do 
processo. Esse impacto ambiental pode ser diminuído pelo aumento da eficiência exergética desses processos. Para conseguir isso, é necessário prestar uma maior atenção ao estudo e desenvolvimento de tecnologias que conduzam ao aumento dessa eficiência.

Um aumento na eficiência exergética teria como consequência uma diminuição no consumo de recursos e, por conseguinte, uma redução dos rejeitos e das emissões desses ao ambiente, o que se traduz em uma melhora no desempenho ambiental desses processos. Dessa forma, pode-se associar à eficiência exergética, além dos aspectos de eficiência exergética inerentes à sua definição, os aspectos ambientais.

Neste trabalho, é utilizada a eficiência exergética como um índice de impacto ambiental, que compreende os aspectos de eficiência exergética e impacto ambiental dos processos de tratamento de esgoto. Na literatura encontram-se referências sobre a eficiência exergética como um parâmetro para avaliar processos de tratamento de esgoto (conforme definido no item 3.9).

A eficiência exergética ambiental é definida como a razão da exergia do produto final (ou efeito útil de um processo) pela exergia total consumida dos recursos humanos e naturais, incluíndo todos os insumos. Essa razão fornece uma indicação do potencial teórico de futuras melhorias para um processo. A eficiência exergética ambiental é calculada de acordo com a eq. (6.1):

$\eta_{\text {exerg,amb }}=\frac{\mathrm{B}_{\text {Prod, final }}}{B_{\text {Rec, nat }}+B_{\text {Prep }}+B_{\text {Desat }}+B_{\text {Re mos }}}$

sendo:

$B_{\text {Rec, nat }}=$ exergia dos recursos naturais consumida pelos processos.

$B_{\text {Prep }}=$ exergia requerida para extração e preparação dos recursos naturais.

$B_{\text {Remoç}}=$ exergia relacionada à remoção dos rejeitos do processo.

$B_{\text {Prod, final }}=$ exergia produzida ou efeito útil de um processo.

$B_{\text {Desat }}=$ exergia dos recursos naturais adicionais, destruída durante a desativação dos rejeitos. 
As diferenças encontradas na literatura entre as definições da eficiência exergética e eficiência exergética ambiental utilizada neste trabalho estão baseadas na escolha de diferentes volumes de controle para cada uma delas. Esse fato determina a inclusão ou exclusão de alguns termos da exergia total consumida dos recursos naturais e humanos. É importante notar que o valor desse índice é influenciado pela definição das fronteiras do sistema considerado.

\subsubsection{Indicador exergético de renovabilidade $(\lambda)$}

A água é essencial para a sobrevivência da humanidade, que é a principal usuária e também sua principal poluidora. A partir do conceito de desenvolvimento sustentável, a água passou a ser considerada um recurso esgotável e objeto de grande preocupação em termos de sua disponibilidade.

É um desafio projetar sistemas de tratamento de esgoto sustentáveis que visem efeitos positivos para o ambiente, a sociedade e a economia.

As visões mais futuristas dos sistemas de tratamento de esgoto valorizam o nível de capacitação do pessoal de operação das ETEs, os empregos na comunidade, a estética da estrutura física da estação de tratamento, e a minimização conjunta das emissões atmosféricas, dos custos de operação e da utilização da energia, assim como a maximização do sistema de tratamento.

Diversos autores têm trabalhado na elaboração de índices de sustentabilidade para sistemas de tratamento de esgoto entre os quais incluem a exergia (Lundin; Molander; Morrison, 1997; Balkema; Preisig; Otterpohl; Lambert, 2002; Miranda; Teixeira, 2004; Palme; Lundin; Tillman; Molander, 2005; Jie; Xiang-sheng; Xuezheng, 2007; Muga; Mihelcic, 2008). Outros autores propõem índices de renovabilidade em base exergética para diferentes processos (Dewulf; Van Langenhove, 2005; Manish; Indu; Rangan, 2006; Chen et al., 2009; Torio; Angelotti; Schmidt, 2009). 
No presente trabalho, foi adaptado para sistemas de tratamento de esgoto o índicador exergético de renovabilidade proposto por Velásquez, Benjumea e Oliveira Jr. (2007); Velásquez, Ruiz e Oliveira Jr. e Velásquez, Pellegrini e Oliveira Jr. (2008).

O índice exergético de renovabilidade para sistemas de tratamento de esgoto é definido neste trabalho como a razão entre a exergia dos produtos pela soma das exergias não renováveis, a exergia destruída, a exergia de desativação e a exergia das emissões e residuos. O índice exergético de renovabilidade é calculado de acordo com a eq. (6.2):

$\lambda=\frac{\mathrm{B}_{\text {Produtos }}}{B_{\text {Não renovável }}+B_{\text {Destruída }}+B_{\text {Desativação }}+B_{\text {Emissões } / \text { Re síduos }}}$

onde:

$B_{\text {Não renovável }}=$ exergias de recursos não renováveis utilizadas no sistema de tratamento de esgoto.

$B_{\text {Destruída }}=$ exergia destruída no sistema de tratamento de esgoto.

$B_{\text {Desativação }}=$ exergia dos recursos adicionais, destruída durante a desativação das emissões e residuos.

$B_{\text {Emissões/Residuos }}=$ exergia das emissões e resíduos caso estes não sejam reaproveitados para fins úteis para o sistema de tratamento de esgoto ou para a sociedade.

$B_{\text {Produtos }}=$ exergia dos produtos do sistema de tratamento de esgoto.

O índice exergético de renovabilidade estará entre $0<\lambda<1$, quando o termo $\left(B_{\text {Não renovável }}+B_{\text {Destruída }}+B_{\text {Desativąão }}+B_{\text {Emissões/Resíduos }}\right)>\mathrm{B}_{\text {Produtos }}$

sendo esse o caso dos sistemas de tratamento de esgoto ambientalmente desfavoráveis. 
O índice exergético de renovabilidade será $\lambda>1$, quando o termo

$\mathrm{B}_{\text {Produtos }}>\left(B_{\text {Não renovável }}+B_{\text {Destruida }}+B_{\text {Desativacăõo }}+B_{\text {Emissões/Residuos }}\right)$

sendo esse o caso dos sistemas de tratamento de esgoto ambientalmente favoráveis.

O índice exergético de renovabilidade será $\lambda=1$, quando o termo

$\mathrm{B}_{\text {Produtos }}=\left(B_{\text {Não renovável }}+B_{\text {Destruida }}+B_{\text {Desativagăõo }}+B_{\text {Emissões/Residuos }}\right)$

esse é o caso dos sistemas de tratamento de esgoto interna e externamente reversíveis, com apenas uso de insumos não renováveis.

O índice exergético de renovabilidade será $\lambda \rightarrow \infty$, quando o termo

$\left(B_{\text {Não renovável }}+B_{\text {Destruida }}+B_{\text {Desativação }}+B_{\text {Emissões/Residuos }}\right) \rightarrow 0$

esse é o caso dos sistemas de tratamento de esgoto interna e externamente reversíveis, com apenas uso de insumos renováveis (Pellegrini, 2009).

É importante observar que devido a esse índice considerar a exergia destruída no processo de tratamento de esgoto, ainda que ele tenha dentro de seus insumos recursos renováveis, uma operação muito ineficiente do ponto de vista exergético prejudica o desempenho ambiental do processo. Por outro lado, processos de tratamento de esgoto que utilizem unicamente dentro dos seus insumos recursos não renováveis, e que apresentem uma operação eficiente terão desempenhos ambientais superiores àqueles com insumos renováveis, como na análise apresentada por Pellegrini (2009).

Outro aspecto importante desse índice é o caso no qual $\lambda$ é superior a 1 . Nessa situação, a exergia dos produtos do processo de tratamento de esgoto poderia ser usada para restaurar o meio ambiente até as condições anteriores ao processo, e ainda obter um fluxo possitivo de exergia para outro uso. Esse conceito está relacionado com a definição da renovabilidade total de um recurso, apresentada por Berthiaume, Bouchard e Rosen (2001) e complementada por Pellegrini (2009), 
segundo a qual a renovabilidade total de um recurso significa que existem mecanismos de regeneração, os quais mantém a disponibilidade do recurso intacta sem causar distúrbios ao meio ambiente dentro de um determinado horizonte de tempo. Nesse caso, o efeito líquido seria que os ciclos naturais de regulação terrestre seriam responsáveis apenas pela regeneração da exergia renovável utilizada.

É importante notar que o valor desse índice é influenciado pela definição das fronteiras do volume de controle considerado. Quanto maior for o volume de controle considerado na análise, maior será o número de processos de conversão de energia considerados, e menor será o valor do índice devido ao aumento das irreversibilidades e da possibilidade do aporte de insumos não renováveis ao processo. Por isso quando é feita uma comparação de processos de tratamento de esgoto diferente, é importante observar o tamanho e a compatibilidade dos volumes de controle, a fim de evitar distorsões nas análises.

\subsection{Metodologia da análise exergoecológica}

$\mathrm{Na}$ aplicação da metodologia da análise foram aplicadas as seguintes considerações e simplificações:

i. As fronteiras do volume de controle para o processo de tratamento de esgoto é desenhada ao redor do processo; isto significa que não é calculada a exergia investida na fabricação das substâncias químicas $\left(\mathrm{FeCl}_{3}, \mathrm{CaO}\right.$ e polímeros) e de outros produtos usados nos diferentes estágios do tratamento do esgoto. A única exergia que é levada em consideração é a exergia do composto e do próprio produto.

ii. São consideradas condições de operação em regime permanente.

iii. Os dados usados para a análise exergética do processo de tratamento de esgoto são os dados médios anuais (reais de operação). 
iv. Não é considerada a diluição dos compostos químicos, nem a exergia da água limpa (Huang et al., 2007; Hellstrom, 1997).

v. A exergia química da matéria orgânica é calculada de acordo com a relação entre a exergia química da substância orgânica e a demanda química de oxigênio (DQO) utilizando a seguinte equação. (Tai; Matsushige e Goda, 1986):

$$
\mathrm{B}_{\text {mat,org. }}=13,6 \mathrm{DQO}
$$

vi. A exergia da mão-de-obra ou trabalho humano, usada na operação da estação é considerada desprezível, quando comparada com outros fluxos de exergia, como a exergia teórica da matéria orgânica (Hellstrom, 1997).

vii. A exergia dos edifícios da estação de tratamento de esgoto não é considerada.

viii. Na análise exergética são incluídos os fluxos exergéticos associados a compostos orgânicos e inorgânicos, nutrientes e metais contidos no esgoto, subprodutos gerados como o lodo desaguado (biossólidos) e o metano, compostos químicos utilizados no processo de estabilização química do lodo, compostos químicos utilizados na melhora do processo de sedimentação primária e o consumo de energia elétrica.

ix. O esgoto é considerado um fluido que contém uma carga poluidora. De acordo com Von Sperling (1996a), cerca de 99,9 \% dos esgotos é constituído por água. Os restantes $0,1 \%$ incluem substâncias em suspensão e dissolvidas que necessitam ser removidas mediante tratamento adequado.

x. A exergia da poluição da água refere-se somente à exergia química, a qual é uma medida do potencial dos poluentes no corpo de água para causar um dano ao ambiente aquático (Huang et al., 2007).

xi. A massa molecular do esgoto foi assumida como a da substância $\mathrm{C}_{10} \mathrm{H}_{18} \mathrm{O}_{3} \mathrm{~N}$ (Owen, 1982). 
xii. O estado de referência considerado na análise exergética foi o estado de referência padrão do Szargut et al., (1988), a Tn $=298,15 \mathrm{~K}$ e Pn $=101,325$ $\mathrm{kPa}$. Assim, as exergias usadas na análise foram calculadas a partir dos dados apresentados por Szargut (1988) (ver Tabela 20).

xiii. A exergia do $\mathrm{NO}_{3}^{-}$foi calculada com uma interpolação a partir dos dados para o NO e NO , como calculado por Ayres; Ayres; Martinás (1997).

xiv. Os fluxos exergéticos associados às vazões afluente e efluente dos processos de tratamento de esgoto, assim como os associados ao lodo desaguado produzido nas ETEs, foram calculados com a equação. (3.10) e as tabelas do Anexo C, considerando-se as seguintes hipóteses simplificadoras:

- mistura não ideal (atividade $\neq$ fração molar: $a_{i} \neq x_{i}$ ) para as vazões afluente e efluente das ETEs;

- mistura ideal (atividade $=$ fração molar: $a_{i}=x_{i}$ ) para o lodo desaguado produzido nas ETEs.

xv. A atividade $a_{i}$ das substâncias orgânicas e das inorgânicas nas vazões afluente e efluente dos processos, foi calculada pela aplicação da formula $a_{i}=r_{i} \cdot m_{i}$; sendo $r_{i}$ é o coeficiente de atividade e $m_{i}$ é a molalidade da substância i. O coeficiente de atividade foi calculado pela aplicação da teoria de Debye - Huckel para soluções aquosas, usando a equação (Karapétiantz, 1975); (Zaleta-Aguilar; Ranz e Valero, 1998); (Gallegos-Muñoz et al., 2003); (Valero et al., 2006):

$\operatorname{Ln} r_{i}=\left(-A_{D H} \cdot z_{i}^{2}(I)^{0,5}\right) \cdot\left(1+B_{D H} \cdot \Phi_{i} \cdot(I)^{0,5}\right)^{-1}$

Sendo:

$\mathrm{A}_{\mathrm{DH}}\left(\right.$ constante de Debye - Huckel para água a $\left.25^{\circ} \mathrm{C}\right)=0,51 \mathrm{~kg}^{0,5} \cdot \mathrm{mol}^{-0,5}$;

$\mathrm{B}_{\mathrm{DH}}\left(\right.$ constante de Debye - Huckel para água a $\left.25^{\circ} \mathrm{C}\right)=$

$3,287 \times 10^{9} \mathrm{~kg}^{0,5} \cdot \mathrm{m}^{-1} \cdot \mathrm{mol}^{-0,5}$

$\mathrm{z}_{\mathrm{i}}=$ carga iônica ou valência; 
$\Phi_{i}=$ diâmetro efetivo do íon na solução $\left(2 \times 10^{-8}-5 \times 10^{-8} \mathrm{~m}\right)$;

$I$ = força iônica que leva em consideração os efeitos dos outros íons na solução e foi calculada pela equação:

$\mathrm{I}=0,5 \cdot \sum \mathrm{m}_{\mathrm{i}} \cdot \mathrm{z}_{\mathrm{i}}^{2}$

xvi. Conforme apresentado no item 3.8, a equação do balanço exergético aplicada para os processos de tratamento de esgoto ficou como segue: ( $\Sigma$ fluxos exergéticos de entrada $-\Sigma$ fluxos exergéticos de saída $)=\left(\sum\right.$ fluxos de exergia perdida) + (exergia destruída).

Para o processo de tratamento de esgoto, os fluxos exergéticos de entrada são: a exergia do esgoto afluente (incluíndo DQO do esgoto afluente), a exergia da energia elétrica, e a exergia associada ao consumo do efluente tratado. $O$ fluxo exergético de saída para o processo é a exergia do efluente final (incluíndo DQO do efluente final). A exergia do lodo desaguado foi considerada como o termo da exergia desperdiçada pelo fato de o lodo não ser aproveitado atualmente para fins agrícolas, nem como insumo na produção do metanol, e na maioria das vezes disposto em aterros sanitários.

A exergia dos compostos químicos utilizados na estabilização química do lodo $(\mathrm{CaO}$, $\mathrm{FeCl}_{3}$, polímeros) é a parcela exergética relacionada à desativação do lodo (rejeito), e por último o termo da exergia destruída é o associado à queima do metano produzido e à exergia destruída no processo devido às irreversibilidades presentes no tratamento do esgoto. Após realizada a análise exergética, procede-se ao cálculo da eficiência exergética ambiental e ao índice exergético de renovabilidade, e posteriormente à comparação e análise dos resultados. 


\section{AVALIAÇÃO DO DESEMPENHO AMBIENTAL E DA RENOVABILIDADE DE PROCESSOS DE TRATAMENTO DE ESGOTO}

Neste capítulo apresenta-se a análise exergética comparativa de três Processos de Tratamento de Esgoto, a partir de dados levantados nas estações em condições representativas de suas operações. Esses dados foram fornecidos pela SABESP, pelo Centro de Pesquisa para o Tratamento do Esgoto de Ginebra (Colômbia) e pela EMCALI.

\subsection{AVALIAÇÃO DO DESEMPENHO E DA RENOVABILIDADE DE TRÊS PROCESSOS DE TRATAMENTO DE ESGOTO}

A avaliação foi aplicada a três processos de tratamento de esgoto, a ETE Barueri localizada na Região Metropolitana de São Paulo(RMSP), o sistema RAFA - Lagoa Facultativa localizado na área rural de Ginebra (Colômbia) e a ETE Cañaveralejo localizada na área urbana de Cali (Colômbia).

O Sistema Principal de Esgotos da RMSP é constituído por cinco ETEs, ABC, Barueri, Parque Novo Mundo, São Miguel e Suzano. Essas cinco estações possuem uma capacidade de tratamento de $18 \mathrm{~m}^{3} \cdot \mathrm{s}^{-1}$, no entanto a vazão média de esgoto tratado atualmente é de $11 \mathrm{~m}^{3} \cdot \mathrm{s}^{-1}$, beneficiando uma população de aproximadamente 6.500.000 habitantes. O Sistema Principal compõe-se ainda de $130 \mathrm{~km}$ de interceptores, sifões e emissários com diâmetro variando de 0,6 a 4,50 m (Companhia de Saneamento Básico do Estado de São Paulo, 2002).

A RMSP foi dividida em duas grandes áreas para efeito de esgotamento sanitário. A área central é densamente urbanizada e comporta um sistema integrado denominado "Sistema Principal" que engloba as bacias drenantes aos rios Tietê, Pinheiros e Tamanduateí, e algumas sub-bacias drenantes aos reservatórios Guarapiranga e Billings. As demais áreas, situadas em regiões periféricas, com 
menor grau de urbanização, são servidas por sistemas próprios, denominados "Sistemas Isolados".

No centro de pesquisa para o tratamento de esgoto de Ginebra (Colômbia) é promovido o melhoramento e o desenvolvimento de tecnologías de descontaminação que permitem não só o tratamento do esgoto mas também a recuperação de nutrientes e o reuso de subprodutos como a água, gases e lodos. Dessa forma, pretende-se ajudar na solução da problemática ambiental e de saúde, na seleção de tecnologias inovadoras, na participação dos usuários e na sustentabilidade dos investimentos realizados.

A concepção e o desenvolvimento da estação de Ginebra fundamentam-se em três conceitos: a gestão integrada do recurso hídrico, a sustentabilidade e o fortalecimento de capacidades de nível local.

A vazão máxima de projeto da estação será de $73,30 \mathrm{~L} \cdot \mathrm{s}^{-1}$, é projetada pela população de 2010. Atualmente, o fluxo médio do esgoto é de $25 \mathrm{~L}$. . $\mathrm{s}^{-1}$, a partir do qual são alimentados todos os sistemas existentes.

As atividades de pesquisa e desenvolvimento tecnológico na estação de Ginebra estão inseridas nos principios básicos da Gestão Integrada do Recurso Hídrico $(G I R H)$. Nesse sentido, é dada ênfase na redefinição do esgoto como um bem econômico que tem um valor agregado por seu conteúdo energético e de nutrientes, os quais podem ser reutilizados em atividades produtivas.

A ETE Cañaveralejo atualmente opera na primeira fase de seu projeto inicial, como um tratamento primário quimicamente assistido, cuja construção foi iniciada em agosto de 1997 e entrou em operação em dezembro de 2001. A construção e entrada em operação para a segunda fase, que é o tratamento secundário, estão planejadas para o ano 2015.

A estação de tratamento de esgoto de Cañaveralejo está localizada ao noreste da cidade de Cali (Colômbia), estado do Valle do Cauca e a uma altitude de 995 m.s.m., na atualidade trata $19 \%$ do esgoto da cidade de Cali, com previsões de aumento até 85\% para o ano 2015 (EMCALI, 2001). 


\subsection{DESCRIÇÃO DOS PROCESSOS DE TRATAMENTO DE ESGOTO ESTUDADOS}

\subsubsection{Estação de tratamento de esgotos de (ETE) Barueri $^{1}$}

Está localizada no município de Barueri, na margem esquerda do Rio Tietê, em terreno limitado por esse curso d'água e pela estrada de ferro da Companhia Paulista de Trens Metropolitanos (CPTM). Serve a maior parte da cidade de São Paulo e aos municípios de Jandira, Itapevi, Barueri, Carapicuíba, Osasco, Taboão da Serra e partes de Cotia e Embu. A ETE de Barueri foi projetada na década de 70 para tratar $63 \mathrm{~m}^{3} \mathrm{~s}^{-1}$ de esgoto. Com a revisão e atualização do Plano Diretor da RMSP - COPLADES, em 1985, o volume de esgoto a ser tratado passou para 28,5 $\mathrm{m}^{3} \mathrm{~s}^{-1}$. O início de operação foi em 11/05/1988, a vazão média de projeto é $9,5 \mathrm{~m}^{3} \mathrm{~s}^{-1}$ e a população atendida considerando a vazão de projeto é 4.460 .000 habitantes, porém em 2003 a estação trabalhou com uma vazão média de tratamento de $7 \mathrm{~m}^{3} \mathrm{~s}^{-1}$ (Companhia de Saneamento Básico do Estado de São Paulo, 2003).

O processo do Tratamento do Esgoto é por lodo ativado do tipo convencional, em nível secundário, com eficiência de $90 \%$, baseada na remoção de carga orgânica expressa em DBO. De acordo com as centrais de informações da SABESP, a estação foi subdividida em nove áreas (ver Figura 2), cujas características básicas serão descritas a seguir.

\footnotetext{
${ }^{1}$ Helou, 2000; Companhia de Saneamento Básico do Estado de São Paulo, 2002.
} 


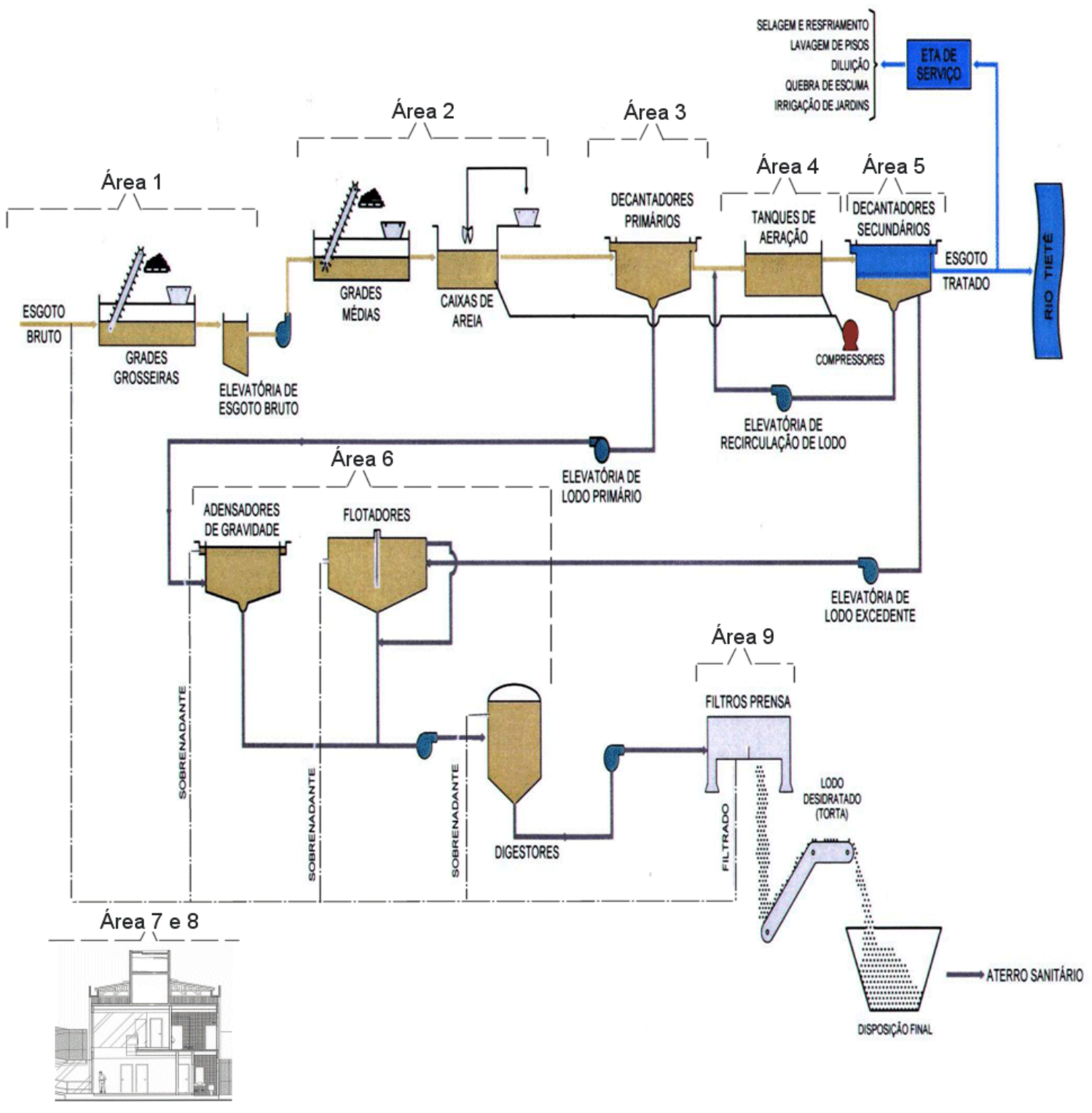

Figura 2 - Fluxograma do processo da ETE Barueri (adaptado de SABESP, 2002).

Área 1 - poço distribuidor e elevatória final: o esgoto chega à ETE por meio do interceptor Tietê Oeste Margem Sul (ITI-6), instalado a cerca de 30 metros de profundidade, que encaminha o fluxo ao poço distribuidor. Devido às longas distâncias percorridas pelos emissários e interceptores, o poço de distribuição tem uma profundidade de $37 \mathrm{~m}$, onde, por bombeamento, o esgoto é recalcado até o canal afluente às grades mecanizadas. Devido às baixas velocidades do esgoto no poço, foi prevista a construção de um pórtico móvel, que, por meio de guindaste (pontes rolantes) provido de caçamba tipo "Clam Shell", promove periodicamente a remoção do material sedimentado e da escuma. O poço é também equipado com 
sistema de insuflamento de ar para a eliminação dos gases liberados pelo esgoto. A água residuária é recalcada a uma altura geométrica de cerca de $30 \mathrm{~m}$, por intermédio de 4 (quatro) conjuntos elevatórios, operando com motores de $3100 \mathrm{HP}$ de velocidade variável e fixa. Cada conjunto trabalha com vazões na faixa de 3 a $6 \mathrm{~m}^{3} \mathrm{~s}^{-1}$.

Está prevista a entrada em funcionamento de um sistema de instrumentação que permitirá o controle automático de velocidade de rotação das bombas, de modo a manter o nível desejado no poço distribuidor. Além de receber a vazão proveniente dos interceptores, o poço de distribuição recebe as recirculações oriundas dos processos de adensamento por gravidade e flotação, de digestão, de desaguamento mecânico do lodo e de todo o sistema de drenagem da ETE.

Área 2 - grades mecanizadas, caixas de areia e tanques de pré-aeração: as grades recebem o esgoto bombeado por meio de canais cobertos e aerados com difusores de bolha grossa, com intuito de evitar problemas de odores e a sedimentação de sólidos em suspensão. A referida unidade é constituída por barras paralelas fixadas em posição inclinada em $75^{\circ}$ com a horizontal, de 12,7 x 76,2 mm (1/2 e 3 ") e espaçadas 25 mm (1") entre si. As duas grades existentes são do tipo "front clean front return" ou seja, o sistema de limpeza, tanto na fase de remoção como no retorno, é feito pela frente da grade de forma que o material eventualmente não removido do rastelo seja lançado à montante da grade e assim reconduzido para uma nova captura. O material retido é removido por meio de um sistema de rastelos de acionamento automático. O controle de acionamento automático de rastelos é efetuado por tempo ou perda de carga (diferença de nível do fluido a montante e jusante da grade). Concomitante ao sistema de rastelos ocorre o acionamento de uma correia transportadora, que encaminha o material removido para as caçambas especialmente destinadas a esse fim.

Os sólidos em suspensão de elevada massa específica, são removidos em duas caixas de areia. Essas unidades são do tipo aerada de fluxo orbital, que se caracterizam pela remoção do material com baixo teor de matéria orgânica, eliminando assim, a necessidade de dispositivos de lavagem. A taxa de ar, nessas unidades, é controlada automaticamente por instrumentação apropriada. O material 
depositado é removido periodicamente por meio de guindastes (pontes rolantes) providos de caçambas tipo "Clam Shell” que alimentam caminhões.

Devido às características sépticas apresentadas pelo esgoto em função do longo tempo de trajeto até a estação, foi prevista a execução de tanques de pré-aeração no sentido de controlar odores. O ar é introduzido à massa líquida, por meio de difusores de bolha grossa, a uma taxa também controlada automaticamente por sistema de instrumentação.

Área 3 - decantadores primários: a remoção dos sólidos em suspensão é realizada em unidades de decantação primária de forma retangular, com 95 metros de comprimento, 18 metros de largura e 3,5 metros de altura útil (Companhia de Saneamento Básico do Estado de São Paulo, SABESP, 2002).

Os oito decantadores primários existentes na ETE Barueri removem sólidos numa fração média de 60 a $70 \%$ e de DBO na faixa de $30 \%$. O lodo assim produzido é conduzido de jusante para montante por meio de um raspador de fundo a três poços existentes na extremidade de montante de cada decantador. $O$ raspador de fundo tem uma periodicidade de 1 hora e cada um dos poços é esgotado por meio de bombas por 20 minutos. Assim, o lodo primário é encaminhado continuamente ao tratamento da fase sólida (Área 6) (Helou, 2000).

Área 4 - tanques de aeração e compressores: o esgoto decantado é conduzido a tanques de aeração de forma retangular com $130 \mathrm{~m}$ de comprimento, $25 \mathrm{~m}$ de largura e $6 \mathrm{~m}$ de altura útil. Os oito tanques de aeração são dotados de 8500 difusores cerâmicos de bolhas finas por tanque, alimentados por meio de um sistema de tubulações de ar de UPVC (cloreto de polivinila não plastificado). As tubulações de alimentação do sistema de distribuição são de aço inoxidável. A alimentação, proveniente dos decantadores primários, é feita lateralmente por meio de um sistema de comportas, e o vertimento é feito na outra extremidade por meio de um sistema de vertedores que encaminham o efluente ao sistema de decantação secundária. A recirculação proveniente dos decantadores secundários aflui ao tanque de aeração por meio da extremidade de montante. O sistema opera como tendendo à mistura completa, sendo porém possível sua operação como tendendo ao fluxo de pistão ('plug-flow') através de um sistema de comportas situados na extremidade de jusante. 
O suprimento de ar para os tanques de aeração e tratamento preliminar é efetuado por quatro compressores do tipo centrífugo multiestágio de $102000 \mathrm{~N} \cdot \mathrm{m}^{3} \mathrm{~h}^{-1}$. Eles têm capacidade para atender a demanda de dois módulos de tratamento.

Área 5 - decantadores secundários: a separação da massa biológica dos tanques de aeração se realiza em clarificadores circulares com diâmetro interno de $46 \mathrm{~m}$ e uma profundidade de $4 \mathrm{~m}$. São 16 decantadores secundários, dos quais quatro foram adicionados posteriormente, devido a um acréscimo de vazões provenientes do emissário Pinheiros.

A extração do lodo do fundo se dá por dispositivos de sucção (por gradiente hidráulico). Esse sistema permite a retirada do lodo ao longo de todo o fundo do decantador, reduzindo os riscos de anaerobiose. O sistema possui uma linha de retorno que encaminha parte do lodo ativado novamente ao tanque de aeração e uma linha de descarte que encaminha o lodo secundário aos adensadores por flotação. O efluente final é descartado no Rio Tietê por meio de três eixos (Helou, 2000; Companhia de Saneamento Básico do Estado de São Paulo, SABESP, 2002).

As elevatórias de recirculação de lodo ativado estão dimensionadas para trabalhar com taxas de recirculação na faixa de $30 \%$ a $90 \%$. A taxa de recirculação é fixada e controlada automaticamente por intermédio de instrumentação apropriada. Existem, ainda, dispositivos que permitem a automação do controle de descarte do lodo em excesso, por meio de uma derivação da linha de retorno ou diretamente do conteúdo do tanque de carga (descarte hidráulico). Quando se utiliza a primeira forma de descarte, o lodo é conduzido para o tratamento de fase sólida por bombeamento em conjuntos elevatórios, especialmente destinados a esse fim (elevatória de excesso de lodo). Por outro lado, quando se utiliza o descarte hidráulico, o lodo é recirculado por gravidade para o início do tratamento. Os clarificadores contam ainda com um sistema de retirada e bombeamento de escuma.

Área 6 - adensadores, digestores e gasômetro: o projeto prevê o adensamento do lodo primário em adensadores por gravidade e do lodo ativado em adensadores por flotação.

São 4 adensadores por gravidade circulares, de diâmetro interno de $29 \mathrm{~m} \mathrm{e}$ profundidade da lâmina d'água de $3,5 \mathrm{~m}$ (lateral), os quais recebem o lodo primário por meio de uma caixa de distribuição situada no centro geométrico dos 
adensadores, de forma a garantir uma distribuição equitativa de vazão para cada um deles. A parte superior é dotada de vertedores triangulares, tipo dente de serra, que encaminham o sobrenadante ao poço distribuidor. Foram previstos dispositivos para a adição de água de diluição ao lodo, de modo a garantir uma taxa de aplicação superficial adequada à prevenção de odores. O controle da vazão de diluição é efetuado por meio de sistema de instrumentação apropriado. A remoção do lodo é feita pelo fundo por meio de um sistema de recalque que encaminha esse lodo ao sistema de digestão.

São seis adensadores circulares de flotação com 14,60 m de diâmetro e volume de $535 \mathrm{~m}^{3}$. Os flotadores por ar difuso recebem o lodo biológico proveniente do descarte do sistema de decantação secundária. Esse lodo é misturado a uma emulsão de ar e efluente tratado proveniente de um tanque de retenção onde o ar é injetado. A mistura provoca a flotação das partículas sólidas que são coletadas por meio de escumadores de superfície que conduzem o lodo flotado para um poço de lodo de onde é bombeado para os digestores. O efluente líquido dos tanques é conduzido para o poço distribuidor através da drenagem de fundo (DFU). Os materiais que sedimentam no fundo do tanque são removidos por raspadores e conduzidos para os poços de lodo.

O lodo proveniente dos adensadores (lodo primário adensado) e dos flotadores (lodo biológico adensado) chega à área dos digestores por linhas independentes, as quais são reunidas em uma única linha para a alimentação de cada grupo de quatro digestores. Para tanto, existem caixas de manobra de válvulas localizadas próximas aos digestores.

Dos oito biodigestores de alta taxa existentes, quatro apresentam sistema de aquecimento, os quatro restantes atuam como tanques de acumulação (TAC). A ausência de aquecimento inibe a destruição de sólidos voláteis. Cada biodigestor tem cobertura fixa e um volume útil de $10492 \mathrm{~m}^{3}$, e é equipado com um sistema de agitação de gás, constituído por tubulação de aço galvanizado para coleta de gás. Esse gás é encaminhado a um compressor. O gás pressurizado é devolvido por meio de doze tubos de injeção. O excesso de gás produzido em cada digestor é coletado individualmente por tubulações de ferro fundido equipadas com cortachamas, acumulador de sedimentos, medidor de gás (gasômetro) e sistemas de 
proteção (válvulas de alívio e quebra vácuo), e encaminhado para os queimadores (Helou, 2000).

Áreas 7 e 8: compreendem as áreas de controle operacional da ETE, localizadas no edifício administrativo.

Área 9 - condicionamento químico do lodo e desaguamento: o lodo digerido é enviado por bombeamento ou por gravidade, ao tanque de acumulação, e posteriormente recalcado por meio de bombas parafuso às células de condicionamento químico onde é feita a adição de cloreto férrico (aplicação entre $3 \%$ e $5 \%$ em base seca). O lodo segue ao tanque de lodo condicionado, é bombeado por bomba pistão de alta pressão (seis bombas disponíveis) e antes de alimentar o filtro prensa é dosado polímero catiônico na linha de recalque do lodo utilizando aplicação máxima de $6 \mathrm{~kg}$ de polímero catiônico em pó para cada tonelada de lodo digerido (base seca).

Em 2003 o desaguamento do lodo era realizado com 3 Filtros Prensa de Placa, composto por 151 placas de $4 \mathrm{~m}^{2}(2 \mathrm{~m} \times 2 \mathrm{~m}$ ) cada e uma série de esteiras que conduzem o lodo descarregado do filtro ao pátio de lodo. A produção de lodo desaguado é de 250 toneladas por dia (em média 20\% de sólidos) e tem como destino o Aterro Sanitário Essencis.

Elevatória de utilidades: em virtude do grande volume de água necessário na operação da estação foi previsto um sistema que promove a reutilização desta, após tratamento adicional do efluente final, para diversas utilidades, entre as quais, selagem de gaxeta de equipamentos, diluição, quebra escuma e lavagem.

\section{Coleta e tratamento dos dados da Estação de Tratamento de Esgoto Barueri}

No ano de 2003, foram feitas visitas à ETE Barueri, e foram coletados os dados (reais de operação) anuais de 2002 com os quais foi feita a análise exergética para esse processo.

Os dados dos principais insumos da ETE Barueri (energia elétrica, água de reuso, polímeros, $\mathrm{FeCl}_{3}$ ), da caracterização do esgoto bruto (afluente) e do efluente final, 
assim como dos subprodutos gerados (lodo desaguado e gás) e a composição química do lodo desaguado, são apresentados nas Tabelas 2, 3 e 4.

Tabela 2 - Dados anuais da caracterização do esgoto bruto (afluente) e do efluente final da Estação de Tratamento de Esgotos Barueri

\begin{tabular}{|c|c|c|}
\hline Parâmetro & Afluente & Efluente \\
\hline Vazão $\left(\mathrm{Ls}^{-1}\right)$ & 6309,5 & 6309,5 \\
\hline$D Q O\left(\mathrm{mgO}_{2} \mathrm{~L}^{-1}\right)$ & 458 & 60 \\
\hline $\mathrm{pH}$ & 7,4 & 7,3 \\
\hline$T\left({ }^{\circ} \mathrm{C}\right)$ & 26,6 & 26,6 \\
\hline$S S\left(m L L^{-1}\right)$ & 5 & 0,2 \\
\hline $\mathrm{SST}\left(\mathrm{mgL}^{-1}\right)$ & 169 & 15 \\
\hline $\operatorname{SSV}\left(\mathrm{mgL}^{-1}\right)$ & 121 & 11 \\
\hline NTK $\left(\mathrm{mgL}^{-1}\right)$ & 29 & 5 \\
\hline $\mathrm{NH}_{3}\left(\mathrm{mgL}^{-1}\right)$ & 31 & 10 \\
\hline $\mathrm{NO}_{3}^{-}\left(\mathrm{mgL}^{-1}\right)$ & 0,2 & 6,9 \\
\hline $\mathrm{NO}_{2}^{-}\left(\mu \mathrm{gL}^{-1}\right)$ & 0,009 & 0,200 \\
\hline$O G\left(\mathrm{mgL}^{-1}\right)$ & 60 & 10,7 \\
\hline $\mathrm{S}_{2}^{-}\left(\mathrm{mgL}^{-1}\right)$ & $\leq 1$ & $\leq 1$ \\
\hline $\mathrm{SO}_{4}\left(\mathrm{mgL}^{-1}\right)$ & 43,5 & 31,3 \\
\hline Cádmio $\left(\mathrm{mgL}^{-1}\right)$ & 0,007 & 0,005 \\
\hline Mercúrio $\left(\mu \mathrm{g} \mathrm{L}^{-1}\right)$ & - & - \\
\hline Níquel $\left(\mathrm{mgL}^{-1}\right)$ & 0,07 & 0,04 \\
\hline Prata $\left(\mathrm{mgL}^{-1}\right)$ & 0,012 & 0,004 \\
\hline Zinco $\left(\mathrm{mgL}^{-1}\right)$ & 0,44 & 0,11 \\
\hline Manganês $\left(\mathrm{mgL}^{-1}\right)$ & 0,093 & 0,070 \\
\hline Molibdênio $\left(\mathrm{mgL}^{-1}\right)$ & $<0,02$ & $<0,02$ \\
\hline Selênio $\left(\mu \mathrm{g} \mathrm{L}^{-1}\right)$ & - & - \\
\hline Chumbo (mgL $\left.{ }^{-1}\right)$ & 0,03 & $<0,02$ \\
\hline Cobre $\left(\mathrm{mgL}^{-1}\right)$ & 0,09 & 0,02 \\
\hline Cromo Total $\left(\mathrm{mgL}^{-1}\right)$ & 0,124 & $<0,032$ \\
\hline Ferro $\left(\mathrm{mgL}^{-1}\right)$ & 3,3 & 0,5 \\
\hline Fenol $\left(\mathrm{mgL}^{-1}\right)$ & 0,220 & 0,034 \\
\hline Fósforo $\left(\mathrm{mgL}^{-1}\right)$ & 5 & 2 \\
\hline Surfactantes $\left(\mathrm{mgL}^{-1}\right)$ & 22 & 1 \\
\hline Estanho $\left(\mathrm{mgL}^{-1}\right)$ & $<0,14$ & $<0,13$ \\
\hline Coliformes totais (NMP) & $1,8 \cdot 10^{7}$ & $5,9 \cdot 10^{6}$ \\
\hline E. Coli (NMP) & $6,1 \cdot 10^{6}$ & $5,8 \cdot 10^{5}$ \\
\hline
\end{tabular}

A coleta destes dados foi feita por Funcionários da Companhia de Saneamento Básico do Estado de São Paulo, SABESP, que trabalham na ETE Barueri (SABESP, 2002). Com o intuito de estabelecer uma comparação entre a ETE 
Barueri, o sistema RAFA - Lagoa Facultativa e a ETE Cañaveralejo, foram usados os valores (reais) médios anuais.

Os parâmetros de qualidade dos esgotos, assim como os padrões de emissão de efluentes, são apresentados nos Anexos A e B respectivamente.

Tabela 3 - Dados dos consumos e dos subprodutos gerados na ETE Barueri

\begin{tabular}{|c|c|}
\hline Consumos & Quantidade \\
\hline Material gradeado (t mês ${ }^{-1}$ ) & 35,2 \\
\hline Areia removida ( t mês $^{-1}$ ) & 55 \\
\hline Lodo desaguado produzido ( $t$ mês ${ }^{-1}$ ) & 6334,3 \\
\hline ST Torta $(\%)$ & 2,8 \\
\hline Consumo de energia elétrica ( $\mathrm{kWh}$ mês $\left.{ }^{-1}\right)$ & 3.743 .926 \\
\hline Consumo de água $\left(\mathrm{m}^{3} \mathrm{mês}^{-1}\right)$ & 10065,3 \\
\hline Consumo de $\mathrm{FeCl}_{3}\left(\mathrm{~kg} \mathrm{mês}^{-1}\right)$ & 106301,3 \\
\hline Consumo de polímeros (kg mês ${ }^{-1}$ ) & 8978,3 \\
\hline Produção de gás ( $\mathrm{m}^{3}$ mês ${ }^{-1}$ ) & 319883,7 \\
\hline Água de reuso $\left(\mathrm{m}^{3} \mathrm{mês}^{-1}\right)$ & 838,3 \\
\hline
\end{tabular}

Tabela 4 - Dados da composição química do lodo desaguado gerado na ETE Barueri

\begin{tabular}{lc}
\hline Componente & mgkg $^{-1}$ de lodo \\
\hline DQO $\left(\mathrm{mgL}^{-1}\right)$ & 22775 \\
Cádmio & 14,4 \\
Chumbo & 165,9 \\
Cobre & 594,5 \\
Cromo & 647,8 \\
Manganês & 258,3 \\
Ferro & 31828,2 \\
Níquel & 308,8 \\
Zinco & 2312,3 \\
Prata & 58,8 \\
Molibdênio & 17,6 \\
\hline
\end{tabular}


Os dados apresentados nas Tabelas 5, 6 e 7 a seguir foram calculados das Tabelas 2,3 e 4 .

Tabela 5 - Caracterização do esgoto bruto (afluente) e do efluente final da Estação de Tratamento de Esgotos Barueri

\begin{tabular}{lll}
\cline { 2 - 3 } & Afluente & Efluente \\
\hline$D Q O\left(\mathrm{~mol} \mathrm{~L}^{-1}\right)$ & $2,30 \mathrm{E}-03$ & $3,01 \mathrm{E}-04$ \\
$\mathrm{NH}_{3}\left(\mathrm{~mol} \mathrm{~L}^{-1}\right)$ & $1,83 \mathrm{E}-03$ & $5,80 \mathrm{E}-04$ \\
$\mathrm{NO}_{3}\left(\mathrm{~mol} \mathrm{~L}^{-1}\right)$ & $2,42 \mathrm{E}-06$ & $1,11 \mathrm{E}-04$ \\
$\mathrm{NO}_{2}\left(\mathrm{~mol} \mathrm{~L}^{-1}\right)$ & $2,01 \mathrm{E}-07$ & $3,50 \mathrm{E}-06$ \\
$\mathrm{SO}_{4}\left(\mathrm{~mol} \mathrm{~L}^{-1}\right)$ & $4,53 \mathrm{E}-04$ & $3,30 \mathrm{E}-04$ \\
$\mathrm{Cádmio}\left(\mathrm{mol} \mathrm{L}^{-1}\right)$ & $6,23 \mathrm{E}-08$ & $4,00 \mathrm{E}-08$ \\
Níquel $\left(\mathrm{mol} \mathrm{L}^{-1}\right)$ & $1,21 \mathrm{E}-06$ & $6,81 \mathrm{E}-07$ \\
Prata $\left(\mathrm{mol} \mathrm{L}^{-1}\right)$ & $1,11 \mathrm{E}-07$ & $3,71 \mathrm{E}-08$ \\
Zinco $\left(\mathrm{mol} \mathrm{L}^{-1}\right)$ & $6,73 \mathrm{E}-06$ & $1,62 \mathrm{E}-06$ \\
Manganês $\left(\mathrm{mol} \mathrm{L}^{-1}\right)$ & $1,70 \mathrm{E}-06$ & $1,30 \mathrm{E}-06$ \\
Molibdênio $\left(\mathrm{mol} \mathrm{L}^{-1}\right)$ & $2,08 \mathrm{E}-07$ & $2,08 \mathrm{E}-07$ \\
Chumbo $\left(\mathrm{mol} \mathrm{L}^{-1}\right)$ & $1,26 \mathrm{E}-07$ & $7,40 \mathrm{E}-08$ \\
Cobre $\left(\mathrm{mol} \mathrm{L}^{-1}\right)$ & $1,42 \mathrm{E}-06$ & $2,72 \mathrm{E}-07$ \\
Cromo Total $\left(\mathrm{mol} \mathrm{L}^{-1}\right)$ & $2,40 \mathrm{E}-06$ & $6,15 \mathrm{E}-07$ \\
Ferro $\left(\mathrm{mol} \mathrm{L}^{-1}\right)$ & $5,91 \mathrm{E}-05$ & $8,43 \mathrm{E}-06$ \\
Fósforo $\left(\mathrm{mol} \mathrm{L}^{-1}\right)$ & $1,65 \mathrm{E}-04$ & $7,75 \mathrm{E}-05$ \\
Surfactantes $\left(\mathrm{mol} \mathrm{L}^{-1}\right)$ & $5,40 \mathrm{E}-04$ & $3,25 \mathrm{E}-05$ \\
Estanho $\left(\mathrm{mol} \mathrm{L}^{-1}\right)$ & $1,20 \mathrm{E}-06$ & $1,10 \mathrm{E}-06$ \\
\hline
\end{tabular}

Tabela 6 - Consumos e subprodutos gerados na ETE Barueri

\begin{tabular}{lc}
\hline Consumos & Quantidade \\
\hline Lodo desaguado produzido $\left(\mathrm{kg} \mathrm{s}^{-1}\right)$ & 2,4 \\
Consumo energia elétrica $(\mathrm{kW})$ & 5128,6 \\
Consumo água $\left(\mathrm{g} \mathrm{s}^{-1}\right)$ & 4149 \\
Consumo $\mathrm{FeCl}_{3}\left(\mathrm{~g} \mathrm{~s}^{-1}\right)$ & 40,5 \\
Consumo polímeros $\left(\mathrm{g} \mathrm{s}^{-1}\right)$ & 3,4 \\
Produção de gás $\left(\mathrm{g} \mathrm{s}^{-1}\right)$ & 121,7 \\
Água de reuso $\left(\mathrm{g} \mathrm{s}^{-1}\right)$ & 318,3 \\
\hline
\end{tabular}


Tabela 7 - Composição química do lodo desaguado gerado na ETE de Barueri

\begin{tabular}{lc}
\hline Componente & molkg $^{-1}$ de lodo \\
\hline$D Q O\left(\mathrm{~mol} \mathrm{~L}^{-1}\right)$ & $1,14 \mathrm{E}-01$ \\
Cádmio & $1,30 \mathrm{E}-04$ \\
Chumbo & $9,70 \mathrm{E}-04$ \\
Cobre & $9,50 \mathrm{E}-03$ \\
Cromo & $1,40 \mathrm{E}-02$ \\
Manganês & $5,50 \mathrm{E}-03$ \\
Ferro & $6,00 \mathrm{E}-01$ \\
Níquel & $5,30 \mathrm{E}-03$ \\
Zinco & $3,54 \mathrm{E}-02$ \\
Prata & $5,60 \mathrm{E}-04$ \\
Molibdênio & $2,10 \mathrm{E}-04$ \\
\hline
\end{tabular}

\subsubsection{Reator Anaeróbio de Fluxo Ascendente com Manta de Lodo (RAFA) e Lagoa Facultativa}

O sistema de tratamento RAFA - Lagoa facultativa pertence à Estação de Pesquisa e Transferência de Tecnología em Tratamento de Esgoto e Água de Reúso, criada em 1993 pela união da Sociedade de Aquedutos e Redes de esgoto do Valle (ACUAVALLE S. A. ESP), a Universidade do Valle e o Instituto Cínara, para a pesquisa e o desenvolvimento tecnológico na área do manejo integral dos esgotos domésticos. Está localizado na cidade de Ginebra, a $59 \mathrm{~km}$ a nordeste de Cali, capital do estado do Valle do Cauca.

O ano de início de operação do centro de pesquisa foi em 1993, com uma vazão de projeto de $31 \mathrm{~L} \mathrm{~s}^{-1}$, e uma vazão de operação de $18 \mathrm{~L} \mathrm{~s}^{-1}$, atendendo uma população de 10.000 habitantes, com uma eficiência de remoção de carga orgânica de $80 \%$. Na Fig. 3 é apresentado um fluxograma do processo do reator RAFA - Lagoa Facultativa. 


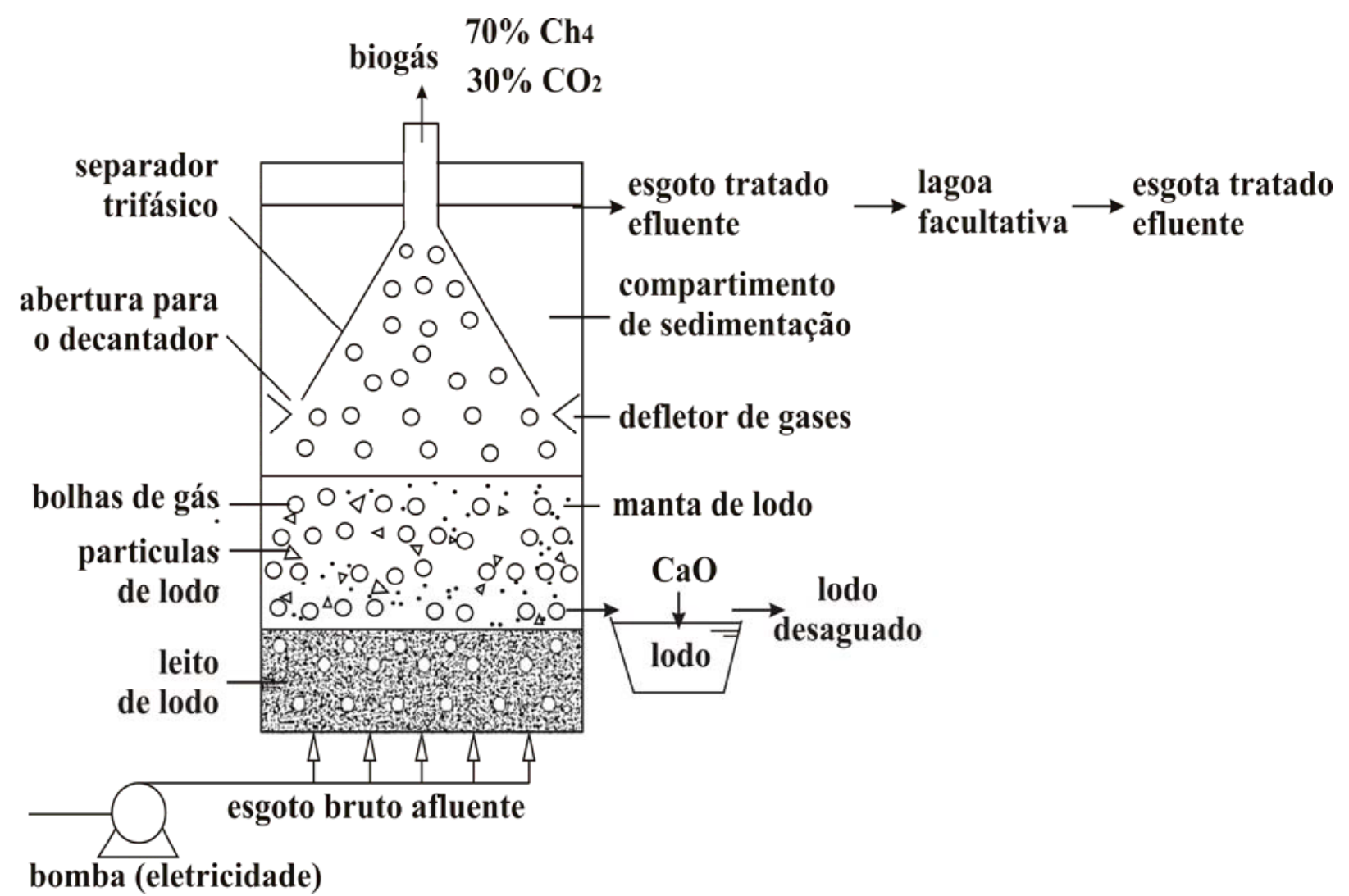

Figura 3 - Esquema do RAFA.

Os parâmetros técnicos do RAFA são:

- $26 \mathrm{~m}$ de largura $\times 5 \mathrm{~m}$ de comprimento $\times 2 \mathrm{~m}$ de profundidade.

- Vazão: $8 L^{-1}$

- Tempo de detenção hidráulico: 13 dias

- Periodo de manutenção: 8 meses para limpeza de campanas extratoras, e 1 mes para extração de lodos

- Produção de lodo: $6,75 \mathrm{~m}^{3} \mathrm{mês}^{-1}$

- Compostos químicos: $15 \mathrm{~kg} \mathrm{CaO}$ mês $^{-1}$

- Eficiência de remoção de DBO: 66\%

- Eficiência de remoção de DQO: 64\%

- Produção de gás: 106,7 $\mathrm{m}^{3}$ mês $^{-1}$

- Consumo de energía elétrica para bombeamento: 20,87 kW 
- Temperatura de operação: $26,3{ }^{\circ} \mathrm{C}$

- pH: 6,7

Os parâmetros técnicos da Lagoa Facultativa são:

- $56 \mathrm{~m}$ de largura $\times 112 \mathrm{~m}$ de comprimento $\times 1,8 \mathrm{~m}$ de profundidade

- Vazão: 8 Ls $^{-1}$

- Tempo de detenção hidráulico: 6 días

- Consumo de energía elétrica para bombeamento: 20,87 kW

- Temperatura de operação: $26,2^{\circ} \mathrm{C}$

- $\mathrm{pH}: 7,56$

- Eficiência de remoção de DBO: 65\%

- Eficiência de remoção de DQO: 67\%

Coleta e tratamento de dados do sistema RAFA - Lagoa Facultativa

Os dados dos principais insumos do sistema RAFA - Lagoa Facultativa (energia elétrica, $\mathrm{CaO}$ ), da caracterização do esgoto bruto (afluente) e do efluente final (Lagoa Facultativa), assim como dos subprodutos gerados (lodo desaguado produzido e biogás) e a composição química do lodo desaguado, são apresentados nas Tabelas 8, 9 e 10.

A coleta dos dados (reais) foi feita por Funcionários do Centro de Pesquisa para o Tratamento de Esgoto de Ginebra, Colômbia, durante os meses de janeiro a dezembro de 2007. Com base nesses dados, no presente trabalho foram calculados, os valores médios anuais que foram usados nesta análise. 
Tabela 8 - Dados da caracterização do esgoto bruto (afluente) do Rafa e do efluente final da Lagoa Facultativa

\begin{tabular}{lcc}
\hline Parâmetro & Afluente & Efluente \\
\hline Vazão $\left(\mathrm{Ls}^{-1}\right)$ & 8 & 8 \\
$D B O\left(\mathrm{mgO}_{2} \mathrm{~L}^{-1}\right)$ & 413 & 144 \\
$\mathrm{DQO}\left(\mathrm{mgO}_{2} \mathrm{~L}^{-1}\right)$ & 668 & 218 \\
$\mathrm{pH}$ & 6,8 & 7,6 \\
$T\left({ }^{\circ} \mathrm{C}\right)$ & 26,5 & 26,2 \\
$\mathrm{SS}\left(\mathrm{mgL}^{-1}\right)$ & 261,43 & 187,1 \\
$\mathrm{SST}\left(\mathrm{mgL}^{-1}\right)$ & 747,64 & 414,1 \\
$\mathrm{CaCO}_{3}\left(\mathrm{mgL}^{-1}\right)$ & 558,51 & 547,9 \\
$\mathrm{NO}_{2}\left(\mathrm{mgL}^{-1}\right)$ & 0,0065 & 0,037 \\
$\mathrm{SO}_{4}\left(\mathrm{mgL}^{-1}\right)$ & 186,25 & - \\
$\mathrm{Cl}\left(\mathrm{mgL}^{-1}\right)$ & 63 & 57,3 \\
Cond. $\left(\mathrm{mScm}^{-1}\right)$ & 0,62 & 0,57 \\
Coliformes totais (NMP) & $1,86.10^{-7}$ & $1,25.10^{+6}$ \\
\hline
\end{tabular}

Tabela 9 - Dados dos consumos e dos subprodutos gerados no sistema RAFA - Lagoa Facultativa

\begin{tabular}{|c|c|}
\hline Consumos & Quantidades \\
\hline Lodo desaguado produzido (t mês ${ }^{-1}$ ) & 6,8 \\
\hline Produção de gás $\left(\mathrm{m}^{3} \mathrm{mês}^{-1}\right)$ & 40 \\
\hline Consumo energia elétrica (kWh mês $\left.{ }^{-1}\right)$ & 26,6 \\
\hline Consumo $\mathrm{CaO}\left(\mathrm{kg} \mathrm{mês}^{-1}\right)$ & 15 \\
\hline
\end{tabular}

Tabela 10 - Dados da composição química do lodo desaguado gerado no RAFA

\begin{tabular}{lc}
\hline Componente & mgkg $^{-1}$ de lodo \\
\hline DQO $\left(\mathrm{mgL}^{-1}\right)$ & 83263 \\
Cálcio $\left(\mathrm{mgkg}^{-1}\right)$ & 4,4 \\
Magnésio $\left(\mathrm{mgkg}^{-1}\right)$ & 0,9 \\
Potássio $\left(\mathrm{mgkg}^{-1}\right)$ & 16 \\
Sódio $\left(\mathrm{mgkg}^{-1}\right)$ & 24 \\
Fósforo $\left(\mathrm{mgkg}^{-1}\right)$ & 174 \\
Boro $\left(\mathrm{mgkg}^{-1}\right)$ & 1,4 \\
Cobre $\left(\mathrm{mgkg}^{-1}\right)$ & 297,6 \\
Zinco $\left(\mathrm{mgkg}^{-1}\right)$ & 350,9 \\
Manganês $\left(\mathrm{mgkg}^{-1}\right)$ & 175,9 \\
Ferro $\left(\mathrm{mgkg}^{-1}\right)$ & 440,5 \\
\hline
\end{tabular}


Os dados apresentados nas Tabelas 11, 12 e 13 a seguir foram calculados das Tabelas 8, 9 e 10.

Tabela 11 - Caracterização do esgoto bruto (afluente) do RAFA e do efluente final da Lagoa Facultativa

\begin{tabular}{lcc}
\cline { 2 - 3 } & Afluente & Efluente \\
\hline $\mathrm{DQO}\left(\mathrm{mol} \mathrm{L}^{-1}\right)$ & $3,34 \mathrm{E}-03$ & $1,09 \mathrm{E}-03$ \\
$\mathrm{CaCO}_{3}\left(\mathrm{~mol} \mathrm{~L}^{-1}\right)$ & $5,88 \mathrm{E}-03$ & $5,50 \mathrm{E}-03$ \\
$\mathrm{NO}_{2}\left(\mathrm{~mol} \mathrm{~L}^{-1}\right)$ & $1,47 \mathrm{E}-07$ & $7,92 \mathrm{E}-07$ \\
$\mathrm{Cl}\left(\mathrm{mol} \mathrm{L}^{-1}\right)$ & $1,77 \mathrm{E}-03$ & $1,62 \mathrm{E}-03$ \\
$\mathrm{SO}_{4}\left(\mathrm{~mol} \mathrm{~L}^{-1}\right)$ & $1,94 \mathrm{E}-03$ & - \\
Total $\left(\mathrm{mol} \mathrm{L}^{-1}\right)$ & $1,29 \mathrm{E}-02$ & $8,50 \mathrm{E}-03$ \\
\hline
\end{tabular}

Tabela 12 - Consumos e subprodutos gerados no sistema RAFA - Lagoa Facultativa

\begin{tabular}{lc}
\hline Consumos & Quantidades \\
\hline Lodo desaguado produzido $\left(\mathrm{kg} \mathrm{s}^{-1}\right)$ & 0,03 \\
Produção de gás $\left(\mathrm{g} \mathrm{s}^{-1}\right)$ & 0,42 \\
Consumo energia elétrica $(\mathrm{kW})$ & 41,80 \\
Consumo CaO $\left(\mathrm{g} \mathrm{s}^{-1}\right)$ & 0,006 \\
\hline
\end{tabular}

Tabela 13 - Composição química do lodo desaguado gerado no RAFA

\begin{tabular}{lc}
\hline Componente & molkg $^{-1}$ de lodo \\
\hline$D Q O\left(\mathrm{~mol} \mathrm{~L}^{-1}\right)$ & $4,16 \mathrm{E}-01$ \\
Cálcio & $1,10 \mathrm{E}-04$ \\
Magnésio & $3,81 \mathrm{E}-05$ \\
Potássio & $3,99 \mathrm{E}-04$ \\
Sódio & $1,02 \mathrm{E}-03$ \\
Fósforo & $5,62 \mathrm{E}-03$ \\
Boro & $1,32 \mathrm{E}-04$ \\
Cobre & $4,68 \mathrm{E}-03$ \\
Zinco & $5,37 \mathrm{E}-03$ \\
Manganês & $3,20 \mathrm{E}-03$ \\
Ferro & $7,89 \mathrm{E}-03$ \\
Total & $4,45 \mathrm{E}-01$ \\
\hline
\end{tabular}




\subsubsection{Estação de tratamento de esgotos de (ETE) Cañaveralejo ${ }^{2}$}

A ETE cañaveralejo está localizada no município de Cali em um terreno de $22 \mathrm{Ha}$. Entre as cordenadas geográficas $110.000 \mathrm{~N}-109.000 \mathrm{~N}$ e $17.000 \mathrm{E}-18.000 \mathrm{E}$, no Bairro Petecuy I, limita ao Este com a rua 84, paralela à proteção do Rio Cauca, pelo Norte com a rua 3, pelo Oeste com a Avenida Ciudad de Cali e pelo Sul com a rua 7, paralela à estrada de ferro do trem.

O processo de tratamento de esgoto é um primário quimicamente assistido com eficiência de $47 \%$ baseada na remoção de carga orgânica expressa em DBO. As características básicas deste são descritas a seguir (Ver Figura 4).

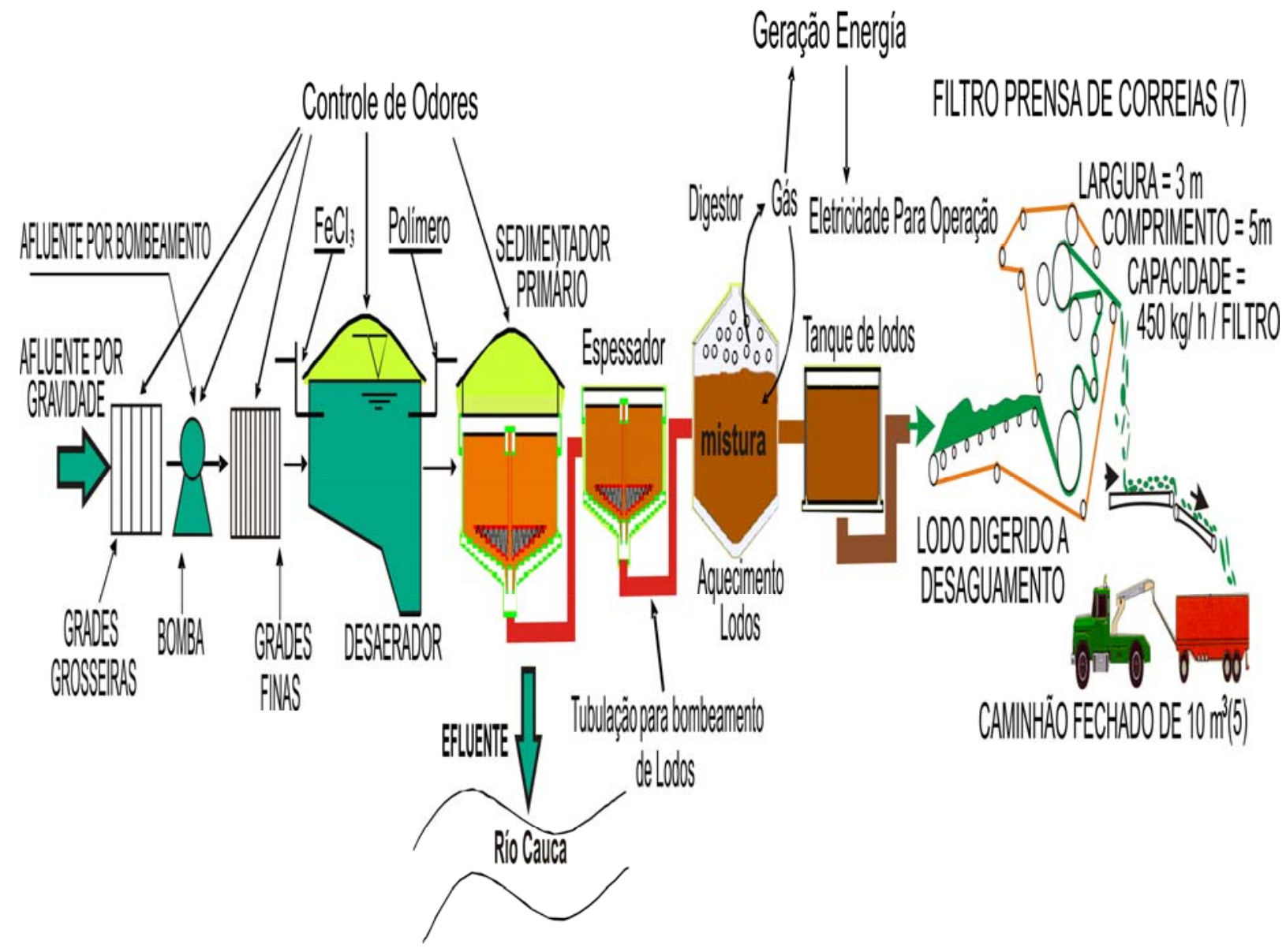

Figura 4 - Fluxograma do processo da ETE Cañaveralejo (Adaptado de EMCALI, 2001).

\footnotetext{
${ }^{2}$ Empresas Municipales de Cali - EMCALI, 2001.
} 
O esgoto chega à ETE por meio de dois interceptores. No primeiro deles são transportados por bombeamento os fluxos das estações de Aguablanca, Navarro e Cañaveralejo até o poço distribuidor, e no segundo são transportados os fluxos do interceptor central até o poço distribuidor.

Uma vez que o esgoto entra na ETE, passa através de duas grades grosseiras espaçadas $100 \mathrm{~mm}$, projetadas para reter sólidos grosseiros, que utilizam uma correia transportadora. O material retido é enviado a uma caçamba de $3 \mathrm{~m}^{3}$ de capacidade que possui acionamento mecânico.

Depois do esgoto passar pelas grades por bombeamento, é transportado por quatro bombas parafuso, de $2,5 \mathrm{~m}$ de diâmetro e $16 \mathrm{~m}$ de comprimento. A vazão de operação de cada parafuso é de $2 \mathrm{~m}^{3} / \mathrm{s}$.

Na sequência, estão dispostas seis grades finas, cujo objetivo é reter o material fino $>20 \mathrm{~mm}$ presente no afluente. Cada grade conta com um sistema de rastelo automático, que é seguido de uma correia transportadora, que encaminha o material retido para uma caçamba de $12 \mathrm{~m}^{3}$ de capacidade.

A seguir o esgoto passa a uma câmara de integração de fluxos que o direciona a uma câmara de distribuição, localizada à entrada de seis desareadores retangulares e arejados (para evitar seu entupimento). O tempo de retenção em cada desareador é de 3 minutos. As areias retidas são coletadas no fundo do desareador por meio de um parafuso $\left(5,4 \mathrm{~m}^{3} / \mathrm{h}\right.$ de capacidade e $290 \mathrm{~mm}$ de diâmetro), e são levadas a uma câmara que tem uma linha de sucção de uma bomba ejetora de $60 \mathrm{~m}^{3} / \mathrm{h}$ de capacidade, $15 \mathrm{~m}$ de pressão de descarga e $7 \mathrm{~m}$ de pressão de aspiração. A areia é descarregada em duas caçambas de $12 \mathrm{~m}^{3}$ de capacidade.

O tratamento quimicamente assistido consiste na utilização de cloreto férrico como coagulante primário (na entrada do canal do desareador) e de um polímero orgânico como floculante (na saída do desareador). São utilizadas bombas dosadoras de cloreto férrico e polímero, além de um equipamento compacto para a preparação do polímero e dois tanques de armazenamento de cloreto férrico. 
O efluente dos desareadores é direcionado por gravidade a câmaras de distribuição de fluxos, com o objetivo de realizar uma distribuição uniforme do fluxo e eliminar a energia remanescente antes do ingresso da água nos 8 decantadores primários.

Os 8 decantadores primários são de fluxo ascendente, localizados em dois grupos de 4 unidades. São tanques circulares de 47,50 m de diâmetro, 4,20 m de profundidade útil e $7,4 \%$ de inclinação de fundo, contendo um raspador de fundo, de funcionamento contínuo e acionamento local e de um sistema de coleta de escuma superficial. O efluente da decantação primária é descartado no Rio Cauca.

Durante a operação das diferentes unidades de tratamento na condição de máxima capacidade, são gerados $9000 \mathrm{~m}^{3} / \mathrm{d}$ de resíduos líquidos que são levados por uma rede de tubulações até o tanque de acumulação de águas do processo, para serem bombeados de volta até a entrada dos desareadores.

Os lodos gerados na decantação primária são extraídos e bombeados até uma grade fina, o material separado do lodo na grade é enviado para uma caçamba. $\mathrm{Na}$ seqüência, os lodos seguem para o espessador por gravidade, que aumenta a concentração de sólidos de $2 \%$ até valores que variam de $4 \%$ a $6 \%$, dependendo da carga aplicada.

Uma vez espessados, os lodos são conduzidos por bombeamento para os 4 digestores, os quais têm uma mistura completa e aquecimento, com um volume efetivo de cada un de $6250 \mathrm{~m}^{3}$. Os lodos digeridos são extraídos do fundo dos digestores por gravidade e levados para o tanque de armazenamento de lodos, que tem um volume útil de $4279 \mathrm{~m}^{3}$.

O lodo é retirado do tanque e enviado por bombeamento para a unidade de filtros prensa, a qual contém 7 unidades de filtração com uma capacidade de 750 - 120 $\mathrm{kg} / \mathrm{h}$. A taxa de desaguamento é maior que $450 \mathrm{~kg} / \mathrm{h}$, e é aplicada uma quantidade de polímero entre 0,2 e 0,8\% como condicionante para o desaguamento. O lodo desaguado é levado por meio de correias transportadoras até o pátio de lodos, onde é removido por um carregador. A percentagem de ST na torta desaguada é no mínimo de $22 \%$.

A água usada na refrigeração dos motores do sistema de geração de energia, é enviada ao tanque de água quente, que tem um volume de $75 \mathrm{~m}^{3}$ e mantém a temperatura a $70{ }^{\circ} \mathrm{C}$. Nesse este ponto a água é bombeada até os trocadores de 
calor (4 unidades) cujo objetivo é o de aquecer o lodo contido nos digestores. A troca térmica pelo aquecimento do lodo provoca o resfriamento da água que é enviada de volta para resfriar os motores, fechando o ciclo de recuperação térmica.

O biogás é produzido nos digestores e depois é circulado através de um purificador de gás seco, com o objetivo de remover $\mathrm{O}_{2} \mathrm{~S}$ e controlar seu nível de corrosão. A concentração de $\mathrm{H}_{2} \mathrm{~S}$ no gás afluente ao purificador é menor que 200 ppm e a concentração de saída menor que 10 ppm. Com o objetivo de armazenar o gás, temse dois tanques cilíndricos de volume variável e pressão constante de $200 \mathrm{~mm}$ de água. Cada tanque de armazenamento está ligado a um queimador de gás de 550 $\mathrm{m}^{3} / \mathrm{h}$ de capacidade. A operação do queimador é intermitente e automática, dependendo do nível do gás no tanque.

Para o processo de geração de energia elétrica, dispõe-se de dois geradores de energia elétrica a partir da combustão do biogás. Cada gerador tem uma capacidade de $100 \mathrm{~kW}$ e são usados para fornecer parte da energia requerida para o consumo interno dos equipamentos e instrumentos disponíveis na estação.

A ETE de Cañaveralejo tem um sistema completo para controlar os odores desagradáveis que são produzidos durante o tratamento do esgoto. Esse sistema é formado pelos seguintes elementos: a) Coberturas: todas as estruturas da estação que armazenam ou transportam esgoto durante o processo de tratamento são fechadas com coberturas de alumínio para evitar o desprendimento de gases; b) Extração: o ar confinado embaixo das coberturas é extraído por meio de equipamentos de ventilação mecânica que removem o ar e por último tem-se c) Tratamento: o qual consiste na filtração do ar através dos filtros biológicos que são leitos filtrantes que fornecem um meio apropriado para que os microrganismos efetuem a transformação dos gases que provocam mau odor.

A ETE de Cañaveralejo é operada por um centro de controle que desempenha as funções de supervisão, processamento da informação e operação de todas as unidades de tratamento. 


\section{Coleta e tratamento dos dados da Estação de Tratamento de Esgoto Cañaveralejo, ETE}

Nos meses de outubro, novembro e dezembro de 2007, foram feitas visitas à ETE de Cañaveralejo, e foram coletados os dados anuais de 2007 com os quais foi feita a análise exergética do processo. Esses dados são apresentados a seguir:

Os dados dos principais insumos da ETE Cañaveralejo (energia elétrica, polímeros, $\mathrm{FeCl}_{3}, \mathrm{CaO}$ ), da caracterização do esgoto bruto (afluente) e do efluente final, assim como dos subprodutos gerados (lodo desaguado e gás) e a composição química do lodo desaguado, são apresentados nas Tabelas 14, 15 e 16.

A coleta desses dados foi feita por Funcionários da Empresas Municipales de Cali, EMCALI, que trabalham na ETE Cañaveralejo. Com o intuito de estabelecer uma comparação entre a ETE Barueri, o Sistema RAFA - Lagoa Facultativa e a ETE Cañaveralejo, foram usados os valores (reais) médios anuais.

Tabela 14 - Dados anuais da caracterização do esgoto bruto (afluente) e do efluente final da Estação de Tratamento de Esgotos Cañaveralejo

\begin{tabular}{|c|c|c|}
\hline Parâmetro & Afluente & Efluente \\
\hline $\operatorname{Vazão}\left(\operatorname{Ls}^{-1}\right)$ & 3849,5 & 3849,5 \\
\hline$D Q O\left(\mathrm{mgL}^{-1}\right)$ & 441 & 277 \\
\hline $\mathrm{pH}$ & 7 & 7 \\
\hline$T\left({ }^{\circ} \mathrm{C}\right)$ & 25 & 25 \\
\hline$S S\left(m L L^{-1}\right)$ & 1,7 & 0,5 \\
\hline $\mathrm{SST}\left(\mathrm{mgL}^{-1}\right)$ & 189,6 & 65 \\
\hline $\operatorname{SSV}\left(\mathrm{mgL}^{-1}\right)$ & 126,9 & 48 \\
\hline $\mathrm{CaCO}_{3}\left(\mathrm{mgL}^{-1}\right)$ & 192,2 & 186 \\
\hline$O G\left(\mathrm{mgL}^{-1}\right)$ & 19,5 & 12 \\
\hline $\mathrm{Cl}\left(\mathrm{mgL}^{-1}\right)$ & 53,6 & 54 \\
\hline Cádmio $\left(\mathrm{mgL}^{-1}\right)$ & 0,006 & 0,006 \\
\hline Mercúrio $\left(\mu \mathrm{g} \mathrm{L}^{-1}\right)$ & 0,0002 & 0,0002 \\
\hline Níquel $\left(\mathrm{mgL}^{-1}\right)$ & 0,05 & 0,04 \\
\hline Prata $\left(\mathrm{mgL}^{-1}\right)$ & 0,012 & 0,012 \\
\hline Zinco $\left(\mathrm{mgL}^{-1}\right)$ & 0,2 & 0,08 \\
\hline Chumbo $\left(\mathrm{mgL}^{-1}\right)$ & 0,11 & 0,11 \\
\hline Cobre $\left(\mathrm{mgL}^{-1}\right)$ & 0,03 & 0,02 \\
\hline Cromo Total $\left(\mathrm{mgL}^{-1}\right)$ & 0,06 & 0,05 \\
\hline Ferro $\left(\mathrm{mgL}^{-1}\right)$ & 2,8 & 2,7 \\
\hline Fósforo $\left(\mathrm{mgL}^{-1}\right)$ & 5,5 & 4 \\
\hline Surfactantes $\left(\mathrm{mgL}^{-1}\right)$ & 6,5 & 5 \\
\hline
\end{tabular}


Tabela 15 - Dados dos consumos e dos subprodutos gerados na ETE Cañaveralejo

\begin{tabular}{lc}
\hline Consumos & Quantidade \\
\hline Lodo desaguado produzido $\left(\mathrm{t} \mathrm{mês}{ }^{-1}\right)$ & 2187 \\
Consumo de energia elétrica $\left(\mathrm{kWh} \mathrm{mês}^{-1}\right)$ & 551.193 \\
Consumo de $\mathrm{FeCl}_{3}\left(\mathrm{~kg} \mathrm{mês}^{-1}\right)$ & 114420,1 \\
Consumo de polímeros $\left(\mathrm{kg} \mathrm{mês}^{-1}\right)$ & 991,7 \\
Consumo de $\mathrm{CaO}\left(\mathrm{kg} \mathrm{mês}^{-1}\right)$ & 131245,8 \\
Produção de gás $\left(\mathrm{m}^{3}\right.$ mês $\left.^{-1}\right)$ & 301671,8 \\
\hline
\end{tabular}

Tabela 16 - Dados da composição química do lodo desaguado gerado na ETE Cañaveralejo

\begin{tabular}{lc}
\hline Componente & mgkg $^{-1}$ de lodo \\
\hline Cádmio & 11 \\
Chumbo & 349,2 \\
Cobre & 258,8 \\
Cromo & 112,3 \\
DQO $\left(\mathrm{mgL}^{-1}\right)$ & 34531 \\
Ferro & 45800,3 \\
Níquel & 99,4 \\
Zinco & 904,6 \\
Prata & 24 \\
Mercúrio & 0,05 \\
\hline
\end{tabular}

Os dados apresentados nas Tabelas 17, 18 e 19 a seguir foram calculados das Tabelas 14, 15 e 16 respectivamente.

Tabela 17 - Caracterização do esgoto bruto (afluente) e do efluente final da Estação de Tratamento de Esgotos Cañaveralejo

\begin{tabular}{lll}
\cline { 2 - 3 } & Afluente & Efluente \\
\hline $\mathrm{DQO}\left(\mathrm{mol} \mathrm{L}^{-1}\right)$ & $2,20 \mathrm{E}-03$ & $1,39 \mathrm{E}-03$ \\
$\mathrm{CaCO}\left(\mathrm{mol} \mathrm{L}^{-1}\right)$ & $1,93 \mathrm{E}-03$ & $1,86 \mathrm{E}-03$ \\
$\mathrm{Cl}\left(\mathrm{mol} \mathrm{L}^{-1}\right)$ & $1,51 \mathrm{E}-03$ & $1,52 \mathrm{E}-03$ \\
Cádmio $\left(\mathrm{mol} \mathrm{L}^{-1}\right)$ & $5,67 \mathrm{E}-08$ & $5,34 \mathrm{E}-08$ \\
Níquel $\left(\mathrm{mol} \mathrm{L}^{-1}\right)$ & $7,86 \mathrm{E}-07$ & $6,01 \mathrm{E}-07$ \\
Prata $\left(\mathrm{mol} \mathrm{L}^{-1}\right)$ & $1,11 \mathrm{E}-07$ & $1,11 \mathrm{E}-07$ \\
Zinco $\left(\mathrm{mol} \mathrm{L}^{-1}\right)$ & $2,56 \mathrm{E}-06$ & $1,24 \mathrm{E}-06$ \\
Chumbo $\left(\mathrm{mol} \mathrm{L}^{-1}\right)$ & $5,31 \mathrm{E}-07$ & $5,31 \mathrm{E}-07$ \\
Cobre $\left(\mathrm{mol} \mathrm{L}^{-1}\right)$ & $4,64 \mathrm{E}-07$ & $2,36 \mathrm{E}-07$ \\
Cromo Total $\left(\mathrm{mol} \mathrm{L}^{-1}\right)$ & $1,16 \mathrm{E}-06$ & $9,14 \mathrm{E}-07$ \\
Ferro $\left(\mathrm{mol} \mathrm{L}^{-1}\right)$ & $4,95 \mathrm{E}-05$ & $4,85 \mathrm{E}-05$ \\
Fósforo $\left(\mathrm{mol} \mathrm{L}^{-1}\right)$ & $1,76 \mathrm{E}-04$ & $1,29 \mathrm{E}-04$ \\
Surfactantes $\left(\mathrm{mol} \mathrm{L}^{-1}\right)$ & $1,62 \mathrm{E}-04$ & $1,25 \mathrm{E}-04$ \\
Mercúrio $\left(\mathrm{mol} \mathrm{L}^{-1}\right)$ & $8,47 \mathrm{E}-10$ & $8,47 \mathrm{E}-10$ \\
\hline
\end{tabular}


Tabela 18 - Consumos e subprodutos gerados na ETE Cañaveralejo

\begin{tabular}{lc}
\hline Consumos & Quantidade \\
\hline Lodo desaguado produzido $\left(\mathrm{kg} \mathrm{s}^{-1}\right)$ & 0,8 \\
Consumo energia elétrica $(\mathrm{kW})$ & 755,2 \\
Consumo $\mathrm{CaO}\left(\mathrm{g} \mathrm{s}^{-1}\right)$ & 49,8 \\
Consumo $\mathrm{FeCl}\left(\mathrm{g} \mathrm{s}^{-1}\right)$ & 43,5 \\
Consumo polímeros $\left(\mathrm{g} \mathrm{s}^{-1}\right)$ & 0,4 \\
Produção de gás $\left(\mathrm{g} \mathrm{s}^{-1}\right)$ & 103,1 \\
\hline
\end{tabular}

Tabela 19 - Composição química do lodo desaguado gerado na ETE Cañaveralejo

\begin{tabular}{lc}
\hline Componente & molkg $^{-1}$ de lodo \\
\hline Cádmio & $9,79 \mathrm{E}-05$ \\
Chumbo & $1,69 \mathrm{E}-03$ \\
Cobre & $4,07 \mathrm{E}-03$ \\
Cromo & $2,16 \mathrm{E}-03$ \\
DQO & $1,73 \mathrm{E}-01$ \\
Ferro & $8,20 \mathrm{E}-01$ \\
Níquel & $1,69 \mathrm{E}-03$ \\
Zinco & $1,38 \mathrm{E}-02$ \\
Prata & $2,23 \mathrm{E}-04$ \\
Mercúrio & $2,38 \mathrm{E}-07$ \\
\hline
\end{tabular}

\subsection{ANÁLISE EXERGÉTICA DAS ETES BARUERI, RAFA - LAGOA FACULTATIVA E DA ETE CAÑAVERALEJO}

A análise exergética dos processos foi realizada aplicando a metodologia descrita no capítulo 6.

A exergia química padrão dos elementos e compostos químicos envolvidos nos processos de tratamento de esgoto analisados neste trabalho foi calculada a partir dos dados encontrados em Szargut et al., (1988). Esses valores são apresentados na Tabela 20. Essas exergias químicas estão definidas para um estado de referência padrão a $T_{n}=298,15 \mathrm{~K}, P_{n}=101,325 \mathrm{kPa}$ (Szargut et al., 1988). A razão pela qual foi assumido o estado de referência padrão de Szargut para as 3 ETEs, se deveu ao fato de que os valores médios anuais de temperatura e pressão no Valle do Cauca (Colômbia) e na cidade de São Paulo são próximos dos valores do estado de referência descrito em Szargut et al., (1988). 
Tabela 20 - Exergia química padrão dos elementos e compostos químicos envolvidos nos processos de tratamento de esgoto $\mathrm{em} \mathrm{kJg}^{-1}$

\begin{tabular}{|c|c|c|c|}
\hline Compostos Nitrogenados & $\mathrm{b}_{\text {qui }}^{\circ}{ }^{*}\left(\mathrm{kJg}^{-1}\right)$ & Metais & $\mathrm{b}_{\text {qui }}^{\circ}{ }^{*}\left(\mathrm{kJg}^{-1}\right)$ \\
\hline Amônia, $\mathrm{NH}_{3}$ & 19,8 & Prata, Ag & 0,6 \\
\hline Nitrato, $\mathrm{NO}_{3}$ & 0,4 & Zinco, Zn & 5,2 \\
\hline Nitrito, $\mathrm{NO}_{2}$ & 1,2 & Manganês, Mn & 8,8 \\
\hline Compostos Inorg. & & Molibdênio, Mo & 7,6 \\
\hline Carbonato de Cálcio, $\mathrm{CaCO}_{3}$ & 0,01 & Selênio, Se & 4,4 \\
\hline Cloro, Cl & 2,46 & Chumbo, $\mathrm{Pb}$ & 1,1 \\
\hline Cálcio, Ca & 17,8 & Cobre, $\mathrm{Cu}$ & 2,1 \\
\hline Magnésio, Mg & 26,07 & Cromo, $\mathrm{Cr}$ & 10,5 \\
\hline Potássio, $\mathrm{K}$ & 9,38 & Ferro, Fe & 6,7 \\
\hline Sódio, $\mathrm{Na}$ & 14,64 & Estanho, Sn & 4,6 \\
\hline Boro, B & 58,14 & Compostos Org. & \\
\hline Arsênico, As & 6,6 & Fenol, $\mathrm{C}_{6} \mathrm{H}_{6} \mathrm{O}$ & 33,2 \\
\hline $\mathrm{Cal}, \mathrm{CaO}$ & 2,0 & Fósforo, $\mathrm{P}$ & 28,1 \\
\hline Cloreto Férrico, $\mathrm{FeCl}_{3}$ & 1,4 & Metano, $\mathrm{CH}_{4}$ & 51,8 \\
\hline Cobalto, Co & 4,5 & Metanol, $\mathrm{CH}_{4} \mathrm{O}$ & 22,41 \\
\hline Água, $\mathrm{H}_{2} \mathrm{O}$ & 0,05 & Surfactante, $\mathrm{NaOH}$ & 1,9 \\
\hline Oxigênio, $\mathrm{O}_{2}$ & 0,1 & Polímero & 40 \\
\hline Sulfeto, $\mathrm{S}_{2}$ & 9,5 & & \\
\hline Sulfato, $\mathrm{SO}_{4}$ & 1,9 & & \\
\hline \multicolumn{4}{|l|}{ Metais } \\
\hline Cádmio, Cd & 2,6 & & \\
\hline Mercúrio, $\mathrm{Hg}$ & 0,6 & & \\
\hline Níquel, Ni & 4,0 & & \\
\hline
\end{tabular}

*Szargut, 1988.

\subsubsection{Análise exergética da ETE Barueri}

Os fluxos de exergia associados ao esgoto bruto (afluente) e ao efluente final da Estação de Tratamento de Esgotos Barueri, foram calculados a partir dos dados das exergias químicas apresentadas na Tabela $20 \mathrm{com}$ os dados apresentados na Tabela 5. Esses resultados são apresentados na Tabela 21, e os detalhes desses cálculos são apresentados no Anexo C. 
Tabela 21 - Fluxos de exergia associados ao esgoto bruto (afluente) e ao efluente final para a Estação de Tratamento de Esgotos Barueri Mistura não ideal

\begin{tabular}{lcc} 
& \multicolumn{2}{c}{ Fluxo de exergia (kW) } \\
\cline { 2 - 3 } & Afluente & Efluente \\
\hline $\mathrm{nQO}$ & $1,67 \mathrm{E}+04$ & $1,05 \mathrm{E}+03$ \\
$\mathrm{NH}_{3}$ & $1,27 \mathrm{E}+03$ & $4,63 \mathrm{E}+02$ \\
$\mathrm{NO}_{2}$ & $8,22 \mathrm{E}-07$ & $1,29 \mathrm{E}-03$ \\
$\mathrm{SO}_{4}$ & $3,98 \mathrm{E}+01$ & $7,73 \mathrm{E}+01$ \\
Cádmio & $1,15 \mathrm{E}-06$ & $1,73 \mathrm{E}-06$ \\
Níquel & $3,41 \mathrm{E}-04$ & $3,94 \mathrm{E}-04$ \\
Prata & $4,40 \mathrm{E}-07$ & $1,65 \mathrm{E}-07$ \\
Zinco & $1,64 \mathrm{E}-02$ & $3,46 \mathrm{E}-03$ \\
Manganês & $1,52 \mathrm{E}-03$ & $3,26 \mathrm{E}-03$ \\
Molibdênio & $3,51 \mathrm{E}-05$ & $1,29 \mathrm{E}-04$ \\
Chumbo & $3,60 \mathrm{E}-06$ & $4,53 \mathrm{E}-06$ \\
Cobre & $2,38 \mathrm{E}-04$ & $3,08 \mathrm{E}-05$ \\
Cromo & $3,45 \mathrm{E}-03$ & $8,28 \mathrm{E}-04$ \\
Ferro & $1,44 \mathrm{E}+00$ & $1,06 \mathrm{E}-01$ \\
Fósforo & $2,70 \mathrm{E}+01$ & $2,19 \mathrm{E}+01$ \\
Surfactantes & $1,92 \mathrm{E}+01$ & $2,24 \mathrm{E}-01$ \\
Estanho & $8,62 \mathrm{E}-04$ & $2,66 \mathrm{E}-03$ \\
Total & $\mathbf{1 , 8 0 E}+04$ & $\mathbf{1 , 6 1 E}+03$ \\
\hline
\end{tabular}

Os fluxos de exergia, associados aos consumos na ETE Barueri, foram calculados multiplicando os dados da Tabela 20 pelos dados da Tabela 6. Esses resultados são apresentados na Tabela 22.

Tabela 22 - Fluxos de exergia associados aos consumos e aos subprodutos gerados na ETE Barueri

\begin{tabular}{lc}
\hline Consumos e subprodutos & Fluxos de exergia (kW) \\
\hline Energia elétrica & 5128,6 \\
Água & 228,2 \\
$\mathrm{FeCl}_{3}$ & 57,4 \\
Polímeros & 136,8 \\
Lodo desaguado & 527,0 \\
Produção de gás & 6309,7 \\
Total consumos & $\mathbf{5 5 5 1 , 0}$ \\
Total subprodutos & $\mathbf{6 8 3 6 , 7}$ \\
\hline
\end{tabular}

O fluxo de exergia associado ao lodo desaguado gerado na ETE Barueri, foi calculado utilizando os dados das exergias químicas apresentadas na Tabela 20 
com os dados apresentados na Tabela 7. Os resultados são apresentados na Tabela 23. (ver Anexo C).

Tabela 23 - Fluxos de exergia do lodo desaguado gerado na ETE de Barueri

\begin{tabular}{lc}
\hline Componentes & Fluxo de exergia (kW) \\
\hline DQO & $1,08 \mathrm{E}+02$ \\
\hline Cádmio & $1,42 \mathrm{E}-05$ \\
Chumbo & $6,27 \mathrm{E}-04$ \\
Cobre & $3,43 \mathrm{E}-02$ \\
Cromo & $3,23 \mathrm{E}-01$ \\
Manganês & $4,38 \mathrm{E}-02$ \\
Ferro & $4,17 \mathrm{E}+02$ \\
Níquel & $1,91 \mathrm{E}-02$ \\
Zinco & $1,28 \mathrm{E}+00$ \\
Prata & $5,05 \mathrm{E}-05$ \\
Molibdênio & $9,65 \mathrm{E}-05$ \\
Total & $\mathbf{5 , 2 7 E + 0 2}$ \\
\hline
\end{tabular}

\subsubsection{Análise exergética do sistema RAFA - Lagoa Facultativa}

Os fluxos de exergia associados ao esgoto bruto (afluente) do RAFA e ao efluente final da Lagoa Facultativa foram calculados utilizando os dados das exergias químicas apresentadas na Tabela 20 com os dados apresentados na Tabela 11. Esses resultados são apresentados na Tabela 24 e no Anexo C.

Tabela 24 - Fluxos de exergia do esgoto bruto (afluente) do RAFA e do efluente final da Lagoa Facultativa

\begin{tabular}{lcc}
\cline { 2 - 3 } & \multicolumn{2}{c}{ Fluxo de exergia (kW) } \\
\cline { 2 - 3 } & Afluente & Efluente \\
\hline$D Q O$ & $1,87 \mathrm{E}+01$ & $3,13 \mathrm{E}+00$ \\
$\mathrm{NO}_{2}$ & $2,23 \mathrm{E}-10$ & $1,27 \mathrm{E}-08$ \\
$\mathrm{Cl}$ & $1,38 \mathrm{E}-01$ & $1,82 \mathrm{E}-01$ \\
$\mathrm{SO}_{4}$ & $3,94 \mathrm{E}-01$ & - \\
Total & $\mathbf{1 , 9 2 E + 0 1}$ & $\mathbf{3 , 3 2 E + 0 0}$ \\
\hline
\end{tabular}


Os fluxos de exergia, associados aos consumos no RAFA, foram calculados multiplicando os dados da Tabela 20 pelos dados da Tabela 12. Esses resultados são apresentados na Tabela 25.

Tabela 25 - Fluxos de exergia associados aos consumos e aos subprodutos gerados no sistema RAFA - Lagoa Facultativa

\begin{tabular}{lc}
\hline Consumos e subprodutos & Fluxos de exergia (kW) \\
\hline Energia elétrica & 41,80 \\
$\mathrm{CaO}$ & 0,01 \\
Lodo desaguado & 27,60 \\
Produção de gás & 21,60 \\
Total consumos & $\mathbf{4 1 , 8 1}$ \\
Total subprodutos & $\mathbf{4 9 , 2 0}$ \\
\hline
\end{tabular}

O fluxo de exergia associado ao lodo desaguado gerado no sistema RAFA - Lagoa Facultativa foi calculado utilizando os dados das exergias químicas apresentadas na Tabela 20 com os dados apresentados na Tabela 13. Os resultados são apresentados na Tabela 26.

Tabela 26 - Fluxos de exergia do lodo desaguado gerado no RAFA

\begin{tabular}{lc}
\hline Componentes & Fluxos de exergia (kW) \\
\hline DQO & $2,76 \mathrm{E}+01$ \\
Cálcio & $4,89 \mathrm{E}-07$ \\
Magnésio & $5,18 \mathrm{E}-08$ \\
Potássio & $3,25 \mathrm{E}-06$ \\
Sódio & $1,96 \mathrm{E}-05$ \\
Fósforo & $1,59 \mathrm{E}-03$ \\
Boro & $6,20 \mathrm{E}-07$ \\
Cobre & $1,57 \mathrm{E}-04$ \\
Zinco & $5,53 \mathrm{E}-04$ \\
Manganês & $2,81 \mathrm{E}-04$ \\
Ferro & $1,33 \mathrm{E}-03$ \\
TOTAL & $\mathbf{2 , 7 6 E + 0 1}$
\end{tabular}




\subsubsection{Análise exergética da ETE Cañaveralejo}

Os fluxos de exergia associados ao esgoto bruto (afluente) e ao efluente final da Estação de Tratamento de Esgotos Cañaveralejo, foram calculados utilizando os dados das exergias químicas apresentadas na Tabela 20 com os dados apresentados na Tabela 17. Esses resultados são apresentados na Tabela 27, os detalhes desses cálculos são apresentados no Anexo C.

Tabela 27 - Fluxos de exergia associados ao esgoto bruto (afluente) e ao efluente final para a Estação de Tratamento de Esgotos Cañaveralejo Mistura não ideal

\begin{tabular}{lcc} 
& \multicolumn{2}{c}{ Fluxo de exergia (kW) } \\
\cline { 2 - 3 } & Afluente & Efluente \\
\hline$D Q O$ & $8,39 \mathrm{E}+03$ & $3,94 \mathrm{E}+03$ \\
$\mathrm{Cl}$ & $1,03 \mathrm{E}+02$ & $1,25 \mathrm{E}+02$ \\
Cádmio & $5,17 \mathrm{E}-07$ & $5,45 \mathrm{E}-07$ \\
Níquel & $7,79 \mathrm{E}-05$ & $5,41 \mathrm{E}-05$ \\
Prata & $2,41 \mathrm{E}-07$ & $2,86 \mathrm{E}-07$ \\
Zinco & $1,28 \mathrm{E}-03$ & $3,56 \mathrm{E}-04$ \\
Chumbo & $3,54 \mathrm{E}-05$ & $4,21 \mathrm{E}-05$ \\
Cobre & $1,35 \mathrm{E}-05$ & $4,07 \mathrm{E}-06$ \\
Cromo & $4,36 \mathrm{E}-04$ & $3,23 \mathrm{E}-04$ \\
Ferro & $5,51 \mathrm{E}-01$ & $6,28 \mathrm{E}-01$ \\
Fósforo & $1,68 \mathrm{E}+01$ & $1,07 \mathrm{E}+01$ \\
Mercúrio & $2,94 \mathrm{E}-11$ & $3,49 \mathrm{E}-11$ \\
Total & $\mathbf{8 , 4 8 E + 0 3}$ & $\mathbf{4 , 0 4 E + 0 3}$ \\
\hline
\end{tabular}

Os fluxos de exergia, associados aos consumos na ETE Cañaveralejo, foram calculados multiplicando os dados da Tabela 20 pelos dados da Tabela 18. Esses resultados são apresentados na Tabela 28. 
Tabela 28 - Fluxos de exergia associados aos consumos e aos subprodutos gerados na ETE Cañaveralejo

\begin{tabular}{lc}
\hline Consumos e subprodutos & Fluxos de exergia (kW) \\
\hline Energia elétrica & 755,2 \\
Cão & 97,9 \\
$\mathrm{FeCl}_{3}$ & 61,7 \\
Polímeros & 15,1 \\
Lodo desaguado & 273,0 \\
Produção de gás & 5355,9 \\
Total consumos & $\mathbf{1 8 7 6 , 8}$ \\
Total subprodutos & $\mathbf{4 6 8 2 , 0}$
\end{tabular}

O fluxo de exergia associado ao lodo desaguado gerado na ETE Cañaveralejo, foi calculado utilizando os dados das exergias químicas apresentadas na Tabela 20 com os dados apresentados na Tabela 19. Os resultados são apresentados na Tabela 29. (ver Anexo C).

Tabela 29 - Fluxos de exergia do lodo desaguado gerado na ETE Cañaveralejo

\begin{tabular}{lc}
\hline Componentes & Fluxo de exergia (kW) \\
\hline Cádmio & $2,12 \mathrm{E}-06$ \\
Chumbo & $5,03 \mathrm{E}-04$ \\
Cobre & $1,63 \mathrm{E}-03$ \\
Cromo & $2,02 \mathrm{E}-03$ \\
DQO & $6,62 \mathrm{E}+01$ \\
Ferro & $2,07 \mathrm{E}+02$ \\
Níquel & $5,09 \mathrm{E}-04$ \\
Zinco & $5,14 \mathrm{E}-02$ \\
Prata & $2,00 \mathrm{E}-06$ \\
Mercúrio & $3,61 \mathrm{E}-12$ \\
Total & $\mathbf{2 , 7 3 E + 0 2}$ \\
\hline
\end{tabular}

Nas Figuras 5, 6 e 7, são apresentados os balanços exergéticos da ETE Barueri, do sistema RAFA - Lagoa Facultativa e da ETE Cañaveralejo. 


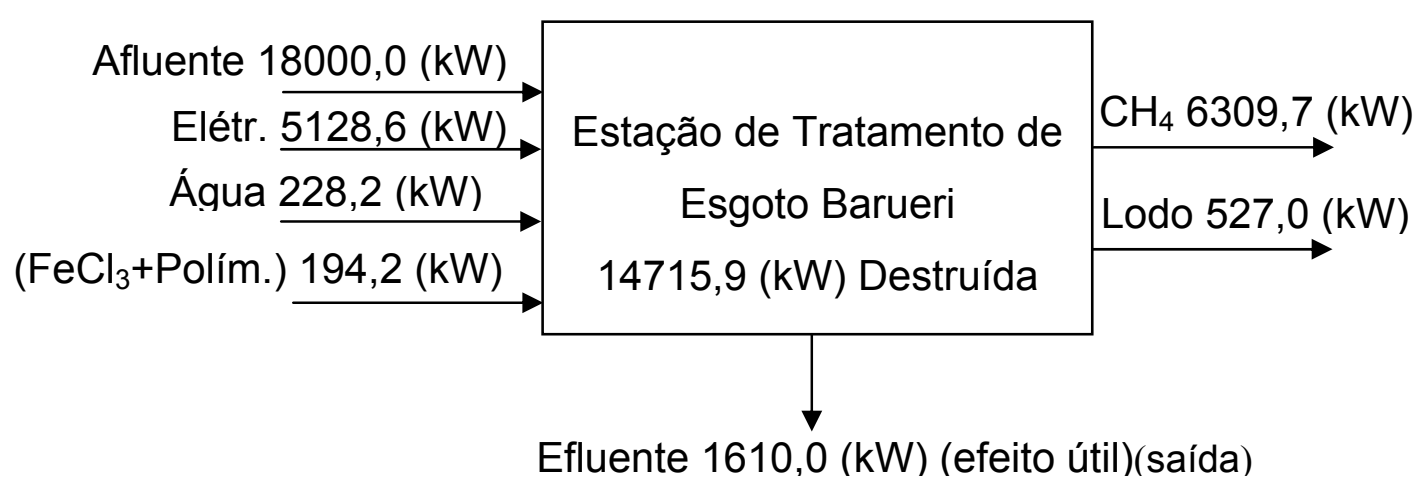

Figura 5 - Balanço exergético da ETE Barueri.

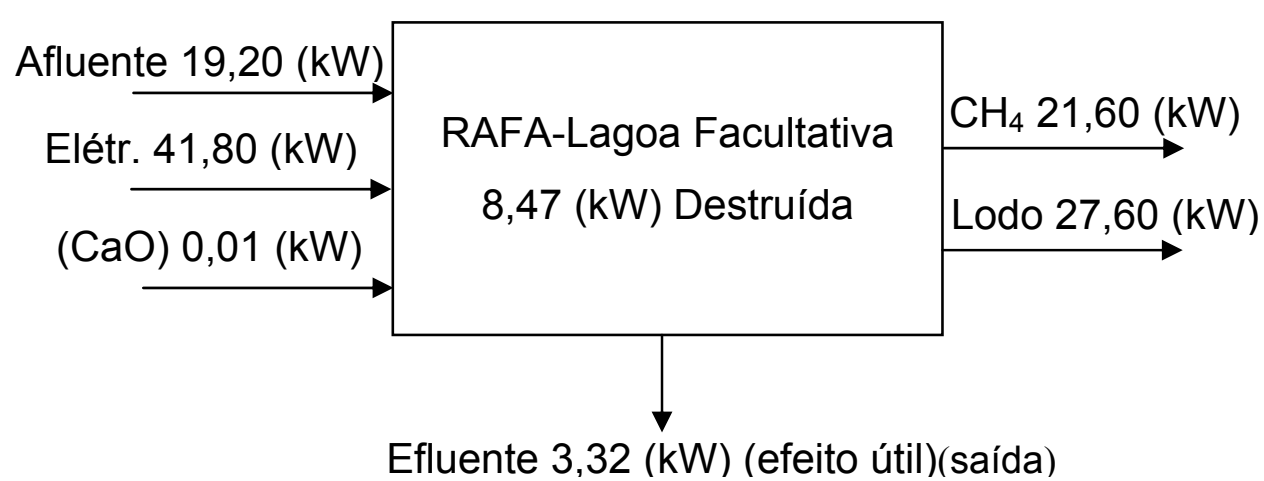

Figura 6 - Balanço exergético do sistema RAFA-Lagoa Facultativa.

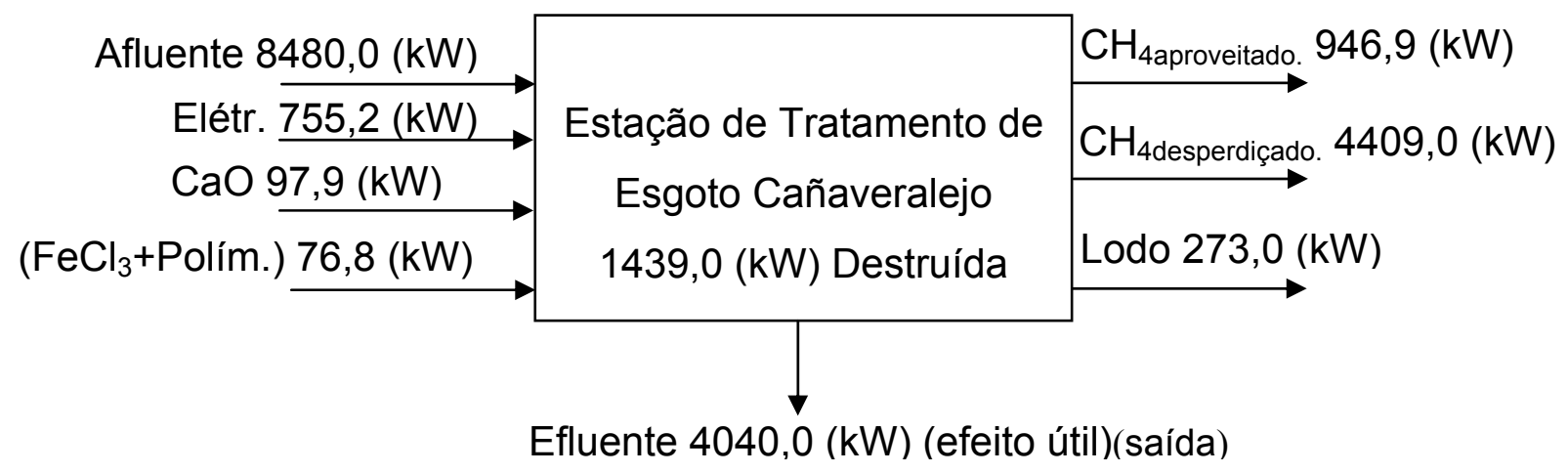

Figura 7 - Balanço exergético da ETE Cañaveralejo.

Na Tabela 30 são apresentados os resultados do balanço exergético realizado para os três Processos de Tratamento de Esgoto (sistema RAFA - Lagoa Facultativa, e 
as ETEs Barueri e Cañaveralejo), aplicando a equação, apresentada no item 3.8. O fluxo exergético associado com a desativação do lodo (rejeito) foi incluído no fluxo exergético destruído para os três casos.

Tabela 30 - Valores dos fluxos de exergia de entrada, saída, destruída e perdida para os Processos de Tratamento de Esgoto da ETE Barueri, do sistema RAFA - Lagoa Facultativa e para a ETE Cañaveralejo

\begin{tabular}{lccc}
\hline Processo & Entrada (kW) & $\begin{array}{c}\text { Saída } \\
\mathbf{( k W )}\end{array}$ & $\begin{array}{c}\text { Destruída e } \\
\text { perdida (kW) }\end{array}$ \\
\hline Estação de Tratamento de Esgoto Barueri & 23356,8 & 1610,0 & 21746,8 \\
RAFA - Lagoa Facultativa & 61,0 & 3,32 & 57,68 \\
Estação de Tratamento de Esgoto Cañaveralejo & 10258,9 & 4040,0 & 6218,9 \\
\hline
\end{tabular}

Na Tabela 31 são apresentados os valores da eficiência exergética ambiental e o indice exergético de renovabilidade, calculados a partir dos resultados do balanço exergético. Esses indicadores foram utilizados na avaliação do desempenho ambiental e da renovabilidade dos três Processos de Tratamento de Esgoto.

Tabela 31 - Valores da eficiência exergética ambiental e do indicador exergético de renovabilidade, para os Processos de Tratamento de Esgoto da ETE Barueri, do sistema RAFA - Lagoa Facultativa e para a ETE Cañaveralejo

\begin{tabular}{lcc}
\hline Processo & $\eta_{\text {exerg,amb }}$ & $\lambda$ \\
\hline Estação de Tratamento de Esgoto Barueri & 0,070 & 0,060 \\
RAFA - Lagoa Facultativa & 0,054 & 0,057 \\
Estação de Tratamento de Esgoto Cañaveralejo & 0,394 & 0,770 \\
\hline
\end{tabular}

Nesta Tabela, observa-se de acordo com os indicadores exergéticos $\left(\eta_{\text {exerg,amb }}, \lambda\right)$, que o processo que tem o melhor desempenho ambiental é o da ETE Cañaveralejo, 
já que apresenta a maior $\eta_{\text {exerg,amb }}(0,394)$ e o valor do $\lambda(0,770)$ mais elevado. $O$ valor mais elevado para o indicador exergético de renovabilidade se deve ao fato de que nesse processo parte do biogás produzido, já está sendo utilizado para a produção de parte da energia elétrica consumida no processo.

Da análise dos valores obtidos (Tabela 31) para o índice exergético de renovabilidade $(\lambda)$, os três processos de tratamento de esgoto podem ser classificados como ambientalmente desfavoráveis do ponto de vista de renovabilidade. Isso é devido às irreversibilidades associadas com os processos de depuração da matéria orgânica, e ao não aproveitamento da exergia contida nos subprodutos úteis dos processos.

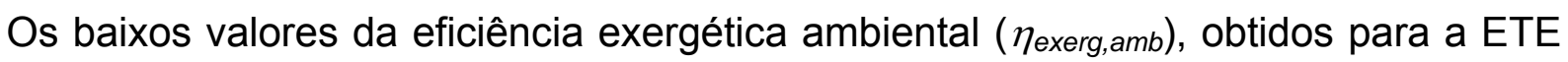
Barueri e o sistema RAFA - Lagoa Facultativa, foram devidos ao elevado consumo de eletricidade para o pequeno produto gerado e à destruição de exergia nos processos aeróbios e anaeróbios. O consumo de energia elétrica representa $68,5 \%$ e $22 \%$ do fluxo de exergia líquida de entrada nos processos do sistema RAFA Lagoa Facultativa e da ETE Barueri respectivamente.

O consumo elevado de energia em unidades de lodos ativados é devido à aeração e mistura. Deve ser notado que as perdas exergéticas em sistemas de tratamento de esgoto aeróbios são relativamente elevadas devido à redução da matéria orgânica para gás carbônico e água.

No presente trabalho foram considerados os subprodutos das ETEs como termos de exergia destruída e perdida, decisão esta que foi baseada na exergia que tem esses produtos e que no presente não está sendo aproveitada: no caso do lodo para fins agrícolas, ou como insumo na produção de metanol, e no caso do metano para produção de energia elétrica, ou como combustível para o setor do transporte. 


\subsubsection{Cálculo dos índices exergéticos considerando o aproveitamento do metano e do lodo para os três processos de tratamento de esgoto}

Na Tabela 32, são apresentados os índices exergéticos $\left(\eta_{\text {exerg,amb }}, \lambda\right)$ no cenário em que a exergia dos rejeitos dos processos é aproveitada (gás produzido e lodo desaguado), se o metano fosse usado como combustível em um motor com uma eficiência $(\eta)$ de 30\% (motor da Ajax modelo CHP120 com capacidade de geração de $120 \mathrm{~kW}$ (AJAX, 2002)), e a exergia do lodo fosse utilizada para produção de metanol, neste caso, para os cálculos apresentados na Tabela 32, foi usada uma relação de fluxos mássicos do lodo e do metanol, apresentada por Ptasinski, Hamelinck e Kerkhof (2002).

Tabela 32 - Valores da eficiência exergética ambiental e do indicador exergético de renovabilidade, para os Processos de Tratamento de Esgoto da ETE Barueri e do sistema RAFA - Lagoa Facultativa

\begin{tabular}{lcc}
\hline Processo & $\eta_{\text {exerg,amb }}$ & $\lambda$ \\
\hline Estação de Tratamento de Esgoto Barueri & 0,348 & 0,410 \\
RAFA - Lagoa Facultativa & 0,983 & 7,06 \\
Estação de Tratamento de Esgoto Cañaveralejo & 0,673 & 4,200 \\
\hline
\end{tabular}

Para a produção do metanol o lodo passa por um proceso de gaseificação o qual produz alcatrão e um gás que serve de insumo para o processo do metanol, este processo é complexo e de um custo elevado.

Outra técnica de tratamento do lodo de esgoto é a fermentação, a qual produz um gás rico em metano que pode ser usado para geração de eletricidade e um lodo digerido com um poder calorífico muito baixo.

A incineração do lodo ou uso de este como combustível depende do poder calorífico do lodo que esta entre $16-21 \mathrm{MJ} / \mathrm{kg}$.

Por último o lodo do esgoto pode ser usado como fertilizante, se a percentagem de metais pesados for muito baixa ou nula e a sejam observado nutrientes na sua composição. 


\subsubsection{Comentários gerais}

De acordo com Belhani et al. (2008), a recuperação de biogás em processos de tratamento de esgoto diminui os impactos ambientais, mas por outro lado aumenta a irreversibilidade no processo pela adição de equipamentos no sistema.

A exergia nos biosólidos devida à matéria orgânica poderia estar disponível pela produção de metano para os três processos e representa 20,5\% (Barueri), 100\% (Reator RAFA) e 24,2\% (Cañaveralejo), ou para produção de metanol. Também há uma exergia considerável nos biossólidos devido aos nutrientes. Esse potencial poderia ser utilizado incluindo processos de separação de nutrientes.

O lodo desaguado produzido na ETE Barueri não contém nutrientes em sua composição (compostos nitrogenados, potássio e fósforo), é o mesmo caso do lodo desaguado produzido na ETE Cañaveralejo. Já os lodos do RAFA contém nutrientes como potássio e fósforo, mas com porcentagens muito baixas da ordem de $1,2 \cdot 10^{-7} \%$ e $5,8 \cdot 10^{-5}$, respectivamente. A ETE Barueri possui no ferro a maior percentagem do fluxo exergético associado ao lodo desaguado, com $79,1 \%$.

As variações obtidas nos valores dos fluxos exergéticos das vazões afluente e efluente para cada um dos processos de tratamento de esgoto, ao comparar mistura ideal com mistura real, foram para a ETE Barueri 1,1\% e 2,4\%; para o sistema RAFA - Lagoa Facultativa $0,5 \%$ e $0,4 \%$; e para a ETE Cañaveralejo $1 \%$ e $2 \%$ para a vazão afluente e efluente respectivamente.

A exergia da matéria orgânica no esgoto bruto afluente e no esgoto tratado representa para o sistema RAFA - Lagoa Facultativa 97,4\% e 94,3; para a ETE Barueri $92,8 \%$ e $65,2 \%$; e para a ETE Cañaveralejo $98,9 \%$ e $97,5 \%$ do fluxo de exergia. Nesses valores é observado que para estes processos a maior remoção da matéria orgânica apresenta-se na ETE Barueri e a menor na ETE Cañaveralejo que é um tratamento primário quimicamente assistido.

Os nutrientes (compostos nitrogenados, potássio e fósforo) representam uma parcela importante do fluxo exergético: no caso da ETE Barueri foram $7,2 \%$ do fluxo 
de exergia associado ao esgoto bruto afluente e $30,11 \%$ do fluxo exergético do efluente final. No caso do RAFA não há presença de nutrientes, e no caso da ETE Cañaveralejo a percentagem do fósforo é muito pequena. Os compostos de nitrogênio e fósforo no esgoto poderiam ser usados na preparação de fertilizantes.

Na Tabela 33 é apresentado um resumo comparativo dos indicadores exergéticos para os processos analisados neste trabalho.

Tabela 33 - Resumo comparativo dos valores da eficiência exergética ambiental e do indicador exergético de renovabilidade para os processos de tratamento de esgoto analisados

\begin{tabular}{|c|c|c|}
\hline Processo & $\eta_{\text {exerg,amb }}$ & $\lambda$ \\
\hline Estação de Tratamento de Esgoto Barueri & 0,070 & 0,060 \\
\hline RAFA - Lagoa Facultativa & 0,054 & 0,057 \\
\hline Estação de Tratamento de Esgoto Cañaveralejo & 0,394 & 0,770 \\
\hline $\begin{array}{l}\text { Estação de Tratamento de Esgoto Barueri } \\
\text { (considerando o metano e o lodo como efeito } \\
\text { útil) }\end{array}$ & 0,348 & 0,410 \\
\hline $\begin{array}{l}\text { RAFA - Lagoa Facultativa (considerando o } \\
\text { metano e o lodo do Reator como efeito útil) }\end{array}$ & 0,983 & 7,060 \\
\hline $\begin{array}{l}\text { Estação de Tratamento de Esgoto Cañaveralejo } \\
\text { (considerando o metano e o lodo da ETE como } \\
\text { efeito útil) }\end{array}$ & 0,673 & 4,200 \\
\hline
\end{tabular}

$\mathrm{Na}$ Tabela 33, observa-se de acordo com os resultados obtidos que o processo mais favorável do ponto de vista ambiental é o Processo de Tratamento de Esgoto do RAFA - Lagoa Facultativa, já que apresenta o maior valor de $\eta_{\text {exerg,amb }}(0,983)$ e o maior valor de $\lambda(7,060)$.

No entanto, deve ser levado em consideração que para que essa comparação possa ser feita com rigor, deveria ser adicionado ao tratamento da ETE Cañaveralejo, um tratamento secundário, pois somente dessa maneira o efluente do tratamento 
obedeceria aos padrões de emissão estabelecidos pela legislação ambiental, e assim ter-se-iam resultados mas realístas.

Outro aspecto que influenciou na análise do sistema RAFA - Lagoa Facultativa foi o fato de que a lagoa facultativa recebe além do efluente do reator RAFA, o efluente de uma lagoa anaeróbia, presente no centro experimental de Ginebra, o que prejudicou o seu desempenho.

Os valores obtidos para o índice exergético de renovabilidade $(\lambda)$ maiores que 1 , (ver Tabelas 32 e 33), significam que a exergia dos produtos dos sistemas de tratamento de esgoto (sistema RAFA - Lagoa Facultativa e a ETE Cañaveralejo), poderia ser usada para restaurar o meio ambiente às condições de antes da poluição da água acontecer e ainda ter um fluxo de exergia positivo para outro uso. Essa restauração do meio ambiente, nesse caso, estaria relacionada com a produção de eletricidade a partir do biogás produzido, que substituiria o efeito que causou no ambiente a produção da eletricidade que é consumida da rede elétrica pelo processo. O fluxo de exergia positivo excedente pode estar representado por um excedente da energia elétrica produzida no processo e pela utilização da exergia do lodo desaguado para fins agrícolas, ou como insumo na produção de metanol.

A maior contribução da utilização do índice exergético de renovabilidade $(\lambda)$ para a análise exergética está no fato de que ele resolve o valor limitado que a análise apresenta quando é utilizada na discussão da renovabilidade, já que a análise exergética não considera se as fontes de exergia são renováveis ou não (Hellstrom, 1999). 


\section{CONCLUSÕES}

A análise exergoecológica, com os índices exergéticos, mostrou ser uma metodologia científica com critérios bem definidos para avaliar e quantificar o desempenho ambiental de processos de tratamento de esgoto, numa base única: a exergia. Com a aplicação dessa metodologia é possível comparar e caracterizar o desempenho exergético ambiental e a renovabilidade desses processos.

A eficiência exergética ambiental é um indicador apropriado para avaliação ecológica porque apresenta uma medida termodinâmica unificada para avaliação objetiva de utilização de recursos, qualidade dos processos de conversão de energia e impacto ambiental. Essa relação mostrou que pode ser usada para determinar o sistema energético mais eficiente entre vários processos de tratamento de esgoto químicos e biológicos.

Os resultados mostraram que a eficiência exergética ambiental é um índice que pode ser utilizado para avaliar e quantificar o desempenho ambiental de um processo de tratamento de esgoto, já que um aumento na eficiência exergética ambiental é uma forma importante para reduzir custos de operação, uso de recursos e emissões ambientais. O aumento da eficiência reduz o impacto ambiental pela redução das perdas exergéticas (emissões de exergia desperdiçada e exergia destruída), e aumenta a sustentabilidade energética do processo pelo prolongamento da vida dos recursos, isto é, maior eficiência exergética ambiental, maior sustentabilidade energética e menor impacto ambiental (ROSEN, DINCER e KANOGLU (2008)).

O índice exergético de renovabilidade é um bom complemento para a eficiência exergética ambiental pois leva em consideração, além da destruição da exergia, as fontes de exergia não renováveis utilizadas pelo processo.

Os valores dos índices exergéticos estão influenciados pela definição das fronteiras do volume de controle considerado. Por isso, é importante, quando for feita uma comparação de processos de tratamento de esgotos diferentes, observarem-se o tamanho e a compatibilidade dos volumes de controle, a fim de evitar distorsões nas análises. 
Ao comparar a eficiência exergética ambiental usada neste trabalho com a definição de eficiência exergética para estações de tratamento de esgoto dada por GallegosMuñoz et al. (2003), que a definiram como a razão da diferença entre as exergias da água não tratada e da água tratada pela exergia do trabalho elétrico e mecânico da estação, observa-se que essa definição está focada no efeito da destruição da exergia realizado pelo processo de tratamento e na porcentagem que representa esse efeito no consumo elétrico e mecânico da estação, ou seja, têm-se maiores eficiências exergéticas para aqueles processos de tratamento de esgoto que destroem mais exergia do esgoto com consumos menores de trabalho elétrico e mecânico. Por outro lado, a eficiência exergética ambiental aqui definida, visa especialmente o aproveitamento da exergia contida no esgoto, através da reciclagem da exergia contida no esgoto tratado e nos seus subprodutos (biogás e lodo desaguado).

A eficiência exergética ambiental é um melhor índice de desempenho ambiental e de sustentabilidade do ponto de vista energético para processos de tratamento de esgoto, porque ela avalia esses processos além da sua finalidade, que é despoluir o recurso aquático, preocupando-se com os outros efeitos energéticos e ambientais que o processo de tratamento pode causar no seu meio ambiente. Isso pode ser observado no fato de ela considerar a exergia de desativação dos rejeitos, que é a exergia dos recursos adicionais usados para deixar em equilíbrio termodinâmico total os rejeitos com o meio ambiente.

Uma limitação da definição da eficiência exergética ambiental aplicada à análise de processos de tratamento de esgoto está associada ao fato de que para processos com uma eficiência de remoção menor de matéria orgânica podem ser obtidos valores de eficiência exergética ambiental maiores, pois o efluente da estação sairia com um conteúdo maior de exergia, o qual é prejudicial para o meio ambiente, e estaria em contraposição à definição usada neste trabalho.

A eficiência exergética identifica as ineficiências técnicas na conversão da matéria orgânica nos fluxos de esgoto, e deixa claro que a tecnologia usada para aproveitar a matéria orgânica do esgoto está longe de ser otimizada.

Não é possível calcular a qualidade biológica de qualquer substância pelo cálculo do conteúdo de exergia. Conseqüentemente, é importante que o conteúdo de metais 
pesados e compostos orgânicos perigosos nos biosólidos seja medido. O conteúdo de diferentes elementos perigosos deve ser baixo se o potencial de exergia devido aos nutrientes é usado.

Da comparação global dos três processos de tratamento de esgoto analisados foi observado que o processo com os maiores valores de desempenho ambiental e renovabilidade, considerando o metano e o lodo do reator como efeitos úteis, foi o sistema RAFA - Lagoa Facultativa, com valores de 0,983 e 7,060 para $\eta_{\text {exerg,amb e }}$ $\lambda$, respectivamente (ver Tabela 33). Isto é, o desempenho ambiental é melhor quanto maior for o potencial de aproveitamento dos subprodutos do processo. O valor do índice exergético de renovabilidade $(\lambda)$ maior que 1 significa que a exergia dos produtos do sistema RAFA - Lagoa Facultativa, poderia ser usada para restaurar o meio ambiente às condições de antes da poluição da água acontecer e ainda ter um fluxo de exergia positivo para outro uso.

Finalmente, a partir desses resultados é concluído que os indicadores exergéticos propostos são úteis na avaliação e comparação do desempenho ambiental de tecnologias de tratamento de esgoto, do ponto de vista de rendimento e renovabilidade.

Como sugestão para trabalhos futuros, propõe-se:

a) Estender a metodologia proposta para um número maior de processos de tratamento de esgoto;

b) Incluir na análise, processos de separação de recursos (urina e fezes), para quantificar, além da redução do consumo de exergia total do processo de tratamento, o valor exergético real dos resíduos úteis do processo (aumento na produção de biogás e recuperação de nutrientes);

c) Complementar esta abordagem com a análise termoeconômica;

d) Estudar melhor outras opções de aproveitamento da exergia do lodo desaguado como por exemplo a gaseificação para produzir insumos para o processo de produção de metanol. 


\section{REFERÊNCIAS BIBLIOGRÁFICAS}

AJAX, 2002. Disponível em: < http://dspace.dial.pipex.com/town/terrace/ae198/ajaxd atasheet.html>. Acesso em: 19 Fev. 2009.

ALMEIDA, S. G; SILVEIRA JÚNIOR, S. C. J; CARVALHO, A. A; MENEZES, S. F. P. Melhora de Desempenho Ambiental em uma Unidade de Tratamento de Água de uma Industria. In: VI SIMPÓSIO DE RECURSOS HIDRICOS DO NORDESTE, 2002, MACEIÓ. Disponível em: <http://teclim.ufba.br/jsfurtado/downloads/viSimpRecHidric os.pdf>. Acesso em: 31 jan. 2008.

ARVIZU, F. J. L. Tratamiento anerobio-aerobio de las aguas residuales de las instalaciones del IIE. 1996. Disponível em: <http://www.iie.org.mx/publica/bolso96/ap lica.htm>. Acesso em: 31 jan. 2008.

AYRES, R. U. ; AYRES, L. W. ; MARTINÁS, K. Eco-thermodynamics: exergy and life cycle analysis. In: Centre for the Management of Environmental Resources, Fontainebleau, France, 1996. p.1-48.

$\overline{\text { Energy, }}$ v.23, n.5, p.355-363, 1997. Exergy, waste accounting, and life-cycle analysis. . Eco-thermodynamics : economics and the second law. Ecological Economics, v.26, n.2, p. 189-209, 1998.

BALKEMA, A. J; PREISIG, H. A; OTTERPOHL, R; LAMBERT, F. J. D. Indicators for the Sustainability Assessment of Wastewater Treatment Systems. Urban Water, v.4, n.2, p. 153-161, June, 2002.

BASTIANONI, S. A definition of 'pollution' based on thermodynamic goal functions. Ecological Modelling, v.113, n.1/3, p.163-166, nov. 1998.

; NIELSEN, S. N; MARCHETTI, N; JORGENSEN, S. E. Use of Thermodynamic Functions for Expressing Some Relevant Aspects of Sustainability. International Journal of Energy Research, v.29, n.1, p.53-64, 2005.

BEJAN, A. ; TSATSARONIS, G. ; MORAN, M. Thermal design and optimization. New York : John Wiley \& Sons, 1996. 542p. 
BELHANI, M; PONS, M. N; ALONSO, D. SFGP 2007 - The Effects of Sludge Digester Biogas Recovery on WWTP Ecological Impacts and Exergetic Balance. International Journal of Chemical Reactor Engineering, v.6, n.A21, p. 1-27, 2008.

BENDORICCHIO, G; JORGENSEN, S. E. Exergy as Goal Function of Ecosystems Dynamic. Ecological Modelling, v.102, n.1, p. 5-15, 1997.

BENVENUTTI, L. P. ; FRANK, B. Barômetro de gestão ambiental em Santa Catarina. In: ENCONTRO NACIONAL DE ENGENHARIA DE PRODUÇÃO, 20., I INTERNATIONAL CONFERENCE ON INDUSTRIAL ENGINEERING AND OPERATION MANAGEMENT., 6, São Paulo, 2000. Anais. São Paulo : EPUSP/FCAV, 2000. p.1-8.

BERTHIAUME, R; BOUCHARD, C; ROSEN, M. A. Exergetic Evaluation of the Renewability of a Biofuel. Exergy, an International Journal, v.1, n.4, p. 256-268, 2001.

BOTERO, E. A. Valoración exergética de recursos naturales, minerales, agua y combustibles fósiles. Zaragoza, 2000. Tese (Doutorado) - Departamento de Ingeniería Mecánica,Universidad de Zaragoza. Disponível em: http://www.circe.cps.unizar.es/pub/publicir.nsf. Acesso em: 10 nov. 2002.

CETE POLI/UFRJ, CENTRO EXPERIMENTAL DE TRATAMENTO DE ESGOTOS DA UFRJ, 2001. Disponível em: < http://www.saneamento.poli.ufrj.br/cete/main_cete missao.htm>. Acesso em: 27 Jan. 2009.

CHEN, G. Q. Exergy Consumption of the Earth. Ecological Modelling, v.184, n.2-4, p.363-380, June, 2005.

Scarcity of Exergy and Ecological Evaluation based on Embodied Exergy. Communications in Nonlinear Science and Numerical Simulation, v.11, n.4, p.531-552, July, 2006.

; JI, Xi. Chemical Exergy Based Evaluation of Water Quality. Ecological Modelling, v.200, n.1-2, p.259-268, January, 2007.

; JIANG, M. M; YANG, Z. F; CHEN, B; JI, X; ZHOU, J. B. Exergetic assessment for ecological economic system: Chinese agriculture. Ecological Modelling, v.220, n.3, p.397-410, February, 2009. 
CHEN, B; CHEN, G. Q; HAO, F. H; YANG, Z. F. The Water Resources Assessment Based on Resource Exergy for the Mainstream Yellow River. Communications in Nonlinear Science and Numerical Simulation, Article in press, August, 2007.

CHERNICHARO, C. A. Princípios do tratamento biológico de águas residuárias: Reatores anaeróbios; Editora UFMG. 1997. p. 171-174.

COMPANHIA DE SANEAMENTO BÁSICO DO ESTADO DE SÃO PAULO. Descrição da estação de tratamento de esgotos Barueri. São Paulo : SABESP, 2002.

Disponível

Tratamento de esgotos por lodos ativados. São Paulo : SABESP, 2003.

http://www.sabesp.com.br/sabesp ensina/intermediario/lodos ativados/default.htm.

Acesso em: 18 de ago. 2003.

CREYTS, J. C; CAREY, V. P. Use of extended exergy analysis as a tool for assessment of the environmental impact of industrial processes. Advanced Energy Systems Division, v.37, p. 129-137, 1997.

DEWULF, J; VAN LANGENHOVE, $\mathrm{H}$. Integrating industrial ecology principles into a set of environmental sustainability indicators for technology assessment. Resources, Conservation and Recycling, v. 43, n.4, p. 419 - 432, march., 2005.

DINCER, I; ROSEN, M. A. A worldwide perspective on energy, environment and sustainable development. International Journal of Energy Research, v. 22, n.15, p. 1305 - 1321, dez., 1998.

EMPRESAS MUNICIPALES DE CALI. Plan de manejo ambiental PTAR Cañaveralejo. Cali : EMCALI, 2001.

FINNVEDEN, G; OSTLUND, P. Exergies of Natural Resources in Life-Cycle Assessment and other Applications. Energy, vol.22, n. 9, p. 923-931, September, 1997.

FULIU, X. Exergy and Structural Exergy as Ecological Indicators for the Development State of the Lake Chaohu Ecosystem. Ecological Modelling, v. 99, n. 1, p. 41-49, June, 1997. 
GAGGIOLI, R. A; WEPFER, W. J. Exergy Economics: I. Cost Accounting Applications. Energy, v.5, n.8-9, p.823-837, August, 1980.

GALLEGOS-MUÑOZ, A; ZALETA-AGUILAR, A; GONZALEZ-ROLÓN, B; RANGELHERNANDEZ, V. H. On an Exergy Efficiency Definition of a Wastewater Treatment Plant. International Journal Thermodynamics, v.6, n.4, p.169-176, December, 2003.

GONG, M. On exergy as an ecological indicator. Göteborg, Suécia, 1999. Master of Science Thesis - Department of Physical Resource Theory, Chalmers University of Technology and Göteborg University. Disponível em: ftp://exergy.se/pub/eei.pdf. Acesso em: 17 nov. 2003.

; WALL, G. On exergy and sustainable development-part 2: indicators and methods. Exergy, v.1, p.217-233, 2001b.

HELOU, L. C. Otimização de estações de tratamento de esgoto (ETE) convencionais por lodos ativados com aproveitamento dos efluentes para reúso. 2000. São Paulo, 2000. 259p. Tese (Doutorado) - Escola Politécnica da Universidade de São Paulo.

HELLSTRÖM, D. An Exergy Analysis for a Wastewater Treatment Plant : an Estimation of the Consumption of Physical Resources. Water Environment Research, v 69, n 1, jan./fev., p 44-51, 1997.

. Exergy Analysis: A comparison of source separation systems and conventional treatment systems. Water Environment Research, v. 71, n. 7, nov./dez., p. 1354-1363, 1999.

Exergy Analysis of nutrient recovery processes. Water Science and Technology, v. 48, n. 1, p. 27-36, 2003a.

; BAKY, A; PALM, O; JEPPSON, U; PALMQUIST, H. Comparison of Resource Efficiency of Systems for the Management of Toilet Waste and Organic Household Waste. In: $2^{\text {nd }}$ INTERNATIONAL SYMPOSIUM ON ECOLOGICAL SANITATION, 2003b, Luebeck, Germany. Disponível em: http://www2.gtz.de/ecosan/ download/ecosan-Symposium-Luebeck-session-h.pdf Acesso em: 18 april. 2008. 
HUANG, L. Q; CHEN, G. Q; ZHANG, Y; CHEN, B; LUAN, S. J. Exergy as a Unified Measure of Water Quality. Communications in Nonlinear Science and Numerical Simulation, v.12, n.5, p.663-672, August, 2007.

JIE, Z; XIANG-SHENG, C; XUE-ZHENG, M. Sustainable Urban Sewerage System and its Application in China. Resources Conservation and Recycling, v.51, p.284293, March, 2007.

JORGENSEN, S. E. Use of Models as Experimental Tool to Show that Structural Changes are Accompanied by Increased Exergy. Ecological Modelling, v.41, n. 1-2, p. 117-126, April, 1988.

. Parameters, Ecological Constraints and Exergy. Ecological Modelling, v.62, n. 1-3, p. 163-170, July, 1992.

; NIELSEN, S. N; MEJER, H. Emergy, Environ, Exergy and Ecological Modelling. Ecological Modelling, v.77, n.2-3, p. 99-109, February, 1995.

Marques, J; Nielsen, S. N. Structural Changes in an Estuary, Described by Models and Using Exergy as Orientor. Ecological Modelling, v.158, n.3, p. 233-240, 2002.

; SVIREZHEV, Y. M. Towards a thermodynamic theory for ecological systems. Elsevier. 2004. p. 118-126, 328-333.

; NIELSEN, S. N. Application of exergy as thermodynamic indicator in ecology. Energy, v.32, n.5, p. 673-685, May, 2007.

KARAPÉTYANTZ, M. Thermodynamique chimique. Moscou; Éditions MIR. 1975. p. 415-417.

KIRK, B; ETNIER, C; KARRMAN, E; JOHNSTONE, S. Methods for Comparing Wastewater Treatment Options. St. Louis: Pro Write Inc., Reynoldsburg, OH., April 2005. (final report WU-HT-03-33, 1-206). Disponível em:

< http://www.ndwrcdp.org/userfiles/WU-HT-03-33.pdf>. Acesso em: 24 apr. 2008.

KOTAS, T. J. The exergy method of thermal plant analysis. London : Butterworths, 1985. $283 \mathrm{p}$. 
LATTOUF, R; OLIVEIRA JUNIOR, Silvio de. Exergy Analysis of Environmental Impact Mitigation Processes. In: Proceedings of the ECOS'2003 Efficiency, Costs, Optimization, Simulation and Environmental Impact of Energy Systems, 1, 2003, Copenhagen. Denmark, 2003. p. 397-404.

LUNDIN, M; MOLANDER, S; MORRISON, G. M. Indicators for the Development of Sustainable Water and Wastewater Systems. In: Sustainable Development Research Conference, 1997, Manchester. United Kingdom, 1997. p. 1-6.

MAKARYTCHEV, S. V. Environmental impact analysis of ACFB-based gas and power cogeneration. Energy, v.23, n. 9, p. 711-717, 1997.

MANISH, S; INDU, R. P; RANGAN, B. Sustainability analysis of renewables for climate change mitigation. Energy for Sustainable Development, v.10, n. 4, p. 2536, 2006.

MARQUES, J. C; PARDAL, M. A; NIELSEN, S. N; JORGENSEN, S. E. Analysis of the Properties of Exergy and Biodiversity Along an Estuarine Gradient of Eutrophication. Ecological Modelling, v.102, n.1, p.155-167, 1997.

METCALF \& EDDY, Ingeniería sanitaria: tratamiento evacuación y reutilización de aguas residuales, Barcelona. Editorial Labor. 1985. p. 969.

MIRANDA, A. B; TEIXEIRA, B. A. N. Indicators of Monitoring Sustainability of the Urban Water Supply and Sewerage Systems. Engenharia Sanitaria Ambiental, v.9, n.4, p.269-279, 2004.

MORA-BEJARANO. C. H; OLIVEIRA JUNIOR, SILVIO de. Exergy Efficiency as a Measure of the Environmental Impact of Energy Conversion Processes. In Proceedings of ECOS 2004, Guanajuato, Mexico, July 7-9, 2004a, Vol. 1, p. 423431.

MORA-BEJARANO. C. H; OLIVEIRA JUNIOR, SILVIO de. Exergy Efficiency as a Measure of the Environmental Impact of Wastewater Treatment Plants. In Proceedings of ENCIT 2004, Rio de Janeiro, Brazil, Nov 29 - Dec 3, 2004b.

MORA-BEJARANO. C. H; OLIVEIRA JUNIOR, SILVIO de. Indicadores Exergéticos para Avaliação do Impacto Ambiental de Processos de Conversão de Energia. Boletim Técnico da Escola Politécnica da USP, São Paulo, v.PME, n. 0410, 2004c. 
MORA-BEJARANO. C. H; OLIVEIRA JUNIOR, SILVIO de. Environmental Exergy Analysis of Wastewater Treatment Plants. In Proceedings of ECOS 2005, Trondheim, Norway, June 20-22, 2005, Vol. 1, p. 85-92.

MORA-BEJARANO. C. H; OLIVEIRA JUNIOR, SILVIO de. Environmental Exergy Analysis of Wastewater Treatment Plants. Engenharia Térmica, v.5, p. 24-29, 2006.

MORA-BEJARANO. C. H; OLIVEIRA JUNIOR, SILVIO de. Environmental Exergy Analysis of an Upflow Anaerobic Sludge Blanket (UASB) Reactor. In Proceedings of ECOS 2008, Cracow - Gliwice, Poland, June 24-27, 2008a, Vol. 1, p. 243-252.

MORA-BEJARANO. C. H; OLIVEIRA JUNIOR, SILVIO de. Comparative Environmental Exergy Evaluation of Wastewater Treatment Processes. In Proceedings of ENCIT 2008, Belo Horizonte, Brazil, Nov 10 -14, 2008b.

MUGA, H. E; MIHELCIC, J. R. Sustainability of Wastewater Treatment Technologies. Journal of Environmental Management, v. 88, p. 437-447, April,2008.

OLIVEIRA JUNIOR, Silvio de. Análise termodinâmica e termoeconômica de processos de conversão de energia. São Paulo : EPUSP/PME, 1996. Notas de aula.

OWEN, F. W. Energy in wastewater treatment. New Jersey : Prentice - Hall 1982. p. 373.

PALME, U; LUNDIN, M; TILLMAN, A. M; MOLANDER, S. Sustainable Development Indicators for Wastewater Systems - Researchers and Indicator User in a Cooperative Case Study. Resources Conservation and Recycling, v.43, p.293-311, June, 2005.

PELLEGRINI, L. F. Análise e otimização termo-econômica-ambiental aplicada à produção combinada de açúcar, álcool e eletricidade. 2009. São Paulo, 2009. 254p. Tese (Doutorado) - Escola Politécnica da Universidade de São Paulo.

PTASINSKI, K. J; HAMELINCK, C; KERKHOF, P. J. A. M. Exergy Analysis of Methanol from the Sewage Sludge Process. Energy Conversion and Management, v.43, p.1445-1457, 2002. 
REIS, M. A. Engenharia desenvolve novo sistema de tratamento de esgotos. Disponível em: < http://www.ufmg.br/boletim/bol1273/pag5.html>. Acesso em: 27 Jan. 2008.

ROSEN, M. A; DINCER, I. On exergy and environmental Impact. International Journal of Energy Research, v. 21, n.7, p. 643-654, june,1997.

; _ Exergy analysis of waste emissions. International Journal of Energy Research, v.23, n. 3, p.1153-1163, out. 1999.

Exergy as the confluence of energy, environment and sustainable development. Exergy, v.1, p.3-13, 2001.

KANOGLU, M. Role of exergy in increasing efficiency and sustainability and reducing environmental impact. Energy Policy, v.36, n.1, p.128137, 2008.

. Assessing energy technologies and environmental impacts with the principles of thermodynamics. Applied Energy, v.72, n.1, p.427-441, maio, 2002.

SCIUBBA, E. Beyond Thermoeconomics? The Concept of Extended Exergy Accounting and its Application to the Analysis and Design of Thermal Systems. Exergy, An International Journal, vol.1, n. 2, p. 68-84, 2001.

Cost Analysis of Energy Conversion Systems Via a Novel Resource-Based Quantifier. Energy, vol.28, n. 5, p. 457-477, April, 2003a.

. Extended Exergy Accounting Applied to Energy Recovery from Waste: the Concept of Total Recycling. Energy, vol.28, n. 13, p. 1315-1334, November, 2003b.

SZARGUT, J. ; MORRIS, D. R.; STEWARD, F. R. Exergy analysis of thermal, chemical, and metallurgical processes. New York : Hemisphere 1988. 332p.

- Application of exergy for the determination of the pro-ecological tax replacing the actual personal taxes. Energy, v.27, p.379-389, 2002.

; ZIEBIK, A; STANEK, W. Depletion of the non-renewable natural exergy resources as a measure of the ecological cost. Energy Conversion and Management, v.43, p.1149-1163, 2002. 
TAI, S; MATSUSHIGE, K; GODA, T. Chemical Exergy of Organic Matter in Wastewater. International Journal Environmental Studies, vol.27, n. 3-4, p. 301315, October, 1986.

TORÍO, H; ANGELOTTI, A; SCHMIDT, D. Exergy analysis of renewable energybased climatisation systems for buildings: a critical view. Energy and Buildings, vol.41, n. 3, p. 248-271, March, 2009.

TSATSARONIS, G. Thermoeconomic analysis and optimization of energy systems. Energy, v.19, n.3, p.227-257, 1993.

TSUKAMOTO, R. Y. Tratamento Primário Avançado: o Paradigma Moderno do Tratamento de Esgotos (Parte 3/3). Revista Água Latino Americana, v.2, n.4, p.5, 2002.

VALERO, A; UCHE, J; VALERO, A; MARTINEZ, A; ESCRIU, J. Physical Hydronomics: Application of the Exergy Analysis to the Assessment of Environmental Costs of Water Bodies. The Case of the Inland Basins of Catalonia. Zaragoza, 2006. CIRCE FOUNDATION - Departamento de Ingeniería Mecánica, Universidad de Zaragoza. Disponível em: http://teide.cps.unizar.es:8080/pub/publicir.nsf/codigos/o43 6/\$FILE/cp0436.pdf Acesso em: 1 mar. 2008.

VAN HAANDEL, A. C; FILHO, B. C; CHERNICHARO, C. A; NETO, C. O; MARQUEZ, D. M; NOUR, E. A; FORESTI, E; ANDREOLI, F; MELO, H. N; CAMPOS, J. R; PEREIRA, R. J. A; PAGLIUSO, J. D; FLORENCIO, L; CYBIS, L. F; MONTEGGIA, L. O; FILHO, M. L; ZAIAT, M; SPERLING, M. V; KATO, M. T; AISSE, M. M; CAVALCANTI, F. P. F; SOBRINHO, P. A; FIGUEIREDO, R. F; STEFANUTTI, $\mathrm{R}$. Tratamento de esgotos sanitários por processo anaeróbio e disposição controlada no solo. Rio de Janeiro : Rima 1999. 435p.

VELÁSQUEZ, H. I; BENJUMEA, P; OLIVEIRA JR. S. Exergy and Environmental Analysis of the Palm Oil Biodiesel Production Process. In: The $20^{\text {th }}$ International Conference on Efficiency, Costs, Optimization, Simulation and Environmental Impact of Energy Systems, Padova, 2007. Proceedings of the $\mathbf{2 0}^{\text {th }}$ International Conference on Efficiency, Costs, Optimization, Simulation and Environmental Impact of Energy Systems, Padova: Sevizi Grafici Editoriali, 2007. v. 1 p. 777-784.

VELÁSQUEZ, H. I; PELLEGRINI, L. F; OLIVEIRA JR. S. Ethanol and Sugar Production Process from Sugarcane: Renewability Evaluation. In: $12^{\text {th }}$ Brazilian Congress of Thermal Sciences and Engineering, 2008, Belo Horizonte. Proceedings of ENCIT 2008, 2008 (em CD-ROM). 
VELÁSQUEZ, H. I; RUIZ, A. A; OLIVEIRA JR. S. Ethanol Production Process from Banana Fruit and its Lignocellulosic Residues: Exergy and Environmental Analysis. In: The $21^{\text {th }}$ International Conference on Efficiency, Costs, Optimization, Simulation and Environmental Impact of Energy Systems, Krakow, 2008. Proceedings of the $21^{\text {st }}$ International Conference on Efficiency, Costs, Optimization, Simulation and Environmental Impact of Energy Systems, Gliwice: Zaklad Graficzny Politechniki Slaskiej, 2008. v. 1 p. 209-216.

VON SPERLING, M. Princípios do tratamento biológico de águas residuárias: Introdução à qualidade das águas e ao tratamento de esgotos. Belo Horizonte : Segrac 1996a. v.1243p.

VON SPERLING, M. Princípios do tratamento biológico de águas residuárias: Lagoas de estabilização. Belo Horizonte : Segrac 1996b. v.3 134p.

WALL, G. Exergy conversion in the Swedish society. Resources and Energy, v.9, n.1, p.55-73, June, 1987. maio, 1990.

Exergy conversion in the japanese society. Energy, v.15, n.5, p.435-444, ; SCIUBBA, E; NASO, V. Exergy use in the Italian society. Energy, v.19, n.12, p.1267-1274, December, 1994.

; GONG, M. On exergy and sustainable development-part 1: conditions and concepts. Exergy, v.1, p.128-145, 2001a.

Conditions and tools in the design of energy conversion and management systems of a sustainable society. Energy Conversion and Management, v.43, n.9/12, p.1235-1248, supl., jun./ago., 2002.

ZALETA-AGUILAR, A; RANZ, L; VALERO A. Towards a Unified Measure of Renewable Resources Availability: the Exergy Method Applied to the Water of a River. Energy Conversion Management, v.39, n.16-18, p.1911-1917, 1998.

ZHOU, J. ; MA, S. ; HINMAN, G. W. Ecological exergy analysis: a new method for ecological energetics research. Ecological modelling, v.84, n.1/3, p.291-303, jan. 1996. 


\section{ANEXO A - PARÂMETROS DE QUALIDADE DOS ESGOTOS ${ }^{3}$}

Os esgotos domésticos contêm aproximadamente $99,9 \%$ de água, e é devido ao $0,1 \%$ restante, o qual inclui sólidos orgânicos e inorgânicos, suspensos e dissolvidos, assim como microrganismos, que é necessário o tratamento dos esgotos. A característica dos esgotos é função dos usos à qual a água foi submetida. Os parâmetros de qualidade usados na caracterização do esgoto são parâmetros indiretos que traduzem o potencial poluidor do despejo a ser estudado, esses podem ser divididos em três categorias: parâmetros físicos, químicos e biológicos.

\section{Principais parâmetros de qualidade dos esgotos}

Os principais parâmetros físicos de qualidade dos esgotos são: temperatura, cor, odor e turbidez. Os químicos são: sólidos totais (em suspensão, dissolvidos e sedimentáveis), matéria orgânica (determinação indireta: $\mathrm{DBO}_{5}, \mathrm{DQO}$ e DBO última, determinação direta: COT), nitrogênio total (nitrogênio orgânico, amônia, nitrito e nitrato), fósforo (orgânico e inorgânico), $\mathrm{pH}$, alcalinidade, cloretos e óleos e graxas. Já os parâmetros biológicos são analisados sob o ponto de vista de organismos indicadores (bactérias, fungos, protozoários, vírus, helmintos). A seguir são apresentados os principais parâmetros.

a) Temperatura: é geralmente medida em ${ }^{\circ} \mathrm{C}$, ligeiramente superior à água de abastecimento, varia de acordo as estações do ano e tem influência na atividade microbiana, na solubiidade dos gases e na viscosidade do líquido.

b) Cor: para o esgoto fresco é ligeiramente cinza e para o esgoto séptico é cinza escuro ou preto.

c) Odor: o esgoto fresco apresenta um odor oleoso, relativamente desagradável, o esgoto séptico tem um odor fétido (desagradável), devido ao gás sulfídrico e a outros produtos da descomposição, e os despejos industriais apresentam odores característicos.

\footnotetext{
${ }^{3}$ Von Sperling, 1996.
} 
d) Turbidez: é causada por uma grande variedade de sólidos em suspensão, os esgotos mais frescos ou mais concentrados geralmente apresentam uma maior turbidez

e) Sólidos totais: todos os contaminantes da água, com exceção dos gases dissolvidos contribuem para a carga de sólidos. Os sólidos podem ser classificados de acordo com o seu tamanho e estado, as suas características químicas e a sua decantabilidade.

Por seu tamanho e estado são classificados em sólidos em suspensão e sólidos dissolvidos, os sólidos em suspensão são a fração dos sólidos orgânicos e inorgânicos que são filtráveis (não dissolvidos), e os sólidos dissolvidos são a fração dos sólidos orgânicos e inorgânicos que não são filtráveis, normalmente considerados com dimensión maior a $10^{-3}$.

Pelas características químicas, os sólidos são submetidos a uma temperatura de $550{ }^{\circ} \mathrm{C}$, nessa temperatura a fração orgânica é oxidada (volatizada), sobrando após a combustão só a fração inerte (não oxidada). Assim os sólidos totais são classificados em sólidos voláteis (estimativa da matéria orgânica) e sólidos fixos ou inertes (matéria inorgânica). Por tanto se tem sólidos em suspensão e dissolvidos, tanto fixos como voláteis.

E pela decantabilidade são classificados em sólidos sedimentáveis e não sedimentáveis. Os sólidos sedimentáveis são a fração dos sólidos orgânicos e inorgânicos que sedimenta em 1 hora. Seu valor é expresso em $\mathrm{mL} / \mathrm{L}$, e é medido em um recipiente denominado cone Imhoff. É uma indicação aproximada da sedimentação em um tanque de decantação. A fração dos sólidos que não se sedimenta representa os sólidos não sedimentáveis.

f) Matéria orgânica: é uma mistura heterogênea de diversos compostos orgânicos entre os quais os principais componentes são as proteínas, os carboidratos e os lipídios. Ela é a responsável pelo maior problema da poluição das águas, que é o consumo do oxigênio dissolvido pelos microrganismos nos seus processos metabólicos de utilização e estabilização da matéria orgânica. A matéria orgânica nos esgotos é classificada com relação a sua forma e tamanho e à sua biodegradabilidade, quanto à forma e tamanho classifica-se em matéria orgânica em suspensão (particulada) e dissolvida (solúvel), e quanto à biodegradabilidade em inerte e biodegradável. Para sua determinação são usados métodos diretos ou 
indiretos. Os métodos indiretos fazem a determinação da matéria orgânica através da medição do consumo de oxigênio. Esses métodos são: Demanda Bioquímica de Oxigênio (DBO), Demanda Última de Oxigênio $\left(\mathrm{DBO}_{\mathrm{u}}\right)$ e Demanda Química de Oxigênio (DQO), o método direto determina a matéria orgânica através da medição do carbono orgânico, esse método é o do Carbono Orgânico Total (COT). Esses métodos são apresentados a seguir:

Demanda Bioquímica de Oxigênio: é uma medida do oxigênio consumido após 5 dias e a $20{ }^{\circ} \mathrm{C}$, pelos microrganismos na estabilização bioquímica da matéria orgânica e está associada à fração biodegradável dos componentes orgânicos carbonáceos.

Demanda Química de Oxigênio: representa a quantidade de oxigênio requerida para para estabilizar quimicamente a matéria orgânica carbonácea. A oxidação química da matéria orgânica é obtida através de um forte agente oxidante (dicromato de potássio) em um meio ácido, o teste demora de 2 a 3 horas para ser realizado.

Demanda Última de Oxigênio: representa o consumo total de oxigênio, ao final de 20 dias, tempo requerido pelos microrganismos para a estabilização bioquímica da matéria orgânica.

Carbono Orgânico Total: é uma medida direta da matéria orgânica carbonácia, e é determinado através da conversão do carbono orgânico a gás carbônico. Para garantir que o carbono sendo medido seja realmente o carbono orgânico, as formas inorgânicas do carbono (como $\mathrm{CO}_{2}, \mathrm{HCO}_{3}{ }^{-}$, etc) devem ser removidas antes da análise ou corrigidas no cálculo.

g) Nitrogênio total: o nitrogênio total inclui o nitrogênio orgânico, amônia (livre $-\mathrm{NH}_{3}$ e ionizada $\left.-\mathrm{NH}_{4}{ }^{+}\right)$nitrito $\left(\mathrm{NO}_{2}{ }^{-}\right)$e nitrato $\left(\mathrm{NO}_{3}{ }^{-}\right)$. É um nutriente indispensável para o desenvolvimento dos microrganismos no tratamento biológico. O nitrogênio orgânico e a amônia compreendem o denominado Nitrogênio Total Kjeldahl (NTK). O nitrogênio orgânico é nitrogênio na forma de proteínas, aminoácidos e uréia, a amonia é produzida no primeiro estágio da descomposição do nitrogênio orgânico, o nitrito aparece no estágio intermediário da oxidação da amônia e o nitrato é o produto final da oxidação da amônia (o nitrito e o nitrato, praticamente não aparecem no esgoto bruto).

h) Fósforo: o fósforo total existe na forma orgânica e inôrganica, e é um nutriente indispensável no tratamento biológico, pois ele é essencial para o crescimento dos 
microrganismos responsáveis pela estabilização da matéria orgânica. O fósforo orgânico aparece combinado à matéria orgânica e nos esgotos é convertido a ortofosfatos. O fósforo inorgânico aparece na forma de ortofosfatos e polifosfatos, os ortofosfatos são utilizados pelo metabolismo biológico sem necessidade de conversões a formas mais simples. As prinicpais fontes de ortofosfatos na água são o solo, detergentes, fertilizantes, despejos industriais e esgotos domésticos. Em esgotos domésticos típicos a forma predominante dos ortofosfatos é $\mathrm{HPO}_{4}{ }^{-2}$.

Os polifosfatos são moléculas mais complexas com dois ou mais átomos de fósforo. Os polifosfatos se transformam em ortofosfatos pelo mecanismo de hidrólise, no entanto essa transformação é usualmente lenta.

i) $\mathrm{pH}$ : é um indicador das características ácidas ou básicas do esgoto. o termo pH (potencial hidrogeniônico) é usado universalmente para expressar o grau de acidez ou basicidade de uma solução, ou seja, é o modo de expressar a concentração de íons de hidrogênio nessa solução. A escala de $\mathrm{pH}$ é constituída de uma série de números variando de 0 a 14 , os quais denotam vários graus de acidez ou alcalinidade. Valores abaixo de 7 e próximos de zero indicam aumento de acidez, enquanto valores de 7 a 14 indicam aumento da basicidade.

Geralmente um pH muito ácido ou muito alcalino está associado à presença de despejos industriais. A determinação do $\mathrm{pH}$ é feita por meio do método eletrométrico, utilizando-se para isso um pHmetro digital. Os processos de oxidação biológica normalmente tendem a reduzir o $\mathrm{pH}$.

j) Alcalinidade: indicador da capacidade tampão do meio (resitencia às variações do $\mathrm{pH}$ ). Representa a capacidade que um esgoto tem de neutralizar (tamponar) ácidos a ele adicionados. Essa capacidade depende de alguns compostos, principalmente bicarbonatos $\left(\mathrm{HCO}_{3}{ }^{-}\right)$, carbonatos $\left(\mathrm{CO}_{3}{ }^{2-}\right)$ e hidróxidos $\left(\mathrm{OH}^{-}\right)$. A alcalinidade é determinada por meio da titulação.

k) Cloretos: esses elementos são provenientes da água de abastecimento e dos dejetos humanos.

I) Óleos e graxas: são a fração da matéria orgânica solúvel em hexanos. Nos esgotos domésticos, as fontes são óleos e gorduras utilizados em alimentos.

m) Indicadores de contaminação fecal: a detecção dos agentes patogênicos, como bactérias, protozoários e vírus em uma amostra de água é muito difícil, em razão das suas baixas concentrações. Esse obstáculo é superado através do estudo dos 
organismos indicadores de contaminação fecal. Os organismos mais comummente usados com essa finalidade são as bactérias do grupo coliforme e as técnicas bacteriológicas para a deteção de coliformes são rápidas e econômicas. Os principais indicadores de contaminação fecal e mais usados são: o grupo de coliformes totais (CT), coliformes fecais (CF) e os estreptococos fecais (EF).

Coliformes totais (CT): é um grande grupo de bactérias que têm sido isoladas de amostras de águas e solos poluídos e não poluídos, bem como de fezes de seres humanos e outros animais de sangue quente.

Coliformes fecais (CF): são um grupo de bactérias indicadoras de organismos originários do trato intestinal humano e outros animais. O teste para esse indicador é feito a uma temperatura elevada, na qual o crecimento de bactérias de origem não fecal é suprimido.

Estreptococos fecais (EF): incluem várias espécies ou variedades de estreptococos, tendo no intestino de seres humanos e outros animais o seu habitat usual. 


\section{ANEXO B - PADRÕES DE EMISSÃO DE EFLUENTES ${ }^{4}$}

\section{Destinação de uso do corpo d'água}

Os corpos d'água receptores de efluentes podem ser destinados a diferentes usos. A legislação federal brasileira, por meio da RESOLUÇÃO CONAMA 20 de 18 de junho de 1986 prevê cinco classes de utilização, baseadas na destinação de uso. Essa destinação de uso é estabelecida por meio da legislação específica, que indica o uso de cada corpo d'água. A legislação do Estado de São Paulo, por meio do Decreto Estadual 8468 de 8 de setembro de 1976, prevê apenas quatro classes de uso. A Tabela 34 mostra as destinações de uso de cada uma delas.

Tabela 34 - Classes de uso de corpos d'água

\begin{tabular}{|c|c|c|}
\hline Destinação de uso & CONAMA 20 & $\begin{array}{l}\text { Decreto } \\
8468 / 76\end{array}$ \\
\hline $\begin{array}{l}\text { Abastecimento doméstico sem prévio tratamento ou com simples } \\
\text { desinfecção }\end{array}$ & \multirow{2}{*}{ Especial } & Classe 1 \\
\hline Preservação do equilíbrio natural das comunidades aquáticas & & 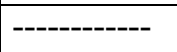 \\
\hline Abastecimento doméstico com tratamento simplificado & \multirow{5}{*}{ Classe 1} & 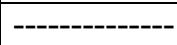 \\
\hline Proteção de comunidades aquáticas & & |------------ \\
\hline Aqüicultura & & 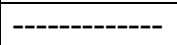 \\
\hline Recreação de contato primário & & \multirow{5}{*}{ Classe 2} \\
\hline Irrigação de hortaliças e frutas consumidas cruas & & \\
\hline Abastecimento doméstico após tratamento convencional & \multirow{5}{*}{ Classe 2} & \\
\hline Recreação de contato primário & & \\
\hline Irrigação de hortaliças e frutas & & \\
\hline Proteção de comunidades aquáticas & & \multirow{4}{*}{ Classe 3} \\
\hline Aqüicultura & & \\
\hline Abastecimento doméstico após tratamento convencional & \multirow{3}{*}{ Classe 3} & \\
\hline Dessedentação de animais & & \\
\hline Irrigação de culturas arbóreas, cerealíferas e forrageiras & & \multirow{6}{*}{ Classe 4} \\
\hline Navegação & \multirow{5}{*}{ Classe 4} & \\
\hline Harmonia paisagística & & \\
\hline Usos menos exigentes & & \\
\hline Abastecimento público após tratamento avançado & & \\
\hline Abastecimento industrial & & \\
\hline
\end{tabular}

\footnotetext{
${ }^{4}$ Helou, 2000.
} 
Cada uma dessas normas legais impõe para cada classe de uso uma qualidade a ser atingida, de forma a atender os usos aos quais se destinam esses corpos d'água. As Tabelas seguintes indicam as classes e os limites dos parâmetros exigidos para cada classe.

Tabela 35 - Limites dos parâmetros de qualidade de acordo com a Resolução CONAMA 20/86

\begin{tabular}{|c|c|c|c|c|c|}
\hline Parâmetro & Unidade & Classe 1 & Classe 2 & Classe 3 & Classe 4 \\
\hline Materiais flutuantes & $\begin{array}{l}---- \\
\end{array}$ & Ausentes & Ausentes & Ausentes & Ausentes \\
\hline Óleos e graxas & & Ausentes & Ausentes & Ausentes & Iridiscência \\
\hline Odor e gosto & & Ausentes & Ausentes & Ausentes & NE \\
\hline Corantes & & Ausentes & Removíveis & Removíveis & NE \\
\hline Depósitos objetáveis & & Ausentes & Ausentes & Ausentes & NE \\
\hline$D B O_{5,20}$ & $\mathrm{mg} \mathrm{L}^{-1}$ & $<3$ & $<5$ & $<10$ & NE \\
\hline OD & $\mathrm{mg} \mathrm{L}^{-1}$ & $>6$ & $>5$ & $>4$ & $>2$ \\
\hline Turbidez & & $<40$ & $<100$ & $<100$ & NE \\
\hline Cor & $\mathrm{mgPt} \mathrm{L}{ }^{-1}$ & (1) & $<75$ & $<75$ & NE \\
\hline $\mathrm{PH}$ & & 6 a 9 & 6 a 9 & 6 a 9 & $\mathrm{NE}$ \\
\hline $\mathrm{Al}$ & $\mathrm{mg} \mathrm{L}^{-1}$ & 0,1 & 0,1 & 0,1 & $\mathrm{NE}$ \\
\hline $\mathrm{NH}_{3}$ & $\mathrm{mg} \mathrm{L}^{-1}$ & 0,02 & 0,02 & 1 & $\mathrm{NE}$ \\
\hline As & $\mathrm{mg} \mathrm{L}^{-1}$ & 0,05 & 0,05 & 0,05 & $\mathrm{NE}$ \\
\hline $\mathrm{Ba}$ & $\mathrm{mg} \mathrm{L}^{-1}$ & 1,0 & 1,0 & 1,0 & NE \\
\hline $\mathrm{Be}$ & $\mathrm{mg} \mathrm{L}^{-1}$ & 0,1 & 0,1 & 0,1 & $\mathrm{NE}$ \\
\hline$B$ & $\mathrm{mg} \mathrm{L}^{-1}$ & 0,75 & 0,75 & 0,75 & $\mathrm{NE}$ \\
\hline Benzeno & $\mathrm{mg} \mathrm{L}^{-1}$ & 0,01 & 0,01 & 0,01 & $\mathrm{NE}$ \\
\hline Benzo-a-pireno & $\mathrm{mg} \mathrm{L}^{-1}$ & 0,00001 & 0,00001 & 0,00001 & $\mathrm{NE}$ \\
\hline $\mathrm{Cd}$ & $\mathrm{mg} \mathrm{L}^{-1}$ & 0,001 & 0,001 & 0,001 & $\mathrm{NE}$ \\
\hline $\mathrm{CN}$ & $\mathrm{mg} \mathrm{L}^{-1}$ & 0,01 & 0,01 & 0,2 & $\mathrm{NE}$ \\
\hline $\mathrm{Pb}$ & $\mathrm{mg} \mathrm{L}^{-1}$ & 0,03 & 0,03 & 0,05 & $\mathrm{NE}$ \\
\hline Cloretos & $\mathrm{mg} \mathrm{L}^{-1}$ & 250 & 250 & 250 & $\mathrm{NE}$ \\
\hline Cloro Residual & $\mathrm{mg} \mathrm{L}^{-1}$ & 0,01 & 0,01 & $\mathrm{NE}$ & $\mathrm{NE}$ \\
\hline Co & $\mathrm{mg} \mathrm{L}^{-1}$ & 0,2 & 0,2 & 0,2 & $\mathrm{NE}$ \\
\hline $\mathrm{Cu}$ & $\mathrm{mg} \mathrm{L}^{-1}$ & 0,02 & 0,02 & 0,5 & $\mathrm{NE}$ \\
\hline $\mathrm{Cr}^{+3}$ & $\mathrm{mg} \mathrm{L}^{-1}$ & 0,5 & 0,5 & 0,5 & $\mathrm{NE}$ \\
\hline $\mathrm{Cr}^{+6}$ & $\mathrm{mg} \mathrm{L}^{-1}$ & 0,05 & 0,05 & 0,05 & $\mathrm{NE}$ \\
\hline 1,1 dicloroeteno & $\mathrm{mg} \mathrm{L}^{-1}$ & 0,0003 & 0,0003 & 0,0003 & $\mathrm{NE}$ \\
\hline 1,2 dicloroetano & $\mathrm{mg} \mathrm{L}^{-1}$ & 0,01 & 0,01 & 0,01 & $\mathrm{NE}$ \\
\hline Sn & $\mathrm{mg} \mathrm{L}^{-1}$ & 2,0 & 2,0 & 2,0 & $\mathrm{NE}$ \\
\hline Fenóis & $\mathrm{mg} \mathrm{L}^{-1}$ & 0,001 & 0,001 & 0,3 & 1 \\
\hline Fe soluble & $\mathrm{mg} \mathrm{L}^{-1}$ & 0,3 & 0,3 & 5 & $\mathrm{NE}$ \\
\hline Fluoreto & $\mathrm{mg} \mathrm{L}^{-1}$ & 1,4 & 1,4 & 1,4 & $\mathrm{NE}$ \\
\hline$P$ total & $\mathrm{mg} \mathrm{L}^{-1}$ & 0,025 & 0,025 & 0,025 & $\mathrm{NE}$ \\
\hline $\mathrm{Li}$ & $\mathrm{mg} \mathrm{L}^{-1}$ & 2,5 & 2,5 & 2,5 & $\mathrm{NE}$ \\
\hline Mn & $\mathrm{mg} \mathrm{L}^{-1}$ & 0,1 & 0,1 & 0,5 & $\mathrm{NE}$ \\
\hline $\mathrm{Hg}$ & $\mathrm{mg} \mathrm{L}^{-1}$ & 0,0002 & 0,0002 & 0,002 & $\mathrm{NE}$ \\
\hline $\mathrm{Ni}$ & $\mathrm{mg} \mathrm{L}^{-1}$ & 0,025 & 0,025 & 0,025 & $\mathrm{NE}$ \\
\hline \multirow[t]{2}{*}{$\mathrm{NO}_{3}$} & $\mathrm{mg} \mathrm{L}^{-1}$ & 10 & 10 & 10 & $\mathrm{NE}$ \\
\hline & & & & & Continua... \\
\hline
\end{tabular}




\begin{tabular}{|c|c|c|c|c|c|}
\hline $\mathrm{NO}_{2}$ & $\mathrm{mg} \mathrm{L}^{-1}$ & 1 & 1 & 1 & $\mathrm{NE}$ \\
\hline $\mathrm{Ag}$ & $\mathrm{mg} \mathrm{L}^{-1}$ & 0,01 & 0,01 & 0,05 & $\mathrm{NE}$ \\
\hline Pentaclorofenol & $\mathrm{mg} \mathrm{L}^{-1}$ & 0,01 & 0,01 & 0,01 & $\mathrm{NE}$ \\
\hline Se & $\mathrm{mg} \mathrm{L}^{-1}$ & 0,01 & 0,01 & 0,01 & $\mathrm{NE}$ \\
\hline Sólidos dissolvidos totais & $\mathrm{mg} \mathrm{L}^{-1}$ & 500 & 500 & 500 & $\mathrm{NE}$ \\
\hline Substâncias tensoativas & $\mathrm{mg} \mathrm{L}^{-1}$ & 0,5 & 0,5 & 0,5 & $\mathrm{NE}$ \\
\hline $\mathrm{SO}_{4}$ & $\mathrm{mg} \mathrm{L}^{-1}$ & 250 & 250 & 250 & $\mathrm{NE}$ \\
\hline $\mathrm{S}^{-2}$ & $\mathrm{mg} \mathrm{L}^{-1}$ & 0,002 & 0,002 & 0,3 & $\mathrm{NE}$ \\
\hline Tetracloroeteno & $\mathrm{mg} \mathrm{L}^{-1}$ & 0,01 & 0,01 & 0,01 & $\mathrm{NE}$ \\
\hline Tricloroeteno & $\mathrm{mg} \mathrm{L}^{-1}$ & 0,03 & 0,03 & 0,03 & $\mathrm{NE}$ \\
\hline Tetracloreto de carbono & $\mathrm{mg} \mathrm{L}^{-1}$ & 0,003 & 0,003 & 0,003 & $\mathrm{NE}$ \\
\hline $2,4,6$ triclorofenol & $\mathrm{mg} \mathrm{L}^{-1}$ & 0,01 & 0,01 & 0,01 & $\mathrm{NE}$ \\
\hline$u$ & $\mathrm{mg} \mathrm{L}^{-1}$ & 0,02 & 0,02 & 0,02 & $\mathrm{NE}$ \\
\hline V & $\mathrm{mg} \mathrm{L}^{-1}$ & 0,1 & 0,1 & 0,1 & $\mathrm{NE}$ \\
\hline $\mathrm{Zn}$ & $\mathrm{mg} \mathrm{L}^{-1}$ & 0,18 & 0,18 & 5 & $\mathrm{NE}$ \\
\hline Aldrin & $\mu g \mathrm{~L}^{-1}$ & 0,01 & 0,01 & 0,03 & $\mathrm{NE}$ \\
\hline Clordano & $\mu \mathrm{g} \mathrm{L}^{-1}$ & 0,04 & 0,04 & 0,3 & $\mathrm{NE}$ \\
\hline DDT & $\mu \mathrm{g} \mathrm{L}^{-1}$ & 0,002 & 0,002 & 1 & $\mathrm{NE}$ \\
\hline Dieldrin & $\mu \mathrm{g} \mathrm{L}^{-1}$ & 0,005 & 0,005 & 0,03 & $\mathrm{NE}$ \\
\hline Endrin & $\mu g \mathrm{~L}^{-1}$ & 0,004 & 0,004 & 0,2 & $\mathrm{NE}$ \\
\hline Endossulfan & $\mu \mathrm{g} \mathrm{L}^{-1}$ & 0,056 & 0,056 & 150 & $\mathrm{NE}$ \\
\hline Epóxido de heptacloro & $\mu \mathrm{g} \mathrm{L}^{-1}$ & 0,01 & 0,01 & 0,1 & $\mathrm{NE}$ \\
\hline Heptacloro & $\mu g L^{-1}$ & 0,01 & 0,01 & 0,1 & $\mathrm{NE}$ \\
\hline Lindano (gama-BHC) & $\mu g \mathrm{~L}^{-1}$ & 0,02 & 0,02 & 3 & $\mathrm{NE}$ \\
\hline Metoxicloro & $\mu \mathrm{g} \mathrm{L}^{-1}$ & 0,03 & 0,03 & 30 & $\mathrm{NE}$ \\
\hline Dodecacloro + nonacloro & $\mu g \mathrm{~L}^{-1}$ & 0,001 & 0,001 & 0,01 & $\mathrm{NE}$ \\
\hline $\mathrm{PCB}$ & $\mu g \mathrm{~L}^{-1}$ & 0,001 & 0,001 & 0,001 & $\mathrm{NE}$ \\
\hline Toxafeno & $\mu g \mathrm{~L}^{-1}$ & 0,01 & 0,01 & 5 & $\mathrm{NE}$ \\
\hline Demeton & $\mu \mathrm{g} \mathrm{L}^{-1}$ & 0,1 & 0,1 & 14 & $\mathrm{NE}$ \\
\hline Gution & $\mu \mathrm{g} \mathrm{L}^{-1}$ & 0,005 & 0,005 & 0,005 & $\mathrm{NE}$ \\
\hline Malation & $\mu \mathrm{g} \mathrm{L}^{-1}$ & 0,1 & 0,1 & 100 & $\mathrm{NE}$ \\
\hline Paration & $\mu \mathrm{g} \mathrm{L}^{-1}$ & 0,04 & 0,04 & 35 & $\mathrm{NE}$ \\
\hline Carbaril & $\mu \mathrm{g} \mathrm{L}^{-1}$ & 0,02 & 0,02 & 70 & $\mathrm{NE}$ \\
\hline $\begin{array}{l}\text { Organofosforados } \\
\text { carbamatos }\end{array}$ & e $\mu \mathrm{g} \mathrm{L}^{-1}$ & 10 & 10 & 100 & $\mathrm{NE}$ \\
\hline $2,4 \mathrm{D}$ & $\mu \mathrm{g} \mathrm{L}^{-1}$ & 4 & 4 & 20 & $\mathrm{NE}$ \\
\hline $2,4,5$ TP & $\mu \mathrm{g} \mathrm{L}^{-1}$ & 10 & 10 & 10 & $\mathrm{NE}$ \\
\hline $2,4,5 \mathrm{~T}$ & $\mu \mathrm{g} \mathrm{L}^{-1}$ & 2 & 2 & 2 & $\mathrm{NE}$ \\
\hline Coliformes Totais & NMP/100 & 1.000 & 5.000 & 20.000 & $\mathrm{NE}$ \\
\hline Coliformes Fecais & NMP/100 & 200 & 1.000 & 4.000 & $\mathrm{NE}$ \\
\hline
\end{tabular}

(1) Igual à do corpo receptor

Para a classe especial valem os limites de potabilidade, pois não há tratamento. 
Tabela 36 - Limites dos parâmetros de qualidade de acordo com o Decreto Estadual 8468/76

\begin{tabular}{|c|c|c|c|c|}
\hline Parâmetro & Unidade & Classe 2 & Classe 3 & Classe 4 \\
\hline Materiais flutuantes & $\begin{array}{l}---- \\
\end{array}$ & Ausentes & Ausentes & Ausentes \\
\hline Óleos e graxas & & Ausentes & Ausentes & Iridiscência \\
\hline Odor e gosto & & Ausentes & Ausentes & NO \\
\hline Corantes & & Removíveis & Removíveis & NE \\
\hline $\mathrm{DBO}_{5,20}$ & $\mathrm{mg} \mathrm{L}^{-1}$ & $<5$ & $<10$ & NE \\
\hline OD & $\mathrm{mg} \mathrm{L}^{-1}$ & $>5$ & $>4$ & $>0,5$ \\
\hline $\mathrm{NH}_{3}$ & $\mathrm{mg} \mathrm{L}^{-1}$ & 0,5 & 0,5 & $\mathrm{NE}$ \\
\hline As & $\mathrm{mg} \mathrm{L}^{-1}$ & 0,1 & 0,1 & NE \\
\hline $\mathrm{Ba}$ & $\mathrm{mg} \mathrm{L}^{-1}$ & 1,0 & 1,0 & NE \\
\hline $\mathrm{Cd}$ & $\mathrm{mg} \mathrm{L}^{-1}$ & 0,01 & 0,01 & $\mathrm{NE}$ \\
\hline $\mathrm{CN}$ & $\mathrm{mg} \mathrm{L}^{-1}$ & 0,2 & 0,2 & NE \\
\hline $\mathrm{Pb}$ & $\mathrm{mg} \mathrm{L}^{-1}$ & 0,1 & 0,1 & NE \\
\hline $\mathrm{Cu}$ & $\mathrm{mg} \mathrm{L}^{-1}$ & 1,0 & 1,0 & NE \\
\hline Cr Total & $\mathrm{mg} \mathrm{L}^{-1}$ & 0,05 & 0,05 & NE \\
\hline Sn & $\mathrm{mg} \mathrm{L}^{-1}$ & 2,0 & 2,0 & NE \\
\hline Fenóis & $\mathrm{mg} \mathrm{L}^{-1}$ & 0,001 & 0,001 & 1 \\
\hline $\mathrm{F}$ & $\mathrm{mg} \mathrm{L}^{-1}$ & 1,4 & 1,4 & NE \\
\hline $\mathrm{Hg}$ & $\mathrm{mg} \mathrm{L}^{-1}$ & 0,002 & 0,002 & $\mathrm{NE}$ \\
\hline $\mathrm{NO}_{3}$ & $\mathrm{mg} \mathrm{L}^{-1}$ & 10 & 10 & NE \\
\hline $\mathrm{NO}_{2}$ & $\mathrm{mg} \mathrm{L}^{-1}$ & 1 & 1 & NE \\
\hline $\mathrm{Se}$ & $\mathrm{mg} \mathrm{L}^{-1}$ & 0,01 & 0,01 & NE \\
\hline $\mathrm{Zn}$ & $\mathrm{mg} \mathrm{L}^{-1}$ & 5 & 5 & NE \\
\hline Coliformes Totais & NMP/100 & 5.000 & 20.000 & NE \\
\hline Coliformes Fecais & NMP/100 & 1.000 & 4.000 & NE \\
\hline
\end{tabular}

Para a classe 1 só são tolerados despejos de efluentes se o corpo d'água já tiver lançamento, e nos limites da classe 2; se não for possível infiltração ou reversão para outras bacias.

Outro conceito importante é o de emissão. Entende-se por padrão de emissão as características físico-químicas que um efluente deve obedecer para que possa ser liberado para os corpos d'água ou para os sistemas públicos de tratamento.

A Legislação Federal brasileira estabelece os padrões de emissão de efluentes em corpos receptores por meio da Resolução CONAMA 20/86. A Legislação Estadual estabelece estes padrões tanto para emissão em corpos d'água quanto nos sistemas de coleta públicos.

A Tabela 37 mostra os limites a que estão submetidos os efluentes a serem lançados nos corpos d'água. 
Tabela 37 - Limites de emissão conforme a Resolução CONAMA 20/86 e Decreto Estadual 8468/76

\begin{tabular}{|c|c|c|c|}
\hline Parâmetro & Unidade & $\begin{array}{l}\text { Resolução } \\
\text { CONAMA } 20\end{array}$ & Decreto Estadual 8468 \\
\hline Vazão & ------- & $<1,5^{*} Q_{\text {media }}$ & $<1,5^{*} Q_{\text {media }}$ \\
\hline Temperatura & ${ }^{\circ} \mathrm{C}$ & 40 & 40 \\
\hline $\mathrm{PH}$ & & 5 a 9 & 5 a 9 \\
\hline Materiais flutuantes & ------ & Ausentes & Ausentes \\
\hline Óleos vegetais e gorduras animais & $\mathrm{mg} \mathrm{L}^{-1}$ & 50 & --- \\
\hline Óleos minerais & $\mathrm{mg} \mathrm{L}^{-1}$ & 20 & --- \\
\hline OG & $\mathrm{mg} \mathrm{L}^{-1}$ & ------- & 100 \\
\hline Sólidos sedimentáveis & $\mathrm{mg} \mathrm{L}^{-1}$ & 1 & 1 \\
\hline$D B O_{5,20}$ & $\mathrm{mg} \mathrm{L}^{-1}$ & -------- & $60 \mathrm{mg} / \mathrm{L}$ ou $80 \%$ de remoção \\
\hline $\mathrm{NH}_{3}$ & $\mathrm{mg} \mathrm{L}^{-1}$ & 5 & --- \\
\hline As & $\mathrm{mg} \mathrm{L}^{-1}$ & 0,5 & 0,2 \\
\hline $\mathrm{Ba}$ & $\mathrm{mg} \mathrm{L}^{-1}$ & 5,0 & 5,0 \\
\hline B & $\mathrm{mg} \mathrm{L}^{-1}$ & 5,0 & 5,0 \\
\hline $\mathrm{Cd}$ & $\mathrm{mg} \mathrm{L}^{-1}$ & 0,2 & 0,2 \\
\hline $\mathrm{CN}$ & $\mathrm{mg} \mathrm{L}^{-1}$ & 0,2 & 0,2 \\
\hline $\mathrm{Pb}$ & $\mathrm{mg} \mathrm{L}^{-1}$ & 0,5 & 0,5 \\
\hline $\mathrm{Cu}$ & $\mathrm{mg} \mathrm{L}^{-1}$ & 1,0 & 1,0 \\
\hline $\mathrm{Cr}^{+3}$ & $\mathrm{mg} \mathrm{L}^{-1}$ & 2,0 & --- \\
\hline $\mathrm{Cr}^{+6}$ & $\mathrm{mg} \mathrm{L}^{-1}$ & 0,5 & 0,1 \\
\hline Cr Total & $\mathrm{mg} \mathrm{L}^{-1}$ & ---- & 5,0 \\
\hline Sn & $\mathrm{mg} \mathrm{L}^{-1}$ & 4 & 4 \\
\hline Fenóis & $\mathrm{mg} \mathrm{L}^{-1}$ & 0,5 & 0,5 \\
\hline $\mathrm{Fe}^{+2}$ & $\mathrm{mg} \mathrm{L}^{-1}$ & 15 & 15 \\
\hline Fluoreto & $\mathrm{mg} \mathrm{L}^{-1}$ & 10 & 10 \\
\hline $\mathrm{Mn}^{+2}$ & $\mathrm{mg} \mathrm{L}^{-1}$ & 1,0 & 1,0 \\
\hline $\mathrm{Hg}$ & $\mathrm{mg} \mathrm{L}^{-1}$ & 0,01 & 0,01 \\
\hline $\mathrm{Ni}$ & $\mathrm{mg} \mathrm{L}^{-1}$ & 2,0 & 2,0 \\
\hline $\mathrm{Ag}$ & $\mathrm{mg} \mathrm{L}^{-1}$ & 0,1 & 0,02 \\
\hline $\mathrm{Se}$ & $\mathrm{mg} \mathrm{L}^{-1}$ & 0,05 & 0,02 \\
\hline$S^{-2}$ & $\mathrm{mg} \mathrm{L}^{-1}$ & 1 & -- \\
\hline $\mathrm{SO}_{3}^{-}$ & $\mathrm{mg} \mathrm{L}^{-1}$ & 1 & ---- \\
\hline $\mathrm{Zn}$ & $\mathrm{mg} \mathrm{L}^{-1}$ & 5 & 5 \\
\hline Organofosforados e carbamatos & $\mathrm{mg} \mathrm{L}^{-1}$ & 1 & --- \\
\hline Sulfeto de carbono & $\mathrm{mg} \mathrm{L}^{-1}$ & 1 & --- \\
\hline Tricloroeteno & $\mathrm{mg} \mathrm{L}^{-1}$ & 1 & --- \\
\hline Clorofórmio & $\mathrm{mg} \mathrm{L}^{-1}$ & 1 & --- \\
\hline Dicloroeteno & $\mathrm{mg} \mathrm{L}^{-1}$ & 1 & ----- \\
\hline Organoclorados & $\mathrm{mg} \mathrm{L}^{-1}$ & 0,05 & ---- \\
\hline
\end{tabular}

Para o caso da Legislação Ambiental Colombiana as normas gerais para a proteção da saúde humana agrupam-se dentro do Código de Saneamento Nacional (Lei 09 
de 1979), as quais contêm todos os padrões que visam proteger a saúde da comunidade, mantendo uma estreita relação com o meio ambiente. O Titulo I trata o relacionado com a proteção do meio ambiente, especificamente com a emissão de efluentes líquidos e resíduos sólidos.

A partir da Lei 99 de 1993, a entidade que regulamenta a emissão dos efluentes líquidos é o Ministério do Meio Ambiente, esta Lei confere ao Ministério a função de estabelecer os limites máximos de descarga de poluentes à água.

$\mathrm{Na}$ atualidade e por disposição do Ministério do Meio Ambiente, continuam vigentes os padrões de emissão exigidos no Decreto 1594 de 1984 do Ministério de Saúde, pelo qual se regulamentam parcialmente o Título I da Lei 09 de 1979, o Capítulo II do Título VI - Parte III - Livro II e o Título III da Parte III - Livro I do Decreto-Lei 2811 de 1974, relacionado a usos da água e resíduos líquidos. Para descarte a redes de esgotos (EMCALI, 2001). Os dados do Decreto 1594 de 1984 que estabelecem os padrões de emissão são apresentados a seguir.

A Tabela 38 mostra os limites a que estão submetidos os efluentes a serem lançados nos corpos d'água.

Tabela 38 - Limites de emissão para os efluentes lançados nos corpos de água, conforme o Decreto 1594 de 1984

\begin{tabular}{llll}
\hline \multicolumn{1}{c}{ Parâmetro } & Unidade & $\begin{array}{c}\text { Usuário } \\
\text { Existente }\end{array}$ & \multicolumn{1}{c}{ Usuário Novo } \\
\hline Temperatura & ${ }^{\circ} \mathrm{C}$ & $<40$ & $<40$ \\
$\mathrm{PH}$ & & 5 a 9 & $5 \mathrm{a} 9$ \\
Materiais flutuantes & ----- & Ausentes & Ausentes \\
OG & $\mathrm{mg} \mathrm{L}^{-1}$ & $>80 \%$ en carga & $>80 \%$ en carga \\
Sólidos em suspensão industriais & $\mathrm{mg} \mathrm{L}^{-1}$ & $>50 \%$ en carga & $>80 \%$ en carga \\
$D B O_{5,20}$ esgotos domésticos & $\mathrm{mg} \mathrm{L}^{-1}$ & $>30 \%$ en carga & $>80 \%$ en carga \\
$D B O_{5,20}$ esgotos industriais & $\mathrm{mg} \mathrm{L}^{-1}$ & $>20 \%$ en carga & $>80 \%$ en carga \\
\hline
\end{tabular}

A Tabela 39 mostra os limites aos quais estão submetidos os efluentes a serem lançados nas redes de esgotos. 
Tabela 39 - Limites de emissão para os efluentes lançados nas redes de esgotos, conforme o Decreto 1594 de 1984

\begin{tabular}{llll}
\hline \multicolumn{1}{c}{ Parâmetro } & Unidade & $\begin{array}{c}\text { Usuário } \\
\text { Existente }\end{array}$ & \multicolumn{1}{c}{ Usuário Novo } \\
\hline Vazão & ------ & $<1,5^{*} Q_{\text {media }}$ & $<1,5^{*} Q_{\text {media }}$ \\
Temperatura & ${ }^{\circ} \mathrm{C}$ & $<40$ & $<40$ \\
$\mathrm{PH}$ & & 5 a 9 & 5 a 9 \\
Acidos, bases, sust. Inflamáveis & ---- & Ausentes & Ausentes \\
Sólidos sedimentáveis & $\mathrm{ml} \mathrm{L}^{-1}$ & 10 & 10 \\
Substâncias solúveis em hexano & $\mathrm{mg} \mathrm{L}^{-1}$ & 100 & 100 \\
Sólidos em suspensão industriais & $\mathrm{mg} \mathrm{L}^{-1}$ & $>50 \%$ en carga & $>80 \%$ en carga \\
Sólidos em suspensão domésticos & $\mathrm{mg} \mathrm{L}^{-1}$ & $>50 \%$ en carga & $>80 \%$ en carga \\
$D B O_{5,20}$ rejeitos industriais & $\mathrm{mg} \mathrm{L}^{-1}$ & $>20 \%$ en carga & $>80 \%$ en carga \\
\hline
\end{tabular}

A Tabela 40 mostra as concentrações para o controle das substâncias de interesse no saneamento.

Tabela 40 - Limites de emissão conforme o Decreto 1594 de 1984

\begin{tabular}{|c|c|c|}
\hline Parâmetro & Unidade & Concentração \\
\hline As & $\mathrm{mg} \mathrm{L}^{-1}$ & 0,5 \\
\hline $\mathrm{Ba}$ & $\mathrm{mg} \mathrm{L}^{-1}$ & 5,0 \\
\hline $\mathrm{Cd}$ & $\mathrm{mg} \mathrm{L}^{-1}$ & 0,1 \\
\hline $\mathrm{CN}$ & $\mathrm{mg} \mathrm{L}^{-1}$ & 1,0 \\
\hline $\mathrm{Pb}$ & $\mathrm{mg} \mathrm{L}^{-1}$ & 0,5 \\
\hline $\mathrm{Cu}$ & $\mathrm{mg} \mathrm{L}^{-1}$ & 3,0 \\
\hline $\mathrm{Cr}^{+6}$ & $\mathrm{mg} \mathrm{L}^{-1}$ & 0,5 \\
\hline Fenóis & $\mathrm{mg} \mathrm{L}^{-1}$ & 0,2 \\
\hline $\mathrm{Hg}$ & $\mathrm{mg} \mathrm{L}^{-1}$ & 0,02 \\
\hline $\mathrm{Ni}$ & $\mathrm{mg} \mathrm{L}^{-1}$ & 2,0 \\
\hline $\mathrm{Ag}$ & $\mathrm{mg} \mathrm{L}^{-1}$ & 0,5 \\
\hline $\mathrm{Se}$ & $\mathrm{mg} \mathrm{L}^{-1}$ & 0,5 \\
\hline Clorofórmio extracto carbono & $\mathrm{mg} \mathrm{L}^{-1}$ & ----- \\
\hline Tetra cloruro de carbono & $\mathrm{mg} \mathrm{L}^{-1}$ & 1,0 \\
\hline Tricloroeteno & $\mathrm{mg} \mathrm{L}^{-1}$ & 1,0 \\
\hline Clorofórmio & $\mathrm{mg} \mathrm{L}^{-1}$ & 1,0 \\
\hline Mercúrio orgânico Hg & $\mathrm{mg} \mathrm{L}^{-1}$ & ---- \\
\hline Difenil policlorados & $\mathrm{mg} \mathrm{L}^{-1}$ & ----- \\
\hline
\end{tabular}




\section{ANEXO C - MEMORIAL DE CÁLCULO - Da ETE BARUERI, Sistema RAFA - Lagoa Facultativa e da ETE Cañaveralejo}

Tabela 41 - Cálculo da exergia associada à vazão afluente do RAFA

\begin{tabular}{|c|c|c|c|c|c|c|c|}
\hline $\begin{array}{l}\text { Espécie } \\
\text { química }\end{array}$ & Afluente $\left(\mathrm{molL}^{-1}\right)$ & $\begin{array}{c}x_{i} \\
\left(\mathrm{molmol}^{-1}\right)\end{array}$ & $\begin{array}{c}\text { Exergia } \\
\text { química } \\
\text { específica } \\
\left(\mathrm{kJmol}^{-1}\right)\end{array}$ & $\begin{array}{c}\sum_{i}\left(\mu_{i}-\mu_{0, i}\right) n_{i} \\
\left(\mathbf{k J m o l}^{-1}\right)\end{array}$ & $\begin{array}{c}R T_{0} \sum_{i} n_{i} \ln \left(a_{i}\right) \\
\left(\mathbf{k J m o l}^{-1}\right)\end{array}$ & $\begin{array}{c}\text { Exergia } \\
\text { química } \\
\text { molar na } \\
\text { mistura } \\
\left(\mathrm{kJmol}^{-1}\right)\end{array}$ & $\begin{array}{c}\text { Exergia } \\
\text { química } \\
\text { específica } \\
\left(\mathrm{kJL}^{-1}\right)\end{array}$ \\
\hline$\overline{\mathrm{DQO}}$ & 0,003340000 & 0,2580000 & 2721,4 & 703,00000 & $-3,650000$ & 700,000000 & 2.3400 \\
\hline $\mathrm{CaCO}_{3}$ & 0,005880000 & 0,4540000 & 1 & 0,455000 & $-7,000000$ & -6.550000 & $-0,0134^{*}$ \\
\hline $\mathrm{NO}_{2}$ & 0,000000147 & 0,0000114 & 55,6 & 0,000634 & $-0,000444$ & 0,000189 & $2,79 \mathrm{E}-11$ \\
\hline $\mathrm{Cl}$ & 0,001770000 & 0,1370000 & 87,1 & 11,900000 & $-2,150000$ & 9,760000 & 0,0172 \\
\hline $\mathrm{SO}_{4}$ & 0,001940000 & 0,1500000 & 184,8 & 27,700000 & $-2,330000$ & 25,400000 & 0,0492 \\
\hline TOTAL & 0,012900000 & 1,0000000 & & 743,00000 & $-15,100000$ & 728,000000 & 2,3900 \\
\hline
\end{tabular}

* O valor negativo da exergia é devido a arredondamento

Os cálculos apresentados nas Tabelas 41 à 49 foram realizados de acordo à metodologia apresentada no capitulo 6.

Tabela 42 - Cálculo da exergia associada à vazão efluente da Lagoa Facultativa

\begin{tabular}{|c|c|c|c|c|c|c|c|}
\hline $\begin{array}{l}\text { Espécie } \\
\text { química }\end{array}$ & $\begin{array}{c}\text { Efluente } \\
\left(\text { molL }^{-1}\right)\end{array}$ & $\begin{array}{c}x_{i} \\
\left(\mathrm{molmol}^{-1}\right)\end{array}$ & $\begin{array}{l}\text { Exergia } \\
\text { química } \\
\text { específica } \\
\left(\mathrm{kJmol}^{-1}\right)\end{array}$ & $\begin{array}{c}\sum_{i}\left(\mu_{i}-\mu_{0, i}\right) n_{i} \\
\left(\mathbf{k J m o l}^{-\mathbf{1}}\right)\end{array}$ & $\begin{array}{c}R T_{0} \sum_{i} n_{i} \ln \left(a_{i}\right) \\
\left(\mathbf{k J m o l}^{-1}\right)\end{array}$ & $\begin{array}{l}\text { Exergia } \\
\text { química molar } \\
\text { na mistura } \\
\left(\mathrm{kJmol}^{-1}\right)\end{array}$ & $\begin{array}{c}\text { Exergia } \\
\text { química } \\
\text { específica } \\
\left(\mathrm{kJL}^{-1}\right)\end{array}$ \\
\hline$\overline{\mathrm{DQO}}$ & 0,001088100 & 0,1330250 & 2720,0 & 361,831400 & $-2,25004$ & 359,58130 & 0,39126 \\
\hline $\mathrm{CaCO}_{3}$ & 0,005474000 & 0,6692190 & 1 & 0,6692190 & $-10,42140$ & $-9,75216$ & $-0,01850^{*}$ \\
\hline $\mathrm{NO}_{2}$ & 0,000000792 & 0,0000968 & 55,6 & 0,0053820 & $-0,00337$ & 0,00201 & 1,59E-09 \\
\hline $\mathrm{Cl}$ & 0,001616788 & 0,1976590 & 87,1 & 17,2161100 & $-3,15072$ & 14,06539 & 0,02274 \\
\hline TOTAL & 0,008179680 & 1,0000000 & & 379,7221000 & $-15,8255$ & 363,89660 & 0,39550 \\
\hline
\end{tabular}


Tabela 43 - Cálculo da exergia associada à vazão afluente da ETE Barueri

\begin{tabular}{|c|c|c|c|c|c|c|c|}
\hline $\begin{array}{l}\text { Espécie } \\
\text { química }\end{array}$ & Afluente $\left(\mathrm{molL}^{-1}\right)$ & $\begin{array}{c}x_{i} \\
\left(\mathrm{molmol}^{-1}\right)\end{array}$ & $\begin{array}{c}\text { Exergia } \\
\text { química } \\
\text { específica } \\
\left(\mathrm{kJmol}^{-1}\right)\end{array}$ & $\begin{array}{c}\sum_{i}\left(\mu_{i}-\mu_{0, i}\right) n_{i} \\
\left(\mathbf{k J m o l}{ }^{-1}\right)\end{array}$ & $\begin{array}{c}R T_{0} \sum_{i} n_{i} \ln \left(a_{i}\right) \\
\left(\mathbf{k J m o l}^{-\mathbf{1}}\right)\end{array}$ & $\begin{array}{c}\text { Exergia } \\
\text { química } \\
\text { molar na } \\
\text { mistura } \\
\left(\mathrm{kJmol}^{-1}\right)\end{array}$ & $\begin{array}{c}\text { Exergia } \\
\text { química } \\
\text { específica } \\
\left(\mathrm{kJL}^{-1}\right)\end{array}$ \\
\hline$\overline{\mathrm{DQO}}$ & 0,0023000000 & 0,4270000 & 2708,2 & 1160,0000 & $-6,430000$ & 1150,000 & 2,6400000 \\
\hline $\mathrm{NH}_{3}$ & 0,0018400000 & 0,3410000 & 337,9 & 115,00000 & $-5,320000$ & 110,0000 & 0,2010000 \\
\hline $\mathrm{NO}_{3}$ & 0,0000024200 & 0,0004490 & 22,3 & 0,01000 & $-0,014400$ & $-0,00438$ & $-1,06 \mathrm{E}-08^{*}$ \\
\hline $\mathrm{NO}_{2}$ & 0,0000002010 & 0,0000373 & 55,6 & 0,00207 & $-0,001430$ & 0,000648 & $1,30 \mathrm{E}-10$ \\
\hline $\mathrm{S}_{2}$ & 0,0000160000 & 0,0029700 & 1219,2 & 3,62000 & $-0,081300$ & 3,540000 & 0,0000566 \\
\hline $\mathrm{SO}_{4}$ & 0,0004530000 & 0,0841000 & 184,8 & 15,50000 & $-1,610000$ & 13,90000 & 0,0063100 \\
\hline Cádmio & 0,0000000623 & 0,0000116 & 293,5 & 0,00339 & $-0,000476$ & 0,002920 & $1,82 \mathrm{E}-10$ \\
\hline Níquel & 0,0000012100 & 0,0002250 & 232,7 & 0,05230 & $-0,007590$ & 0,044700 & $5,40 \mathrm{E}-08$ \\
\hline Prata & 0,0000001110 & 0,0000206 & 70,2 & 0,00145 & $-0,000818$ & 0,000628 & $6,97 \mathrm{E}-11$ \\
\hline Zinco & 0,0000067300 & 0,0012500 & 339,2 & 0,42400 & $-0,036900$ & 0,387000 & 0,0000026 \\
\hline Manganês & 0,0000017000 & 0,0003160 & 482,3 & 0,15200 & $-0,010400$ & 0,142000 & 0,0000002 \\
\hline Molibdênio & 0,0000002080 & 0,0000386 & 730,3 & 0,02820 & $-0,001480$ & 0,026700 & 5,56E-09 \\
\hline Chumbo & 0,0000001260 & 0,0000234 & 232,8 & 0,00544 & $-0,000921$ & 0,004520 & $5,70 \mathrm{E}-10$ \\
\hline Cobre & 0,0000014200 & 0,0002640 & 134,2 & 0,03540 & $-0,008800$ & 0,026600 & 3,77E-08 \\
\hline Cromo $\mathrm{T}$. & 0,0000024000 & 0,0004450 & 544,3 & 0,24200 & $-0,014300$ & 0,228000 & 0,0000005 \\
\hline Ferro & 0,0000591000 & 0,0110000 & 376,4 & 4,13000 & $-0,265000$ & 3,860000 & 0,0002280 \\
\hline Fenol & 0,0000023400 & 0,0004340 & 3128,5 & 1,36000 & $-0,014000$ & 1,340000 & 0,0000031 \\
\hline Fósforo & 0,0001650000 & 0,0306000 & 869,7 & 26,600000 & $-0,663000$ & 26,00000 & 0,0042800 \\
\hline Surfactante & 0,0005400000 & 0,1000000 & 74,9 & 7,51000 & $-1,870000$ & 5,640000 & 0,0030400 \\
\hline Estanho & 0,0000012000 & 0,0002230 & 544,9 & 0,12100 & $-0,007540$ & 0,114000 & 0,0000001 \\
\hline TOTAL & 0,0053900000 & 1,0000000 & & 1330,0000 & $-16,400000$ & 1310,000 & 2,8600000 \\
\hline
\end{tabular}

* O valor negativo da exergia é devido a arredondamento 
Tabela 44 - Cálculo da exergia associada à vazão efluente da ETE Barueri

\begin{tabular}{|c|c|c|c|c|c|c|c|}
\hline $\begin{array}{l}\text { Espécie } \\
\text { química }\end{array}$ & Efluente $\left(\mathrm{molL}^{-1}\right)$ & $\begin{array}{c}x_{i} \\
\left(\mathrm{molmol}^{-1}\right)\end{array}$ & $\begin{array}{c}\text { Exergia } \\
\text { química } \\
\text { específica } \\
\left(\mathrm{KJmol}^{-1}\right)\end{array}$ & $\begin{array}{c}\sum_{i}\left(\mu_{i}-\mu_{0, i}\right) n_{i} \\
\left(\mathbf{k J m o l}{ }^{-1}\right)\end{array}$ & $\begin{array}{c}R T_{0} \sum_{i} n_{i} \ln \left(a_{i}\right) \\
\left(\mathbf{k J m o l}^{-\mathbf{1}}\right)\end{array}$ & $\begin{array}{c}\text { Exergia } \\
\text { química } \\
\text { molar na } \\
\text { mistura } \\
\left(\mathrm{kJmol}^{-1}\right)\end{array}$ & $\begin{array}{c}\text { Exergia } \\
\text { química } \\
\text { específica } \\
\left(\mathrm{kJL}^{-1}\right)\end{array}$ \\
\hline$\overline{\mathrm{DQO}}$ & 0,0003010000 & 0,2050000 & 2720 & 558,00000 & $-4,12000$ & 554,00000 & 0,1660000 \\
\hline $\mathrm{NH}_{3}$ & 0,0005800000 & 0,3960000 & 337,9 & 134,00000 & $-7,31000$ & 126,0000 & 0,0733000 \\
\hline $\mathrm{NO}_{3}$ & 0,0001110000 & 0,0757000 & 22,3 & 1,69000 & $-1,71000$ & $-0,02110$ & $-0,000002^{*}$ \\
\hline $\mathrm{NO}_{2}$ & 0,0000035000 & 0,0023900 & 55,6 & 0,13300 & $-0,07440$ & 0,05840 & 0,0000002 \\
\hline $\mathrm{S}_{2}$ & 0,0000160000 & 0,0109000 & 1219,2 & 13,30000 & $-0,29900$ & 13,00000 & 0,0002080 \\
\hline $\mathrm{SO}_{4}$ & 0,0003300000 & 0,2250000 & 184,8 & 41,60000 & $-4,48000$ & 37,10000 & 0,0123000 \\
\hline Cádmio & 0,0000000400 & 0,0000273 & 293,5 & 0,00802 & $-0,00115$ & 0,00686 & $2,75 E-10$ \\
\hline Níquel & 0,0000006810 & 0,0004650 & 232,7 & 0,10800 & $-0,01640$ & 0,09180 & $6,25 E-08$ \\
\hline Prata & 0,0000000371 & 0,0000253 & 70,2 & 0,00178 & $-0,00107$ & 0,000703 & $2,61 \mathrm{E}-11$ \\
\hline Zinco & 0,0000016200 & 0,0011100 & 339,2 & 0,37500 & $-0,03650$ & 0,33800 & 0,0000005 \\
\hline Manganês & 0,0000013000 & 0,0008870 & 482,3 & 0,42800 & $-0,02980$ & 0,39800 & 0,0000005 \\
\hline Molibdênio & 0,0000002080 & 0,0001420 & 730,3 & 0,10400 & $-0,00542$ & 0,09820 & $2,04 \mathrm{E}-08$ \\
\hline Chumbo & 0,0000000740 & 0,0000505 & 232,8 & 0,01180 & $-0,00206$ & 0,00970 & $7,18 \mathrm{E}-10$ \\
\hline Cobre & 0,0000002720 & 0,0001860 & 134,2 & 0,02490 & $-0,00695$ & 0,01790 & 4,88E-09 \\
\hline Cromo $\mathrm{T}$. & 0,0000006150 & 0,0004200 & 544,3 & 0,22800 & $-0,01490$ & 0,21300 & 0,0000001 \\
\hline Ferro & 0,0000084300 & 0,0057500 & 376,4 & 2,16000 & $-0,16700$ & 2,00000 & 0,0000168 \\
\hline Fenol & 0,0000003610 & 0,0002460 & 3128,5 & 0,77100 & $-0,00906$ & 0,76100 & 0,0000002 \\
\hline Fósforo & 0,0000775000 & 0,0529000 & 869,7 & 46,00000 & $-1,24000$ & 44,70000 & 0,0034700 \\
\hline Surfactante & 0,0000325000 & 0,0222000 & 74,9 & 1,66000 & $-0,56800$ & 1,09000 & 0,0000355 \\
\hline Estanho & 0,0000011000 & 0,0007500 & 544,9 & 0,40900 & $-0,02560$ & 0,38300 & 0,0000004 \\
\hline TOTAL & 0,0014700000 & 1,0000000 & & 800,00000 & $-20,10000$ & 780,0000 & 0,2560000 \\
\hline
\end{tabular}

* O valor negativo da exergia é devido a arredondamento 
Tabela 45 - Cálculo da exergia associada à vazão afluente da ETE Cañaveralejo

\begin{tabular}{|c|c|c|c|c|c|c|c|}
\hline $\begin{array}{l}\text { Espécie } \\
\text { química }\end{array}$ & Afluente $\left(\mathrm{molL}^{-1}\right)$ & $\begin{array}{c}x_{i} \\
\left(\mathrm{molmol}^{-1}\right)\end{array}$ & $\begin{array}{c}\text { Exergia } \\
\text { química } \\
\text { específica } \\
\left(\mathrm{kJmol}^{-1}\right)\end{array}$ & $\begin{array}{c}\sum_{i}\left(\mu_{i}-\mu_{0, i}\right) n_{i} \\
\left(\mathbf{k J m o l}^{-\mathbf{1}}\right)\end{array}$ & $\begin{array}{c}R T_{0} \sum_{i} n_{i} \ln \left(a_{i}\right) \\
\left(\mathbf{k J m o l}^{-\mathbf{1}}\right)\end{array}$ & $\begin{array}{c}\text { Exergia } \\
\text { química } \\
\text { molar na } \\
\text { mistura } \\
\left(\mathrm{kJmol}^{-1}\right)\end{array}$ & $\begin{array}{c}\text { Exergia } \\
\text { química } \\
\text { específica } \\
\left(\mathrm{kJL}^{-1}\right)\end{array}$ \\
\hline$\overline{\mathrm{DQO}}$ & 0,0022000000 & 0,3650000 & 2720,0 & 994,00000 & $-5,540000$ & 988,0000 & 2,1800000 \\
\hline $\mathrm{CaCO}_{3}$ & 0,0019300000 & 0,3190000 & 1,0 & 0,3190000 & $-5,250000$ & $-4,930000$ & $-0,0070700^{*}$ \\
\hline $\mathrm{Cl}$ & 0,0015100000 & 0,2500000 & 87,1 & 21,800000 & $-4,030000$ & 17,80000 & 0,0269000 \\
\hline Cádmio & 0,0000000567 & 0,0000094 & 293,5 & 0,00276 & $-0,000389$ & 0,002370 & $1,34 \mathrm{E}-10$ \\
\hline Níquel & 0,0000007860 & 0,0001300 & 232,7 & 0,03030 & $-0,004540$ & 0,025800 & 2,02E-08 \\
\hline Prata & 0,0000001110 & 0,0000184 & 70,2 & 0,00129 & $-0,000732$ & 0,000562 & $6,26 \mathrm{E}-11$ \\
\hline Zinco & 0,0000025600 & 0,0004240 & 339,2 & 0,14400 & $-0,013500$ & 0,130000 & 0,0000003 \\
\hline Chumbo & 0,0000005310 & 0,0000880 & 232,8 & 0,02050 & $-0,003150$ & 0,017300 & 9,20E-09 \\
\hline Cobre & 0,0000004640 & 0,0000769 & 134,2 & 0,01030 & $-0,002780$ & 0,007540 & 3,50E-09 \\
\hline Cromo $\mathrm{T}$. & 0,0000011600 & 0,0001920 & 544,3 & 0,10400 & $-0,006500$ & 0,097800 & 0,0000001 \\
\hline Ferro & 0,0000495000 & 0,0082100 & 376,4 & 3,09000 & $-0,202000$ & 2,890000 & 0,0001430 \\
\hline Fenol & 0,0000004000 & 0,0000662 & 3128,5 & 0,20700 & $-0,002420$ & 0,205000 & $8,18 \mathrm{E}-08$ \\
\hline Fósforo & 0,0001760000 & 0,0292000 & 869,7 & 25,400000 & $-0,629000$ & 24,80000 & 0,0043700 \\
\hline Surfactante & 0,0001620000 & 0,0268000 & 74,9 & 2,01000 & $-0,581000$ & 1,430000 & 0,0002320 \\
\hline Mercúrio & $8,47 E-10$ & 0,0000001 & 115,9 & 0,00002 & $-0,000007$ & 0,000009 & $7,63 \mathrm{E}-15$ \\
\hline TOTAL & 0,0060300000 & 1,0000000 & & 1050,0000 & $-16,300000$ & 1030,000 & 2,2000000 \\
\hline
\end{tabular}

* O valor negativo da exergia é devido a arredondamento 
Tabela 46 - Cálculo da exergia associada à vazão efluente da ETE Cañaveralejo

\begin{tabular}{|c|c|c|c|c|c|c|c|}
\hline $\begin{array}{l}\text { Espécie } \\
\text { química }\end{array}$ & Efluente $\left(\mathrm{molL}^{-1}\right)$ & $\begin{array}{c}x_{i} \\
\left(\mathrm{molmol}^{-1}\right)\end{array}$ & $\begin{array}{c}\text { Exergia } \\
\text { química } \\
\text { específica } \\
\left(\mathrm{kJmol}^{-1}\right)\end{array}$ & $\begin{array}{c}\sum_{i}\left(\mu_{i}-\mu_{0, i}\right) n_{i} \\
\left(\mathbf{k J m o l}^{-\mathbf{1}}\right)\end{array}$ & $\begin{array}{c}R T_{0} \sum_{i} n_{i} \ln \left(a_{i}\right) \\
\left(\mathbf{k J m o l}^{-\mathbf{1}}\right)\end{array}$ & $\begin{array}{c}\text { Exergia } \\
\text { química } \\
\text { molar na } \\
\text { mistura } \\
\left(\mathrm{kJmol}^{-1}\right)\end{array}$ & $\begin{array}{c}\text { Exergia } \\
\text { química } \\
\text { específica } \\
\left(\mathrm{kJL}^{-1}\right)\end{array}$ \\
\hline$\overline{D Q O}$ & 0,0013900000 & 0,2730000 & 2716,1 & 742,00000 & $-4,460000$ & 738,0000 & 1,0200000 \\
\hline $\mathrm{CaCO}_{3}$ & 0,0018600000 & 0,3660000 & 1,0 & 0,36600 & $-6,010000$ & $-5,640000$ & $-0,008290^{*}$ \\
\hline $\mathrm{Cl}$ & 0,0015200000 & 0,3000000 & 87,1 & 26,10000 & $-4,830000$ & 21,30000 & 0,0325000 \\
\hline Cádmio & 0,0000000534 & 0,0000105 & 293,5 & 0,00309 & $-0,000440$ & 0,00265 & $1,41 \mathrm{E}-10$ \\
\hline Níquel & 0,0000006010 & 0,0001190 & 232,7 & 0,02760 & $-0,004210$ & 0,02340 & $1,41 \mathrm{E}-08$ \\
\hline Prata & 0,0000001110 & 0,0000219 & 70,2 & 0,00154 & $-0,000870$ & 0,00067 & $7,44 \mathrm{E}-11$ \\
\hline Zinco & 0,0000012400 & 0,0002440 & 339,2 & 0,08280 & $-0,008230$ & 0,07460 & $9,24 \mathrm{E}-08$ \\
\hline Chumbo & 0,0000005310 & 0,0001050 & 232,8 & 0,02440 & $-0,003750$ & 0,02060 & 1,09E-08 \\
\hline Cobre & 0,0000002360 & 0,0000465 & 134,2 & 0,00624 & $-0,001760$ & 0,00448 & 1,06E-09 \\
\hline Cromo $\mathrm{T}$. & 0,0000009140 & 0,0001800 & 544,3 & 0,09800 & $-0,006210$ & 0,09180 & 8,39E-08 \\
\hline Ferro & 0,0000485000 & 0,0095600 & 376,4 & 3,60000 & $-0,236000$ & 3,36000 & 0,0001630 \\
\hline Fenol & 0,0000001490 & 0,0000293 & 3128,5 & 0,09170 & $-0,001140$ & 0,09060 & $1,35 \mathrm{E}-08$ \\
\hline Fósforo & 0,0001290000 & 0,0254000 & 869,7 & 22,10000 & $-0,567000$ & 21,60000 & 0,0027800 \\
\hline Surfactante & 0,0001250000 & 0,0246000 & 74,9 & 1,84000 & $-0,549000$ & 1,30000 & 0,0001620 \\
\hline Mercúrio & 8,47E-10 & 0,0000002 & 115,9 & 0,00002 & $-0,000009$ & 0,00001 & $9,07 E-15$ \\
\hline TOTAL & 0,0050700000 & 1,0000000 & & 797,00000 & $-16,70000$ & 780,0000 & 1,0500000 \\
\hline
\end{tabular}

* O valor negativo da exergia é devido a arredondamento 
Tabela 47 - Cálculo da exergia associada ao lodo desaguado produzido no Rafa

\begin{tabular}{|c|c|c|c|c|c|c|c|}
\hline $\begin{array}{l}\text { Espécie } \\
\text { química }\end{array}$ & $\begin{array}{l}\text { Lodo gerado } \\
\qquad\left(\mathrm{molkg}^{-1}\right)\end{array}$ & $\begin{array}{c}x_{i} \\
\left(\mathrm{molmol}^{-1}\right)\end{array}$ & $\begin{array}{c}\text { Exergia } \\
\text { química } \\
\text { específica } \\
\left(\mathrm{kJmol}^{-1}\right)\end{array}$ & $\begin{array}{c}\sum_{i}\left(\mu_{i}-\mu_{0, i}\right) n_{i} \\
\left(\mathbf{k J m o l}^{-1}\right)\end{array}$ & $\begin{array}{c}R T_{0} \sum_{i} n_{i} \ln \left(a_{i}\right) \\
\left(\mathbf{k J m o l}^{-1}\right)\end{array}$ & $\begin{array}{c}\text { Exergia } \\
\text { química } \\
\text { molar na } \\
\text { mistura } \\
\left(\mathrm{kJmol}^{-1}\right)\end{array}$ & $\begin{array}{c}\text { Exergia } \\
\text { química } \\
\text { específica } \\
\left(\mathrm{kJkg}^{-1}\right)\end{array}$ \\
\hline DQO & 0,4163150 & 0,9360000 & 2720 & 2550 & $-0,15300$ & 2550 & 1060 \\
\hline $\mathrm{Ca}$ & 0,0001100 & 0,0002470 & 712,14 & 0,176 & $-0,00509$ & 0,17100 & 0,0000188 \\
\hline $\mathrm{Mg}$ & 0,0000381 & 0,0000857 & 633,8 & 0,054 & $-0,00199$ & 0,05230 & 0,0000020 \\
\hline $\mathrm{K}$ & 0,0003990 & 0,0008970 & 366,6 & 0,329 & $-0,01560$ & 0,31300 & 0,0001250 \\
\hline $\mathrm{Na}$ & 0,0010200 & 0,0022900 & 336,6 & 0,772 & $-0,03460$ & 0,73700 & 0,0007520 \\
\hline$P$ & 0,0056200 & 0,0126000 & 875,8 & 11 & $-0,13700$ & 10,9000 & 0,0610000 \\
\hline B & 0,0001320 & 0,0002970 & 628,5 & 0,187 & $-0,00598$ & 0,18100 & 0,0000238 \\
\hline $\mathrm{Cu}$ & 0,0046800 & 0,0105000 & 134,2 & 1,410 & $-0,11900$ & 1,29000 & 0,0060500 \\
\hline $\mathrm{Zn}$ & 0,0053700 & 0,0121000 & 339,2 & 4,100 & $-0,13200$ & 3,96000 & 0,0213000 \\
\hline $\mathrm{Mn}$ & 0,0032000 & 0,0071900 & 482,3 & 3,470 & $-0,08800$ & 3,38000 & 0,0108000 \\
\hline Fé & 0,0078900 & 0,0177000 & 376,4 & 6,680 & $-0,17700$ & 6,50000 & 0,0513000 \\
\hline TOTAL & 0,4450000 & 1,0000000 & & 2578,178 & $-0,87000$ & 2577,48 & 1060,152 \\
\hline
\end{tabular}

Tabela 48 - Cálculo da exergia associada ao lodo desaguado produzido na ETE Barueri

\begin{tabular}{|c|c|c|c|c|c|c|c|}
\hline $\begin{array}{l}\text { Espécie } \\
\text { química }\end{array}$ & $\begin{array}{c}\text { Lodo } \\
\text { gerado } \\
\left(\text { molkg }^{-1}\right)\end{array}$ & $\begin{array}{c}x_{i} \\
\left(\mathrm{molmol}^{-1}\right)\end{array}$ & $\begin{array}{c}\text { Exergia } \\
\text { química } \\
\text { específica } \\
\left(\mathrm{kJmol}^{-1}\right)\end{array}$ & $\begin{array}{c}\sum_{i}\left(\mu_{i}-\mu_{0, i}\right) n_{i} \\
\left(\mathbf{k J m o l}^{-1}\right)\end{array}$ & $\begin{array}{c}R T_{0} \sum_{i} n_{i} \ln \left(a_{i}\right) \\
\left(\mathbf{k J m o l}^{-1}\right)\end{array}$ & $\begin{array}{c}\text { Exergia } \\
\text { química } \\
\text { molar na } \\
\text { mistura } \\
\left(\mathrm{kJmol}^{-1}\right)\end{array}$ & $\begin{array}{c}\text { Exergia } \\
\text { química } \\
\text { específica } \\
\left(\mathrm{kJkg}^{-1}\right)\end{array}$ \\
\hline$\overline{\mathrm{DQO}}$ & 0,11400 & 0,145000 & 2720 & 394,0000 & $-0,694000$ & 394,0000 & 44,8000000 \\
\hline Cádmio & 0,00013 & 0,000166 & 293,5 & 0,048600 & $-0,003570$ & 0,045000 & 0,00000585 \\
\hline Níquel & 0,00530 & 0,006750 & 232,7 & 1,570000 & $-0,083600$ & 1,490000 & 0,00788000 \\
\hline Prata & 0,00056 & 0,000713 & 70,2 & 0,050100 & $-0,012800$ & 0,037200 & 0,00002090 \\
\hline Zinco & 0,03540 & 0,045100 & 339,2 & 15,30000 & $-0,346000$ & 14,90000 & 0,52900000 \\
\hline Manganês & 0,00550 & 0,007000 & 482,3 & 3,380000 & $-0,086100$ & 3,290000 & 0,01810000 \\
\hline Chumbo & 0,00097 & 0,001230 & 232,8 & 0,288000 & $-0,020500$ & 0,267000 & 0,00025900 \\
\hline Cobre & 0,00950 & 0,012100 & 134,2 & 1,620000 & $-0,132000$ & 1,490000 & 0,01420000 \\
\hline Cromo & 0,01400 & 0,017800 & 544,3 & 9,700000 & $-0,178000$ & 9,520000 & 0,13300000 \\
\hline Molibdênio & 0,00021 & 0,000267 & 730,3 & 0,195000 & $-0,005450$ & 0,190000 & 0,00003990 \\
\hline Ferro & 0,60000 & 0,764000 & 376,4 & 288,0000 & $-0,510000$ & 287,0000 & 172,000000 \\
\hline TOTAL & 0,78500 & 1,000000 & & 714,0000 & $-2,070000$ & 712,0000 & 218,000000 \\
\hline
\end{tabular}


Tabela 49 - Cálculo da exergia associada ao lodo desaguado produzido na ETE Cañaveralejo

\begin{tabular}{|c|c|c|c|c|c|c|c|}
\hline $\begin{array}{l}\text { Espécie } \\
\text { química }\end{array}$ & $\begin{array}{c}\text { Lodo } \\
\text { gerado } \\
\left(\text { molkg }^{-1}\right)\end{array}$ & $\begin{array}{c}x_{i} \\
\left(\mathrm{molmol}^{-1}\right)\end{array}$ & $\begin{array}{c}\text { Exergia } \\
\text { química } \\
\text { específica } \\
\left(\mathrm{kJmol}^{-1}\right)\end{array}$ & $\begin{array}{c}\sum_{i}\left(\mu_{i}-\mu_{0, i}\right) n_{i} \\
\left(\mathbf{k J m o l}^{-\mathbf{1}} \mathbf{)}\right.\end{array}$ & $\begin{array}{c}R T_{0} \sum_{i} n_{i} \ln \left(a_{i}\right) \\
\left.\mathbf{( k J m o l}^{-1}\right)\end{array}$ & $\begin{array}{c}\text { Exergia } \\
\text { química } \\
\text { molar na } \\
\text { mistura } \\
\left(\mathrm{kJmol}^{-1}\right)\end{array}$ & $\begin{array}{c}\text { Exergia } \\
\text { química } \\
\text { específica } \\
\left(\mathrm{kJkg}^{-1}\right)\end{array}$ \\
\hline Cádmio & 0,000098 & 0,000094 & 293,5 & 0,028300 & $-0,002210$ & 0,026100 & 0,00000255 \\
\hline Níquel & 0,001690 & 0,001670 & 232,7 & 0,388000 & $-0,026400$ & 0,361000 & 0,00061200 \\
\hline Prata & 0,000223 & 0,000219 & 70,2 & 0,015400 & $-0,004570$ & 0,010800 & 0,00000240 \\
\hline Zinco & 0,013800 & 0,013600 & 339,2 & 4,620000 & $-0,145000$ & 4,470000 & 0,06190000 \\
\hline $\mathrm{DQO}$ & 0,173000 & 0,170000 & 2720,0 & 462,0000 & $-0,746000$ & 461,00000 & 79,6000000 \\
\hline Chumbo & 0,001690 & 0,001660 & 232,8 & 0,386000 & $-0,026300$ & 0,360000 & 0,00060600 \\
\hline Cobre & 0,004070 & 0,004010 & 134,2 & 0,538000 & $-0,054800$ & 0,483000 & 0,00197000 \\
\hline Cromo & 0,002160 & 0,002120 & 544,3 & 1,160000 & $-0,032400$ & 1,120000 & 0,00243000 \\
\hline Mercúrio & 2,38E-07 & 2,34E-07 & 115,9 & 0,000027 & $-0,000009$ & 0,000018 & $4,35 \mathrm{E}-12$ \\
\hline Ferro & 0,820000 & 0,807000 & 376,4 & 304,0000 & $-0,429000$ & 303,00000 & 249,000000 \\
\hline TOTAL & 1,020000 & 1,000000 & & 773,0000 & $-1,470000$ & 771,00000 & 328,000000 \\
\hline
\end{tabular}

